\title{
WATER AS A REAGENT FOR SOIL REMEDIATION
}

Final Report

Reporting Period: August 1999 through November 2001

Prepared by:

Indira S. Jayaweera

Montserrat Marti-Perez

Jordi Diaz-Ferrero

Angel Sanjurjo

Hydrothermal Program

Materials Research Laboratory

Prepared for:

Nancy C. Comstock

Environmental Project Manager

DOE-NPTO

P.O. Box 3628

Tulsa, OK 74101

DOE Contract DE-AC26-99BC15224

SRI Project 10387

Approved by:

Angel Sanjurjo

Director

Materials Research Laboratory 


\section{DISCLAIMER}

This report was prepared as an account of work sponsored by an agency of the United States Government. Neither the United States Government nor any agency thereof, nor any of their employees, makes any warranty, express or implied, or assumes any legal liability or responsibility for the accuracy, completeness, or usefulness of any information, apparatus, product, or process disclosed, or represents that its use would not infringe privately owned rights. Reference herein to any specific commercial product, process, or service by trade name, trademark, manufacturer, or otherwise does not necessarily constitute or imply its endorsement, recommendation, or favoring by the United States Government or any agency thereof. The views and opinions of the authors expressed herein do not necessarily state or reflect those of the United States Government or any agency thereof. 


\begin{abstract}
SRI International conducted experiments in a two-year, two-phase process to develop and evaluate hydrothermal extraction technology, also known as hot water extraction (HWE) technology, to separate petroleum-related contaminants and other hazardous pollutants from soil and sediments. In this process, water with added electrolytes (inexpensive and environmentally friendly) is used as the extracting solvent under subcritical conditions $\left(150^{\circ} \mathrm{C}-300^{\circ} \mathrm{C}\right)$. The use of electrolytes allows us to operate reactors under mild conditions and to obtain high separation efficiencies that were hitherto impossible. Unlike common organic solvents, water under subcritical conditions dissolves both organics and inorganics, thus allowing opportunities for separation of both organic and inorganic material from soil.

In developing this technology, our systematic approach was to (1) establish fundamental solubility data, (2) conduct treatability studies with industrial soils, and (3) perform a benchscale demonstration using a highly contaminated soil. The bench-scale demonstration of the process has shown great promise.

The next step of the development process is the successful pilot demonstration of this technology. Once pilot tested, this technology can be implemented quite easily, since most of the basic components are readily available from mature technologies (e.g., steam stripping, soil washing, thermal desorption). The implementation of this technology will revolutionize the conventional use of water in soil remediation technologies and will provide a stand-alone technology for removal of both volatile and heavy components from contaminated soil.
\end{abstract}




\section{CONTENTS}

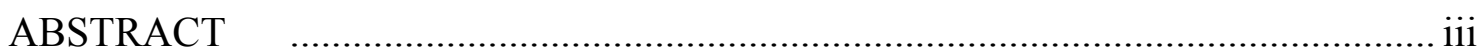

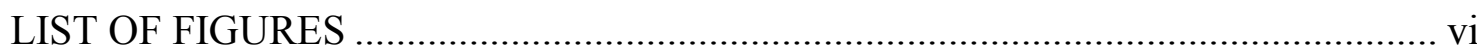

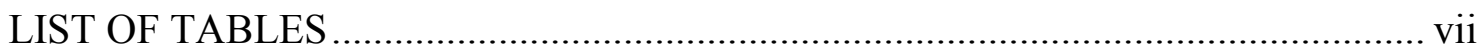

EXECUTIVE SUMMARY …….................................................................................. vii

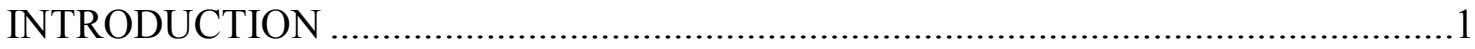

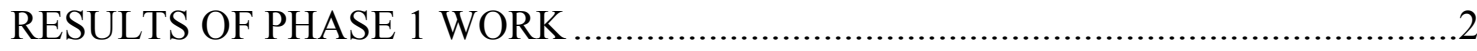

Task 1: Conduct In-Situ Spectrophotometric Studies To Determine Solubility............2

Data for Solubility of PAH under Hydrothermal Conditions ..................................

Rate of Solubilization Measurements …………………....................................

Estimation of Rate of Solubilization of an Unknown Compound .........................

Task 2: Extract Neat Organic Compounds From Soil ..............................................10

Spiked Soil Experiments..............................................................................

Industrial Soil Experiments..............................................................................11

Special Experimental Apparatus and Procedures ................................................13

Results for Spiked Soil Experiments ...............................................................14

Solubility of Pyrene in Water Under Varying Conditions....................................17

Organic Adsorption Mechanisms ………………………...............................18

Results for Industrial Soil Samples................................................................19

Results for EPA-Certified Reference Material (CRM103)..................................20

Technology Comparison ..................................................................................22

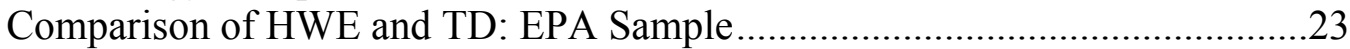

Comparison of TD with Added Steam: EPA-Certified Sample ...........................24

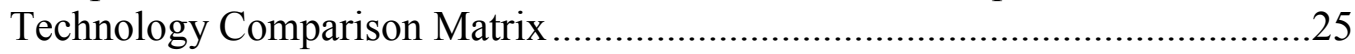

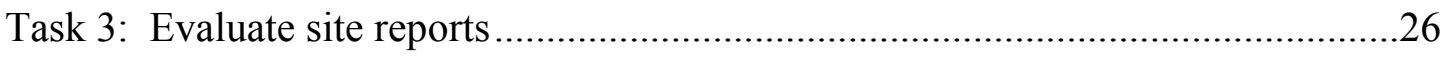

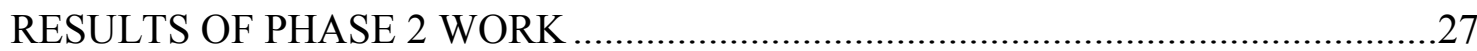

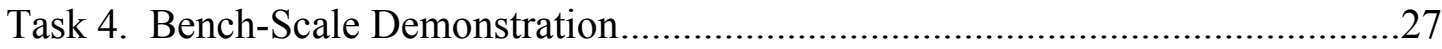

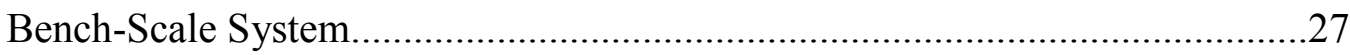

Performance Testing with Single-Component-Spiked Soil Samples ..................29

Technology Demonstration with Highly Concentrated Soil Samples ..................31

Task 5: Evaluate Parameters for Technology Transfer ..................................................34

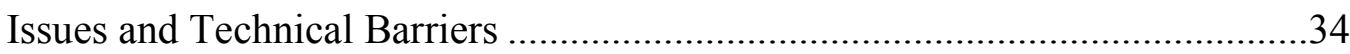

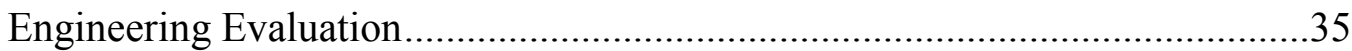

Contaminated Soil Pretreatment and Feed System..............................................35

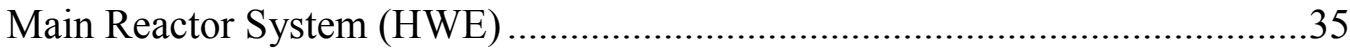

Treated Soil Removal System........................................................................36

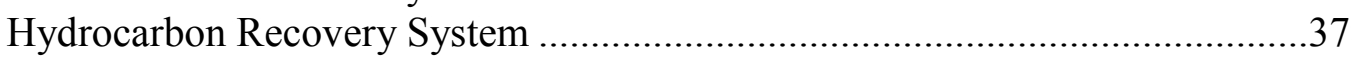

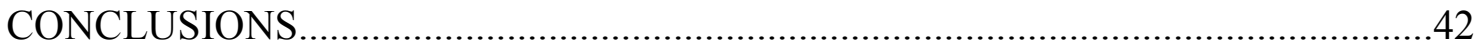

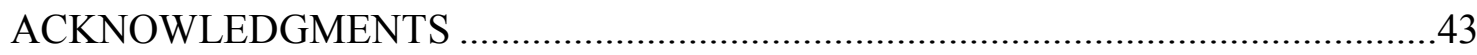

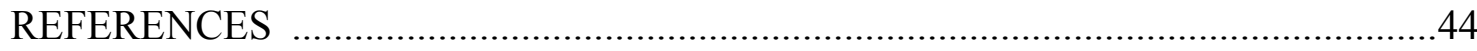


APPENDIX A: UV SPECTRA AND PHYSICAL PROPERTIES OF

SELECTED PAHS A-1

APPENDIX B: THE UV CELL AND THE EXPERIMENTAL PROCEDURE..........B-1 APPENDIX C: CHROMATOGRAPHIC CONDITIONS ………………………......... APPENDIX D: SAMPLE CHROMATOGRAMS FOR SOIL SAMPLES ................. D-1 APPENDIX E: STATIC STAINLESS STEEL SETUP …………………………........ APPENDIX F: MASS BALANCE STUDY ……………………………….......... APPENDIX G: FACT SHEET ON THERMAL DESORPTION ………………….... G-1 APPENDIX H: THE BENCH-SCALE REACTOR SYSTEM …………………….... H-1 APPENDIX I: CORSA-PEMEX SAMPLE ……………......................................... APPENDIX J: PRETREATMENT USING STEAM FLUSHING ................................... APPENDIX K: RESULTS FOR EPA SAMPLE ………...................................... K-1 APPENDIX L: SOME COMMONLY MEASURED SOIL PARAMETERS ...............L-1 APPENDIX M: REACTOR VESSEL SIZING AND THE BASIS OF DESIGN INFORMATION. M-1 


\section{LIST OF FIGURES}

Figure No.

Page No.

S-1. A simplified flow diagram of the HWE process ............................................

1. UV spectrophotometer set-up for in-situ solubility measurements .......................2

2. Solubility of $\mathrm{PAH}$ in water in temperature range $\mathrm{RT}-325^{\circ} \mathrm{C}$................................4

3. Variation of $\mathrm{pK}_{\mathrm{W}}$ of water with temperature at saturation pressure .......................5

4. Variation of density and dielectric constant of water with temperature .................6

5. Solubility of pyrene in water in the presence and absence of sodium carbonate ....6

6. Solubility curve for 9,10-dimethylanthracene .............................................

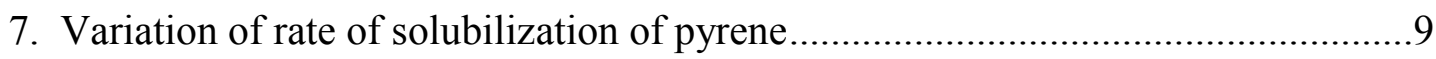

8. Dependence of rate of solubilization with equilibrium solubility .........................10

9. Adsorption isotherm for pyrene-sand system in water at $275^{\circ} \mathrm{C} \ldots \ldots \ldots \ldots \ldots \ldots \ldots . . . . . . . . .19$

10. Comparison of PAH removal effciencies from EPA-certified soil sample ..........21

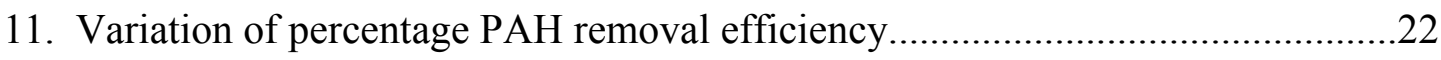

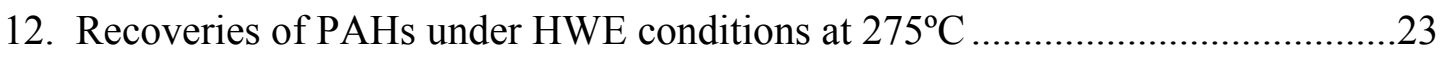

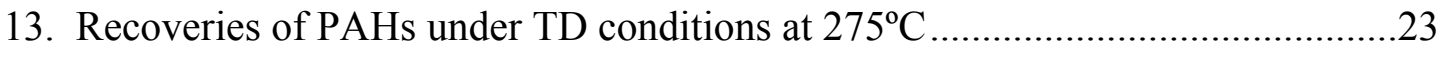

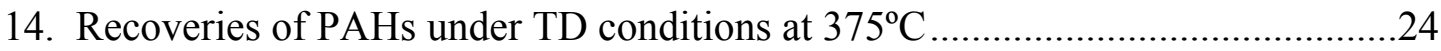

15. Recoveries of PAHs under steam-assisted thermal desorption conditions...........24

16. Bench-scale reactor system for treatability studies.........................................28

17. Photograph of the drilling mud container as received ....................................... 31

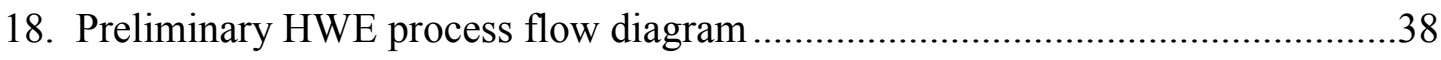

19. Preliminary mechanical layout of the main reactor vessel ...............................40

A1. Spectra \& wavelength: pyrene, fluoranthene and 9,10-dimethylanthracene .... A-1

B1. Schematic of the block heater assembly .....................................................

B2. Schematic of the stainless-steel reactor system. ….....................................

C1. Chromatogram of standard $(10 \mu \mathrm{g} / \mathrm{ml}$ in each PAH) ........................................

D1. GC/MS (scan) chromatogram from solvent extraction of soil....................... D-1

D2. Mass spectra of peaks at retention times of 15.2 and 19.4 ......................... D-2

D3. Total ion chromatogram of solvent extraction of soil................................ D-2

E1. Schematic of a small-scale continuous soil cleaning system. ...........................

I1. Chromatogram of a standard $(100 \mu \mathrm{g} / \mathrm{ml} \mathrm{TPH})$ analyzed through GC/FID......... I-1 


\section{LIST OF TABLES}

Table No.

Page No.

1. Molar absorption coefficients for pyrene in water................................................

2. Solubility of PAH under hydrothermal conditions ............................................4

3. Comparison of rates of solubilization for selected compounds ............................8

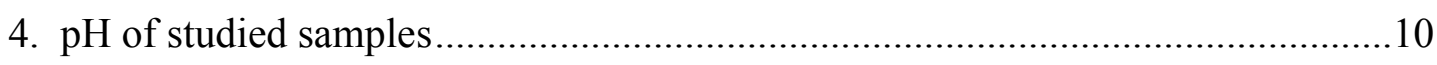

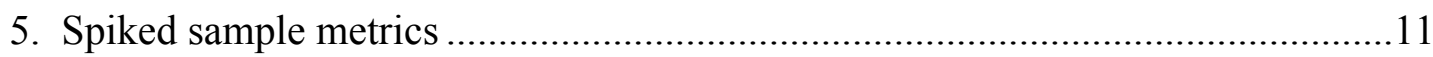

6. Analyte concentrations in EPA certified soil CRM103 ......................................13

7. Recoveries of pyrene obtained (treatment with water and $\mathrm{Na}_{2} \mathrm{CO}_{3}$ solutions) .....15

8. Comparison between pyrene and fluoranthene extraction.................................15

9. Examples of $\mathrm{pH}$ values and appearance of precipitate ......................................16

10. Influence of ratio of sand/extracting agent in recovery of pyrene .......................17

11. Comparison of the concentrations of PAH (hydrothermal extractions) ..............20

12. Comparison of results (static \& continuous hydrothermal extraction) ................21

13. Comparison of thermal desorption and steam-assisted thermal desorption .........25

14. Summary of technology efficiencies in soil remediation .................................25

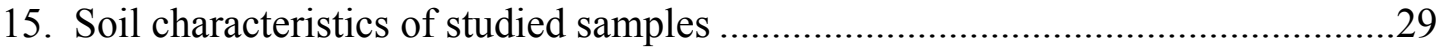

16. Influence of differents parameters in the recovery of pyrene ..............................30

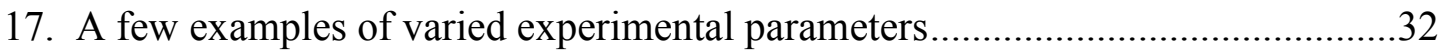

18. Comparison of results of drilling mud extraction experiments ..........................33

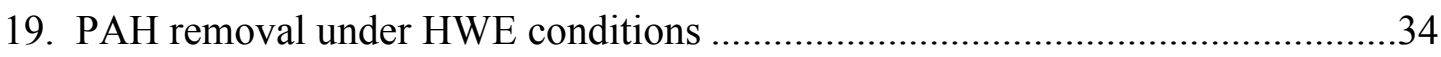

A1. Physical properties of selected PAHs ....................................................... A-2

F1. Pyrene obtained in the adsorption experiment ......................................... F-1

J1. Extraction by steam flushing technique at $100^{\circ} \mathrm{C}$...........................................

$\mathrm{K} 1$. EPA sample - Bench scale system - first experiment ................................... K-1

K2. EPA sample - Bench scale system - second experiment ….......................... K-1

K3. EPA sample - Bench scale system - third experiment …........................... K-2

K4. EPA sample - Bench scale system ............................................................. K-2

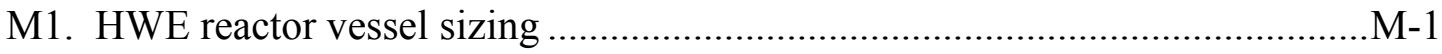

M2. Basis of design - HWE processing system ................................................ 


\section{EXECUTIVE SUMMARY}

\section{INTRODUCTION}

SRI International conducted experiments in a two-year, two-phase process to develop and evaluate hydrothermal extraction technology, also known as hot water extraction (HWE) technology, for remediating petroleum-contaminated soils. The bench-scale demonstration of the process has shown great promise, and the implementation of this technology will revolutionize the conventional use of water in soil remediation technologies and provide a standalone technology for removal of both volatile and heavy components from contaminated soil.

\section{BACKGROUND}

During operations related to recovery, refining, and transport of oil from domestic sources, contamination of soil, air, and ground water is inevitable. The soil contamination results primarily from (1) drilling operations in which drilling fluid becomes contaminated in the reserve pit during and/or after completion of the well; (2) production operations in which oil, condensate, or produced water are spilled or released into the ground; and (3) pipeline breaks or leaks that release crude oil and/or produced water into the soil. Cleanup operations for environmental compliance add significantly to the operation costs of domestic oil production. In many cases, intrinsic biochemical remediation, which is one of the least expensive soil remediation methods, is either ineffective because of high concentrations of contaminants, or too slow. Other remediation alternatives can be very expensive. This remediation barrier has contributed to the continuous decline of U.S. crude oil production, which in turn has increased our dependence on foreign supplies. Therefore, to lower production costs and to maintain access to domestic resources, we need improvements in existing technologies or new technologies for soil and water remediation.

Biodegradation, bioventing, pyrolysis, solvent extraction, thermal desorption, and incineration are some of the in-situ and ex-situ technologies currently available for soil remediation. However, most current remediation practices either (1) cost too much, (2) fail to remove all the polycyclic aromatic hydrocarbons (PAHs) found in petroleum-contaminated sites, or (3) require the use of organic solvents to remove contaminants, at the expense of additional contamination and with the added cost of recycling solvents. Alternative innovations must be more economical and efficient, meet environmental regulatory requirements, and gain public acceptance. Hydrothermal extraction offers the promise of efficiently extracting PAHs and other kinds of organics from contaminated soils at moderate temperatures and pressures.

\section{SRI APPROACH}

In remediating soil contaminated with oil, separation technologies are better than destruction technologies because the pollutant itself may not be hazardous and the heat value of 
the recovered fuel can be used to compensate the cost of the remediation process. Therefore, to remediate soil contaminated with petroleum compounds, solvent extraction seems to be more appropriate. However, if organic solvents are used for either ex-situ or in-situ remediation, the removal or disposal of the used solvent is a problem. These solvents may be volatile, causing secondary pollution. One way to minimize the secondary pollution is to find substitutes for organic solvents that are less hazardous to the environment.

SRI developed an advanced hydrothermal technology to separate the petroleum-related contaminants and other hazardous pollutants from soil and sediments. In this process, water with added electrolytes (inexpensive and environmentally friendly) is used as the extracting solvent under subcritical conditions $\left(150^{\circ} \mathrm{C}-300^{\circ} \mathrm{C}\right)$. The use of electrolytes allows us to operate reactors under mild conditions and to obtain high separation efficiencies that were hitherto impossible. Also, the importance of water as a solvent is that, unlike common organic solvents, water under subcritical conditions dissolves both organics and inorganics, thus allowing opportunities for separation of both organic and inorganic material from soil.

In developing this technology, our systematic approach was to (1) establish fundamental solubility data, (2) conduct treatability studies with industrial soils, and (3) perform a benchscale demonstration using a highly contaminated soil.

We conducted initial work with selected PAHs, which are difficult to remove from soil, to measure solubility under hydrothermal extraction conditions. No literature data are available on in-situ measurements of solubilities of PAHs, and to our knowledge this is the first recording of solubility data for PAHs measured under hydrothermal conditions by in-situ measurements. The solubilities of all the tested PAHs in water increase with temperature. Compared with the reported solubilities at room temperature, the values obtained are 900-3,600,000 times higher, depending on the temperature and the PAH selected. These solubility data help determine the appropriate conditions for our treatability studies with contaminated soil.

To conduct the treatability studies, SRI used several different industrial soils (e.g., Tallman Oil Company site, Colorado, and an organic wood preserving site in the Northwestern United States) and EPA-certified soils for evaluating the effectiveness of hydrothermal extraction. Collectively, these samples contained benzene, ethylbenzene, toluene, BETEX pentachlorophenol (PCP), creosote and 20 different PAHs. The removal efficiency for the industrial samples was very promising, with a greater than $99.99 \%$ removal of PAHs, including benzo(a)pyrene under HWE conditions.

We performed the bench-scale demonstration using drilling mud obtained from a site in Mexico. This mud contained 20\% TPH (total petroleum hydrocarbon), including heavy components. Since this sample contained large amounts of volatiles, we were able to demonstrate the ability of the HWE technology to recover the volatiles for reuse as a fuel and reduce the energy cost. Figure S-1 shows a block flow diagram of the process, along with photographs of oil-drilling mud and its cleaning stages. In this process, mud is injected into the reactor along with the preheated water. In the reactor, volatile hydrocarbons are first separated from the mud, then recovered for reuse and to use as fuel for heating water. The semivolatiles and PAHs are then removed to obtain ultra-clean soil. We were able to exceed the cleanup goal of $200 \mathrm{mg} / \mathrm{kg} \mathrm{TPH}$ specified for this site. The temperature and pressure ranges used in the process were $50^{\circ} \mathrm{C}-250^{\circ} \mathrm{C}$ and 3-50 atmospheres, respectively. 


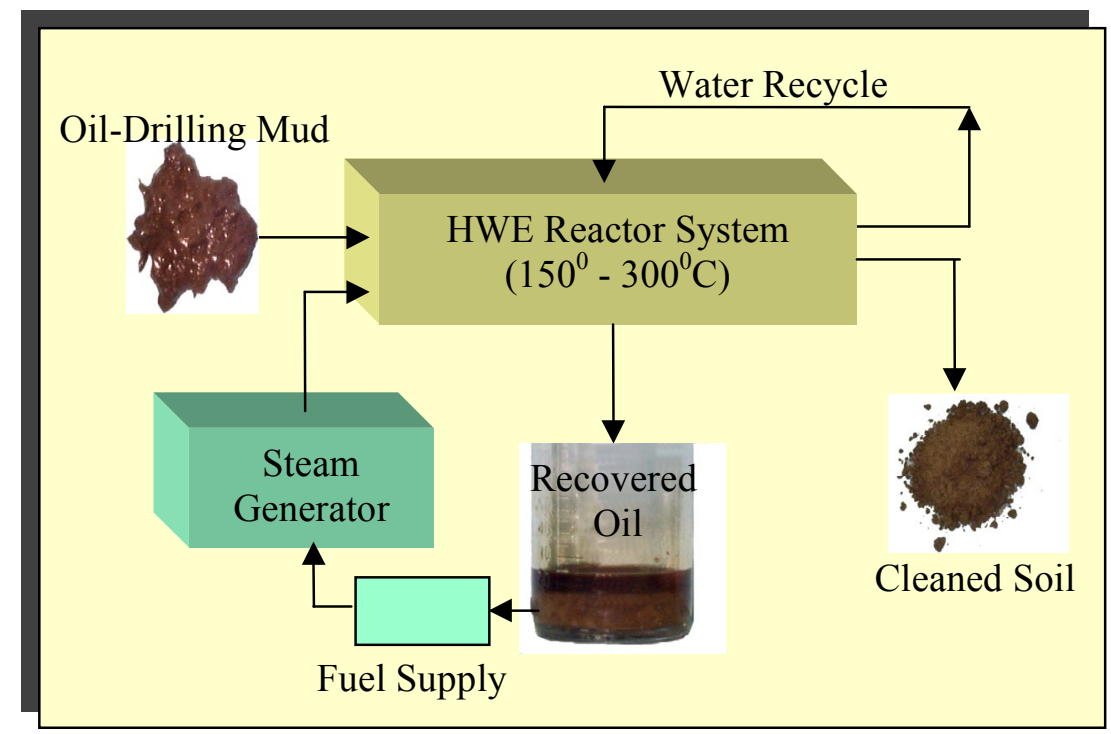

Figure S-1. A simplified flow diagram of the HWE process.

\section{PROPOSED FUTURE WORK}

The next step of the development process is the successful pilot demonstration of this technology. Once pilot tested, this technology can be implemented quite easily, since most of the basic components are readily available from mature technologies (e.g., steam stripping, soil washing, thermal desorption). We believe a 1 ton/hr pilot-scale plant would be ideal for demonstrating this technology.

We believe SRI's current bench-scale system can be used to conduct optimization studies to gather key engineering parameters for designing the pilot-scale system. Also, more fundamental studies are required for advancement of hydrothermal processes for removing not only organics, but also trace amounts of hazardous inorganics from soils. SRI is currently seeking funding opportunities to achieve the above goals. 


\section{INTRODUCTION}

SRI International conducted a research project under DOE Contract No. DE-AC2699BC15224 to evaluate the efficiency of hot water extraction (or hydrothermal extraction) for remediating soil contaminated with petroleum-related pollutants. This two-year study was conducted in two phases:

Phase 1 (Year 1): Evaluation of solubilities of neat polycyclic aromatic hydrocarbons (PAHs) in water. The emphasis was on determining the optimal pressure and temperature conditions for efficient removal of PAHs from real-world contaminated soils. This phase consisted of three tasks:

- Task 1: Measurements of solubilities of selected organic compounds (e.g., fluoranthene, pyrene, chrysene, and 9,10-dimethylanthracene) in water with and without added compounds

- Task 2: Measurements of extraction efficiencies of selected soil samples under the conditions selected in Task 1

- Task 3: Technical evaluation of contaminated petroleum sites.

Phase 2 (Year 2): Technology demonstration using a bench-scale stirred reactor system and assessment of important parameters for performance evaluation. This phase consisted of two tasks:

- Task 4: Design and assembly of the bench-scale setup and treatment of real-world soil samples containing volatile organic compounds (VOCs), semi-volatile organic compounds (SVOCs), PAHs, and PCBs

- Task 5: Analysis of engineering parameters required for technology transfer.

This report discusses our experiments and results in two major sections: Results of Phase 1 Work and Results of Phase 2 Work. Conclusions are presented at the end of the main text. Appendixes to this report contain supporting data and details of our experiment setups and methods. 


\section{RESULTS OF PHASE 1 WORK}

\section{TASK 1: CONDUCT IN-SITU SPECTROPHOTOMETRIC STUDIES TO DETERMINE SOLUBILITY}

The goal of Task 1 was to study the solubility of PAH under hydrothermal conditions, using an UV spectrophotometer to determine both the equilibrium solubility and the solubilization rates. Appendix A gives the measured UV spectra of each PAH under hydrothermal conditions. We conducted in-situ measurements to unambiguously determine and quantify organic solubility under hydrothermal conditions because the ability to process and separate organic material from soil in a hydrothermal medium depends on the equilibrium solubility of the organics. SRI's UV spectrophotometer is equipped with an optical cell for using UV spectroscopy to perform in-situ concentration measurements on organic species. The UV measurements were conducted in quartz reactors for low-pressure applications and in a range of temperatures between $125^{\circ}$ and $200^{\circ} \mathrm{C}$. The experiments in the high-temperature range $\left(200^{\circ} \mathrm{C}\right.$ to $325^{\circ} \mathrm{C}$ ) were performed in stainless steel reactors. The cells and the experimental procedures used are described in Appendix B. Figure 1 shows photographs of the UV cell assembly for insitu solubility measurements.
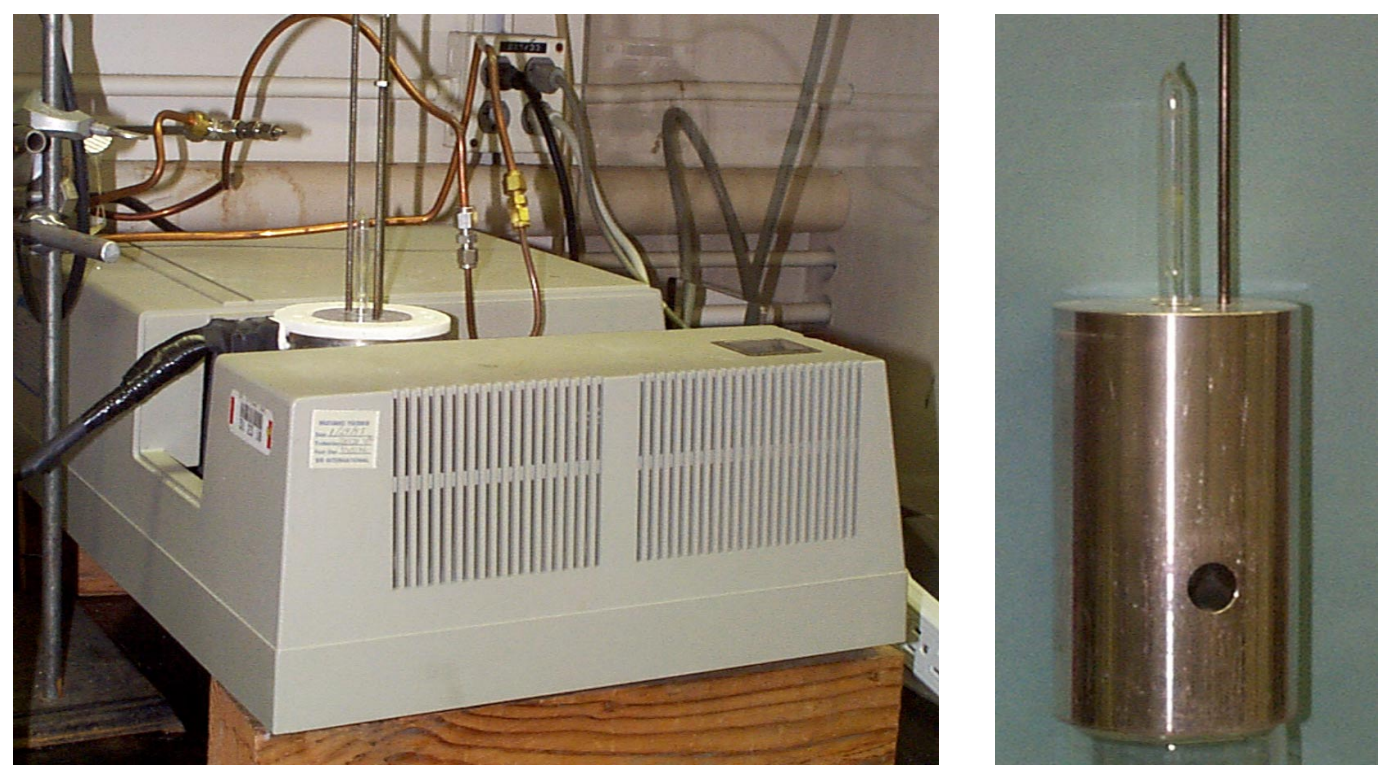

Figure 1.UV spectrophotometer set-up for in-situ solubility measurements of organic compounds. 
In Task 1, we used fluoranthene, pyrene, chrysene, and 9,10 dimethylanthracene as model compounds. We performed quantitative analyses using either a UV detector for lowtemperature experiments or stainless steel reactors for the high-temperature experiments, and using chromatographic methods (HP 5890 and HP 6890 spectrophotometers) with flame ionization detection (FID) and mass detectors.

\section{Data for Solubility of PAH under Hydrothermal Conditions}

The solubilities of fluoranthene, pyrene, chrysene, and 9,10-dimethylanthracene were measured in the temperature range $125^{\circ}$ to $325^{\circ} \mathrm{C}$. We also measured the rate of solubilization of PAHs under hydrothermal conditions in the temperature range $125^{\circ}$ to $200^{\circ} \mathrm{C}$. Based on the spectra of the studied PAH, we chose the appropriate wavelength for each measurement as marked on each spectrum in Appendix A. Appendix A also gives some important physical parameters of selected PAHs under ambient conditions.

The measured molar absorption coefficient for pyrene in the temperature range $125^{\circ}$ $200^{\circ} \mathrm{C}$ is given in Table 1. Similar measurements were performed for each of the selected PAHs to determine their solubilities at different temperatures. The measured solubilities of pyrene (Pyr), fluoranthene (Flu), chrysene (Chr), and 9,10-dimethylanthracene (DMAn) in water at different temperatures are shown in Table 2 and Figure 2. The solubilities of all the tested PAHs in water increase with the temperature as evident from the data in Figure 2. Compared with the bibliographic solubilities at room temperature (Mackay and Shiu, 1977), the values obtained are 900 to 3,600,000-fold higher, depending on the temperature and the PAH selected.

Table 1

MOLAR ABSORPTION COEFFICIENTS FOR PYRENE IN WATER*

\begin{tabular}{cc}
\hline Temperature $\left({ }^{\circ} \mathbf{C}\right)$ & $\begin{array}{c}\text { Absorption Coefficient } \\
\left(\mathbf{M}^{-1} \mathbf{~} \mathbf{~ m}^{-1}\right)\end{array}$ \\
\hline 125 & 429 \\
150 & 530 \\
175 & 690 \\
200 & 690 \\
\hline
\end{tabular}

Absorbance was measured at $350 \mathrm{~nm}$. 
Table 2

SOLUBILITY OF PAH UNDER HYDROTHERMAL CONDITIONS

\begin{tabular}{ccccc}
\hline & \multicolumn{4}{c}{ Solubility $(\mathbf{m g}$ PAH/ml Water) } \\
\cline { 2 - 5 } Temperature $\left({ }^{\circ} \mathrm{C}\right)$ & Flu & Pyr & Chr & DMAn \\
\hline 125 & 235 & 148 & & 136 \\
150 & 321 & 287 & 13 & 332 \\
175 & 1054 & 635 & 64 & 1173 \\
200 & 1608 & 1516 & 200 & \\
250 & & 770 & & \\
275 & & 1000 & 400 & \\
300 & & 720 & \\
325 & & & 230 & \\
\hline
\end{tabular}

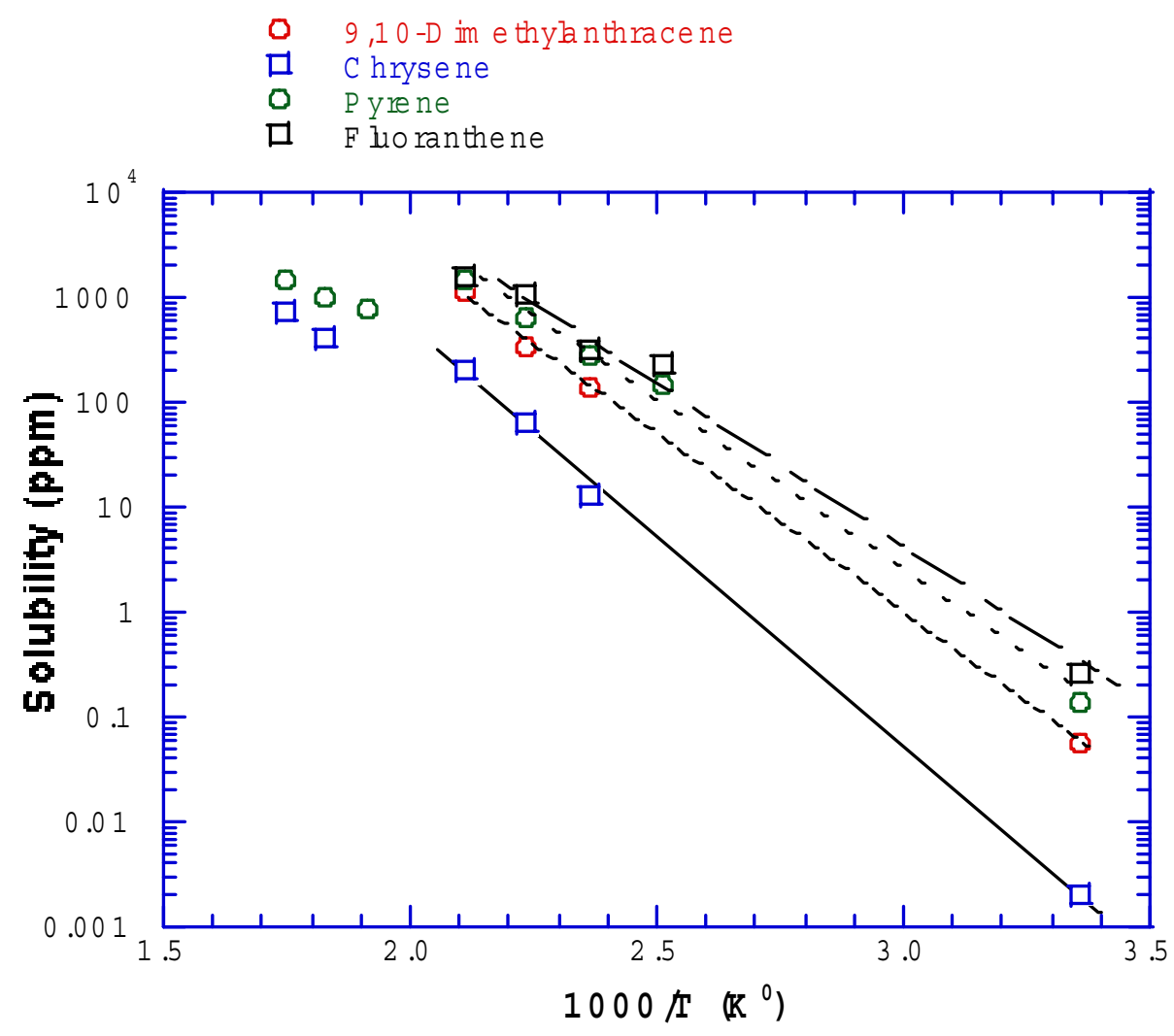

Figure 2. Solubility of $\mathrm{PAH}$ in water in temperature range $\mathrm{RT}-325^{\circ} \mathrm{C}$. 
The data above clearly show the enhancement of solubility with increase in temperature. The increase in solubility in the temperature range $120^{\circ}-200^{\circ} \mathrm{C}$ is quite significant. The data we measured are very encouraging, clearly indicating the possibility of complete removal of heavy PAHs from soil and other solid materials. No literature data are available on in-situ measurements of solubilities of PAHs, and this is the first recording of solubility data for PAHs as measured under hydrothermal conditions by in-situ measurements.

We have also noticed a region $\left(200^{\circ}-275^{\circ} \mathrm{C}\right)$ where the increase in solubility with temperature is not as significant as in the $125^{\circ}-200^{\circ} \mathrm{C}$ region. The change in solubility behavior around the noted temperature range corresponds with the physical properties of water, which are drastic above $200^{\circ} \mathrm{C}$. The basic properties of hydrothermal media (such as viscosity, the dissociation constant of water, the dielectric constant, compressibility, and the coefficient of expansion) all play a role in determining optimal reaction conditions for obtaining maximum benefits in hydrothermal processes. Figure 3 shows the variation of $\mathrm{pK}_{\mathrm{w}}$ with temperature at the saturation pressure, as a well-known example. The dissociation constant goes through a maximum around $250^{\circ} \mathrm{C}\left(\mathrm{pK}_{\mathrm{w}}\right.$ minimum) and then undergoes a sharp decline when the temperature approaches the critical point. The density and dielectric constant of water also show sharp changes close to the critical point, as shown in Figure 4. However, these changes should enhance the solubility and should show up as a curved Arrhenius behavior. Initially, we suspected that the static stainless steel system that we used for determining the solubility may have caused these reduced solubilities at higher temperature. However, we found another report of reduced solubilities with increasing temperature above $250^{\circ} \mathrm{C}$ [Hawthorne et al, 1994] and decided to conduct more experiments with pyrene under Task 2.

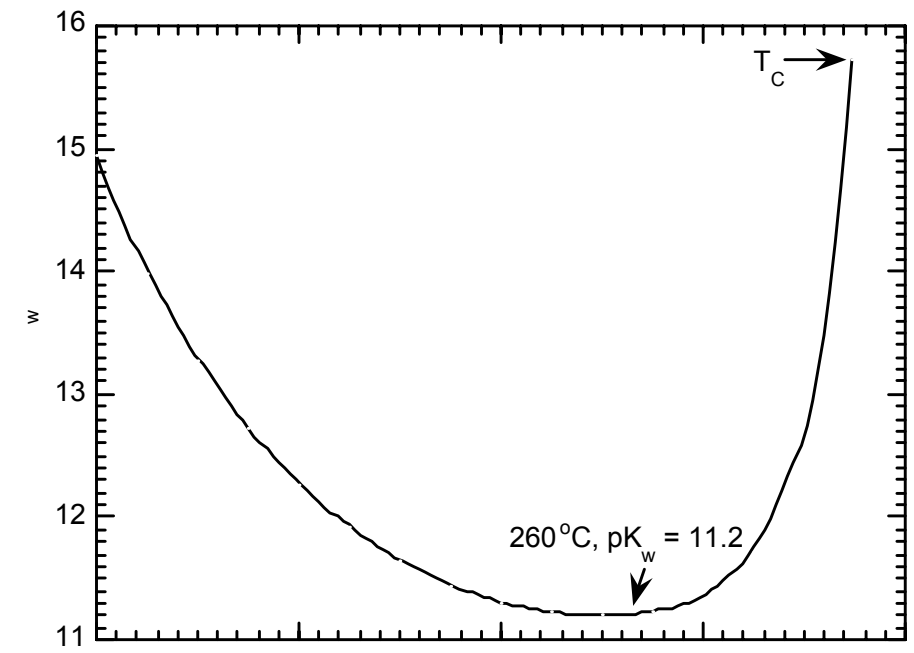

Figure 3. Variation of $\mathrm{pK}_{\mathrm{W}}$ of water with temperature at saturation pressure. 


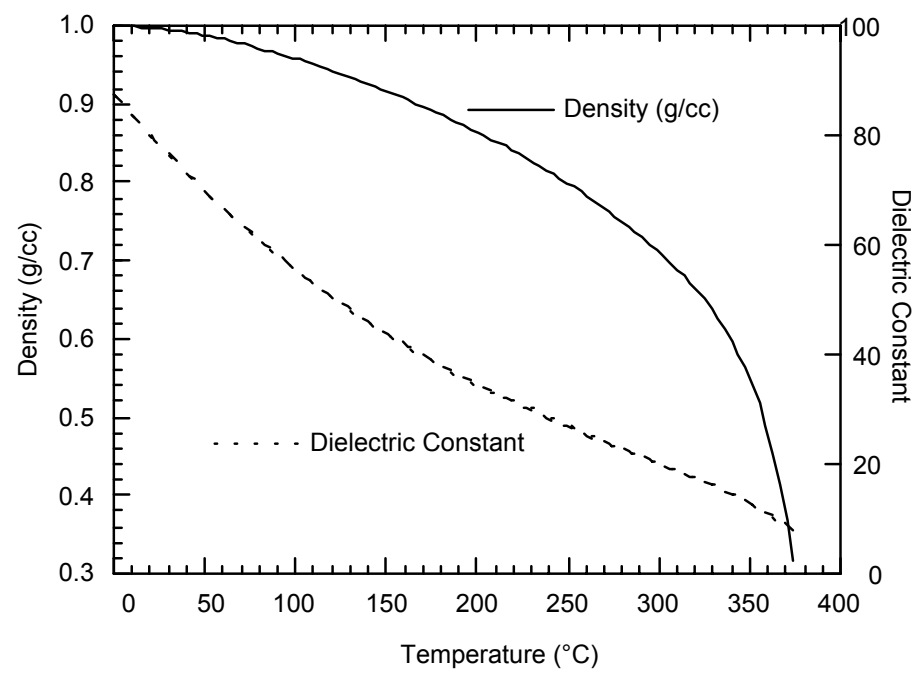

Figure 4. Variation of density and dielectric constant of water with temperature at saturation pressure.

In addition to the solubility in pure water under hydrothermal conditions, we also measured the solubility in sodium carbonate solutions (1\% in water) at temperatures between $125^{\circ}-200^{\circ} \mathrm{C}$. The results of the measurements of pyrene are shown in Figure 5.

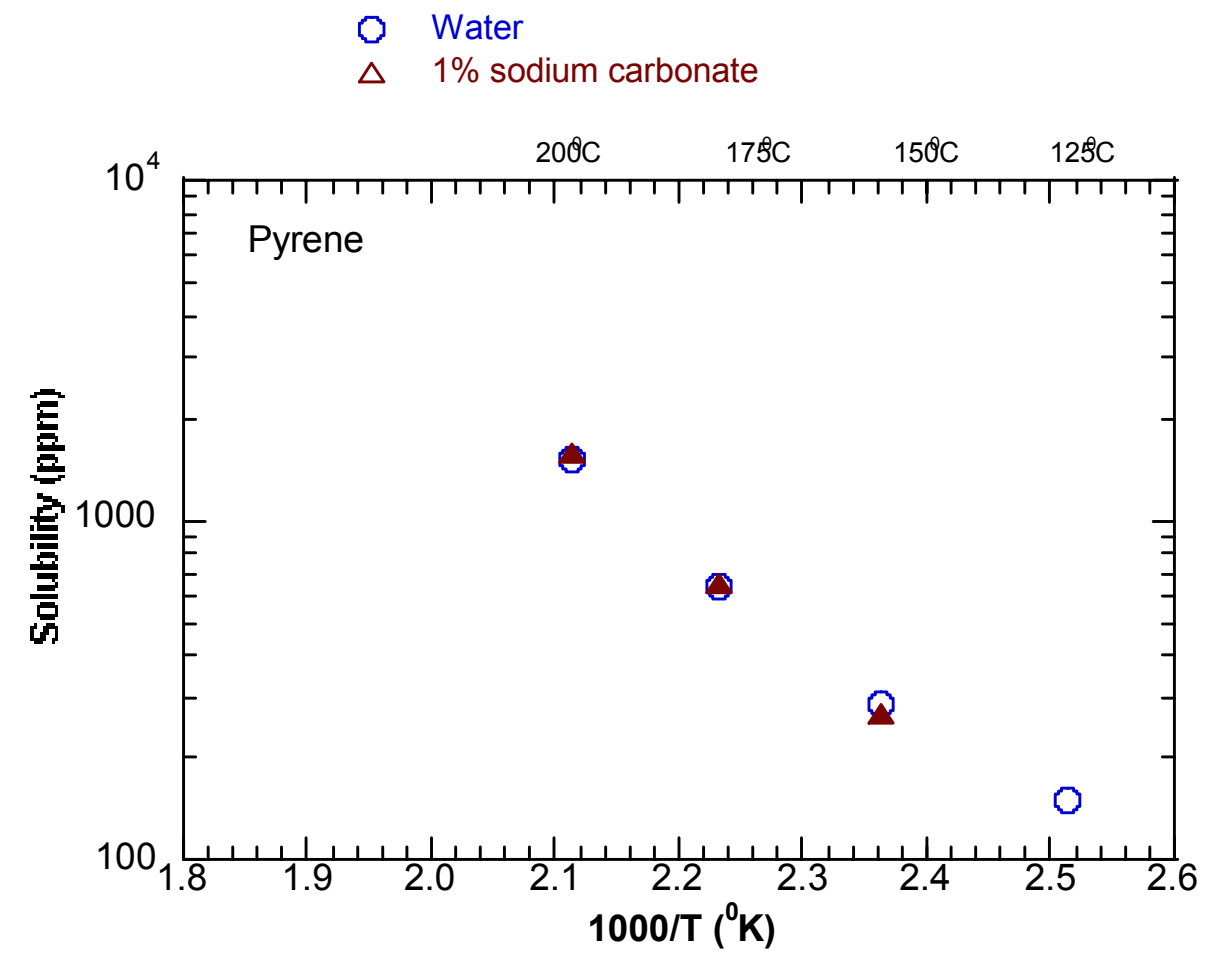

Figure 5. Solubility of pyrene in water in the presence and absence of sodium carbonate in temperature range $125^{\circ}-200^{\circ} \mathrm{C}$. 
The results in Figure 5 show that the solubility of pyrene in water and in sodium carbonate solutions is similar under hydrothermal conditions. The results also show that solutions of sodium carbonate, which help shift the P-T curve downward, can be used instead of water for the hydrothermal process without a decrease in the PAH solubility. The main purpose of the addition of electrolytes is to operate the hydrothermal extraction process under moderate pressure conditions. However, only a few electrolytes would enhance the solubility while reducing the saturated vapor pressure of water.

\section{Rate of Solubilization Measurements}

The rate of solubilization is a critical parameter for determining the efficiency of the hydrothermal process. We measured the rate of solubilization of pyrene, fluoranthene, chrysene, and 9,10-dimethylanthracene in the temperature range $125^{\circ}-200^{\circ} \mathrm{C}$. We also measured the average rate of solubilization and estimated the initial rate of solubilization.

We estimated the initial rate of solubilization by fitting the measured solubility data to the relationship given in equation (1). This equation was derived by considering the following equilibrium between PAH in solid phase $\left(\mathrm{S}_{\mathrm{S}}\right)$ and in aqueous phase $\left(\mathrm{S}_{\mathrm{aq}}\right)$ :

$$
\begin{aligned}
& \mathrm{S}_{\mathrm{S}} \rightarrow \mathrm{S}_{\mathrm{aq}} \mathrm{k}_{1} \\
& \mathrm{~S}_{\mathrm{aq}} \rightarrow \mathrm{S}_{\mathrm{S}} \mathrm{k}_{2} \\
& {\left[\mathrm{~S}_{\mathrm{aq}}\right]=\mathrm{k}_{1}\left[\mathrm{~S}_{0}\right] /\left\{\mathrm{k}_{1}+\mathrm{k}_{2}\right\}-\exp \left[\mathrm{K}-\left(\mathrm{k}_{1}+\mathrm{k}_{2}\right)\right\}}
\end{aligned}
$$

where $\mathrm{S}_{0}$ is the initial PAH concentration and $\mathrm{K}=\mathrm{k}_{1} / \mathrm{k}_{2}$. An example solubility curve is given in Figure 6.

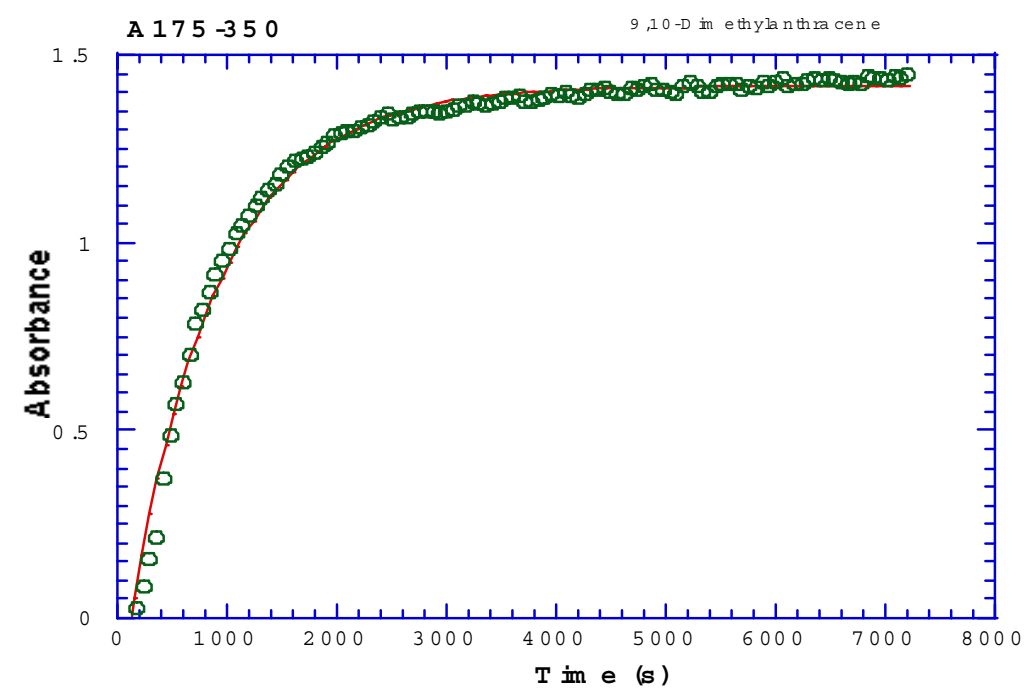

Figure 6. Solubility curve for 9,10-dimethylanthracene.

Solid line is equation (1) fit to the experimental data. 
The average rate of solubilization was determined by measuring the slope of the initial part of the solubility curve. Table 3 compares the measured average rates of solubilization and the estimated initial rates of solubilization.

\section{Table 3}

COMPARISON OF RATES OF SOLUBILIZATION FOR SELECTED COMPOUNDSa

\begin{tabular}{lll}
\hline Compound & $\mathbf{R}$ av, ppm/s & $\mathbf{R} \mathbf{0}, \mathbf{p p m} / \mathbf{s}$ \\
\hline Chrysene & 0.109 & 0.242 \\
9,10-dimethylanthracene & 0.378 & 0.406 \\
Pyrene & 0.556 & 0.464 \\
Fluoranthene & 1.10 & 1.05 \\
\hline
\end{tabular}

${ }^{\mathrm{a}} \mathrm{R}_{\mathrm{av}}=$ Measured average rate of solubilization.

$\mathrm{R}_{0}=$ Estimated initial rate of solubilization from curve fitting.

Our data show that the rate of solubilization of PAHs at temperatures above $200^{\circ} \mathrm{C}$ is very high and difficult to measure accurately. We believe that the high-temperature numbers cans be extracted by extrapolating the low-temperature rates of solubilization.

The lower limit for solubility $\left(\mathrm{C}_{\mathrm{W}}\right)$ at a higher temperature can be estimated from values at two or more lower temperatures and the assumption that the change in $\mathrm{C}_{\mathrm{W}}$ with temperature follows an Arrhenius relation, where

$$
\log \mathrm{C}_{\mathrm{W}}=\mathrm{A}\{\exp (-\mathrm{E} / \mathrm{RT})\}
$$

This is a safe assumption, since if the solubility changes in a non-Arrhenius manner, very likely the change will lead to a higher than estimated solubility and in turn to a higher than estimated solubilization rate, thus erring on the side of safety. As an example, Figure 7 shows the experimental data for the rate of solubilization of pyrene in the temperature range $150^{\circ}$ $200^{\circ} \mathrm{C}$. The rate of solubilization extracted from Figure 7 by extrapolating the low-temperature curve to $275^{\circ} \mathrm{C}$ was $6.5 \mathrm{ppm} / \mathrm{s}$. This number indicates that the equilibrium will be reached in less than $3 \mathrm{~min}$ at $275^{\circ} \mathrm{C}$; the equilibrium solubility of pyrene at $275^{\circ} \mathrm{C}$ is $1000 \mathrm{ppm}$. 


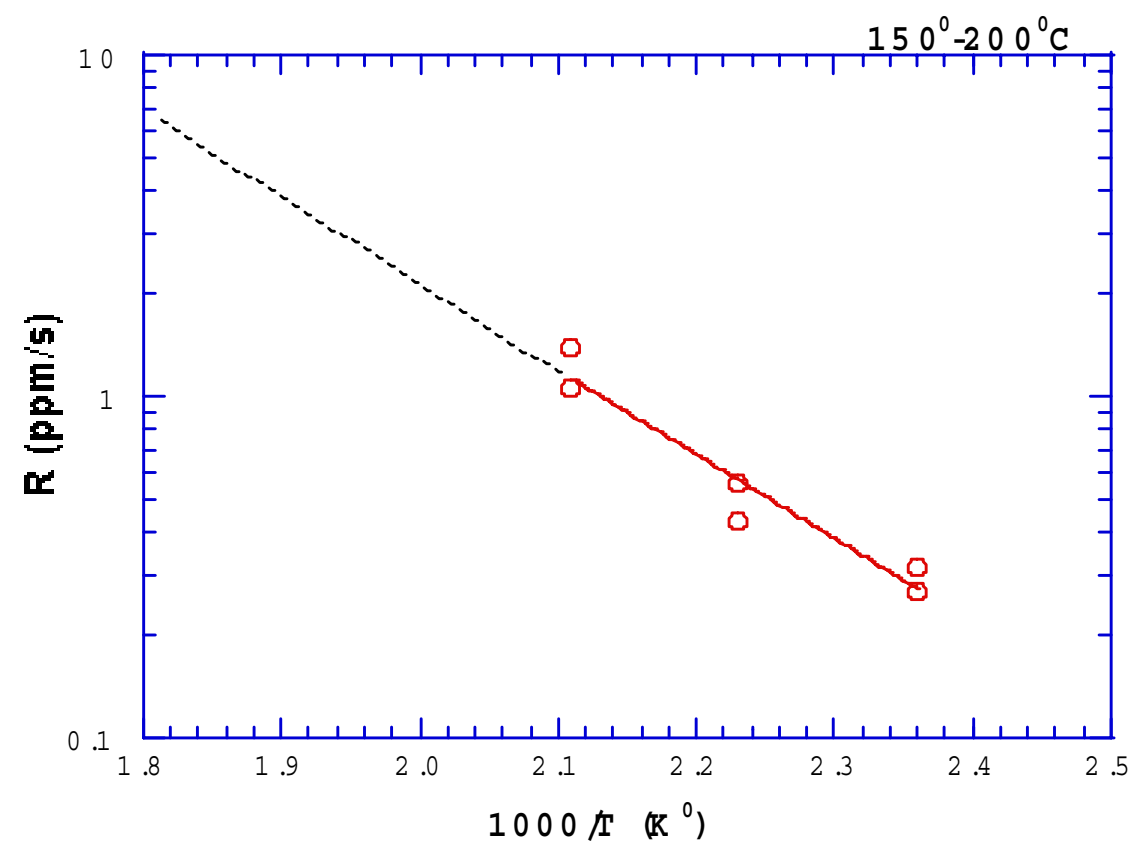

Figure 7. Variation of rate of solubilization of pyrene in the temperature range $150^{\circ}-275^{\circ} \mathrm{C}$.

\section{Estimation of Rate of Solubilization of an Unknown Compound}

Our data are very useful in estimating a rate of solubilization $(\mathrm{R})$ for an unknown organic (UNORG). We can use the relation between the initial rate of solubilization $(\mathrm{R})$ of organic compounds slightly soluble in water and their solubility $\left(\mathrm{C}_{\mathrm{w}}\right)$ such that

$$
\mathrm{R}=\mathrm{kC}_{\mathrm{W}}
$$

Use of Equation (3) for estimating UNORG's rate of solubilization at high temperature requires values of $\mathrm{R}$ and $\mathrm{C}_{\mathrm{w}}$ for at least two other thermally stable compounds at the same temperature, with similar surface areas for the liquid droplets. Figure 8 shows the relationship for four PAHs used in our study at $175^{\circ} \mathrm{C}$. We can easily use this plot to determine the value of $\mathrm{R}$ for an UNORG. 


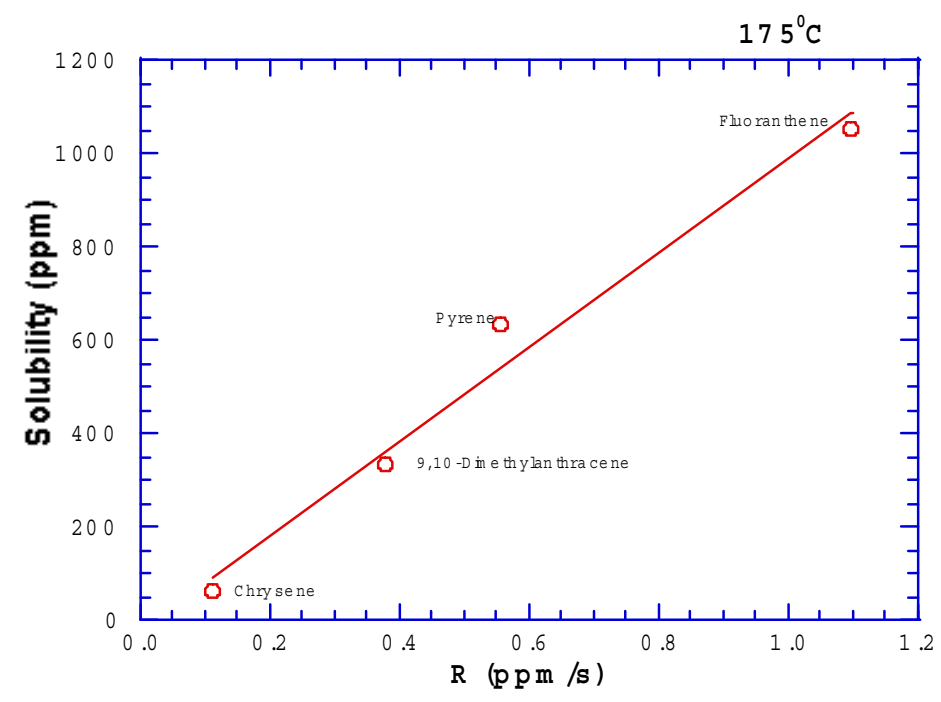

Figure 8. Dependence of rate of solubilization with equilibrium solubility.

\section{TASK 2: EXTRACT NEAT ORGANIC COMPOUNDS FROM SOIL}

The goal of this task is to determine the efficiency of the hot water process for removing PAHs from several soil types and sediments. We worked with three types of samples: (1) neat soil samples spiked with PAH at two levels of concentration, (2) real-world contaminated soil samples, and (3) EPA certified samples.

\section{Spiked Soil Experiments}

The two soils spiked for these experiments were sand and bentonite. Sand [CAS 1480860-7] was supplied by Mallinckrodt and consisted of crystalline quartz $\left(\mathrm{SiO}_{2}\right)$. Bentonite [CAS 1302-78-9] was supplied by Fisher Scientific. It was a very fine powder that consisted principally of aluminum silicate (clay). These soils were chosen for their differences, especially in particle size and porosity, to represent two extreme situations that could be found in real-world samples. The $\mathrm{pH}$ values of both soils were measured to better characterize them. As can be observed in Table 4, the $\mathrm{pH}$ of sand is neutral while bentonite is a basic soil.

Table 4

pH OF STUDIED SAMPLES

\begin{tabular}{cc}
\hline Sample & pH \\
Sand & 7.1 \\
Bentonite & 9.0 \\
\hline
\end{tabular}


We prepared five spiked soil samples by mixing a known volume of solutions of pyrene or fluoranthene in dichloromethane/acetone (1/1) with a known amount of dried sand or with bentonite. Soils were spiked with pyrene at two levels of concentration (around $350 \mu \mathrm{g} / \mathrm{g}$ and $5000 \mu \mathrm{g} / \mathrm{g}$ ). The low-level spiked sand reproduces the situation of a polluted soil, while the high level simulates a very severe pollution (e.g., a spill, where the pollutant can exist in a separate phase). Table 5 shows the information on spiked samples used in this study. After being spiked, the samples were shaken vigorously to favor the interaction of the PAH with the sand matrix. Then, they were allowed to equilibrate for several hours. Before starting the extraction experiments, the flasks containing spiked soil samples were left in a fume hood for 7 days to completely remove the solvent. Sample analysis was done using a Hewlett Packard GC-MS. The chromatographic conditions and sample chromatogram for standards used in this study are given in Appendix C.

\section{Table 5}

\section{SPIKED SAMPLE METRICS}

Sand with a concentration level of $350 \mu \mathrm{g} / \mathrm{g}$ of pyrene

Bentonite with a concentration level of $375 \mu \mathrm{g} / \mathrm{g}$ of pyrene

Sand with a concentration level of $350 \mu \mathrm{g} / \mathrm{g}$ of fluoranthene

Sand with a concentration level of $5000 \mu \mathrm{g} / \mathrm{g}$ of pyrene

Bentonite with a concentration level of $5000 \mu \mathrm{g} / \mathrm{g}$ of pyrene

\section{Industrial Soil Experiments}

Soil Sample from Organic Wood Preserve Site. The samples were obtained from a heterogeneous pile of contaminated soil that was generated during the past operations of an organic wood preserver company in the northwestern United States. The pile's volume is in excess of 10,000 cubic yards. The soil samples reportedly contain two basic types of contamination: pentachlorophenol (PCP) and creosote. Those are the typical contaminants of concern for sites affected by organic wood preservatives. Organic wood preserver sites are among the most common sites on the National Priorities List (NPL) maintained by the U.S. Environmental Protection Agency (EPA). 
The PCP concentration in the soil samples is estimated to be about $200 \mathrm{mg} / \mathrm{kg}$, and the PCP remedial goal established by the EPA for the site is $37 \mathrm{mg} / \mathrm{kg}$. Creosote is a mixture of hazardous organic compounds, and the EPA has established a remedial goal of $58 \mathrm{mg} / \mathrm{kg}$ of benzo(a)pyrene ( $\mathrm{BaP})$ equivalents for this particular site's soils. $\mathrm{BaP}$ is one of a series of $\mathrm{PAH}$ compounds present in creosote formulations and of particular concern to the EPA. "BaP equivalents" is a number that equals the sum of the BaP concentration and the toxicity equivalents of the concentrations of the other PAH compound of EPA concern present in the soil sample.

During the analysis of this soil sample, SRI developed an analytical protocol for extraction and analysis of heavy PAHs from the soil metrics; sample chromatograms are shown in Appendix D.

Soil Sample from Tallman Oil Company Site. The sample was obtained from a large stockpile of contaminated soil generated during the excavation of a contaminated site at 2401 North Elizabeth Street in Pueblo, Colorado, formerly occupied by the Tallman Oil Company. The subsurface soils were reportedly affected by uncontrolled releases of petroleum products from leaking underground storage tanks (LUSTs). The soil sample reportedly contains petroleum hydrocarbon compounds including benzene, ethylbenzene, toluene, and three xylene isomers (collectively referred to as BETX). A key aspect of this particular site is that the soil has an elevated clay content.

According to the State of Colorado's cleanup standards for hydrocarbon-contaminated soil, the following cleanup standards are applicable for the soil at the Pueblo site:

- Total petroleum hydrocarbons: $500 \mathrm{mg} / \mathrm{kg}$

- Benzene: $0.26 \mathrm{mg} / \mathrm{kg}$

- Toluene: $170 \mathrm{mg} / \mathrm{kg}$

- Ethylbenzene: $200 \mathrm{mg} / \mathrm{kg}$

- Xylenes: $1900 \mathrm{mg} / \mathrm{kg}$.

Our analysis of this sample showed very little high PAHs. The BTEX, toluene, and benzene were removed very efficiently from this sample at $275^{\circ} \mathrm{C}$.

EPA Certified Reference Material (CRM103). This sample, obtained from Resource Technology Corporation, is a USEPA certified soil with a high content of PAH (mainly, phenanthrene, fluoranthene, and pyrene) and pentachlorophenol. The values of concentration (Table 6) were determined by USEPA SW846 Methods 3540A (Soxhlet extraction) and 8270A (Semivolatile organics by GC/MS) and certified after extensive interlaboratory testing. 
Table 6

ANALYTE CONCENTRATIONS IN U.S. EPA CERTIFIED SOIL CRM103

\begin{tabular}{lcc}
\hline & Reference Value (mg/kg d.w.) & S.D. (mg/kg d.w.) \\
\hline Naphthalene & 34.8 & 10.3 \\
2-Methylnaphthalene & 60.4 & 15.4 \\
Acenaphthylene & $16.5^{*}$ & ---- \\
Acenaphthene & 627.2 & 214.0 \\
Dibenzofuran & 305.7 & 78.5 \\
Fluorene & 443.0 & 110.0 \\
Phenanthrene & 1924.9 & 493.0 \\
Anthracene & 431.1 & 103.0 \\
Fluoranthene & 1425.8 & 401.0 \\
Pyrene & 1075.1 & 341.0 \\
Benzo(a)Anthracene & 264.4 & 57.9 \\
Chrysene & 316.1 & 71.2 \\
Benzo(b)Fluoranthene & $114.7^{*}$ & ---- \\
sBenzo(k)Fluoranthene & $63.7^{*}$ & ---- \\
Benzo(b+k)Fluoranthene & 188.6 & 74.5 \\
Benzo(a)Pyrene & 96.5 & 28.6 \\
Pentachlorophenol & 1425.4 & 798.0 \\
Indeno(1,2,3-c,d)Pyrene & 31.9 & 17.7 \\
Dibenz(a,h)Anthracene & $14.2^{*}$ & ---- \\
Benzo(g,h,i)Perylene & $25.5^{*}$ & ---- \\
\hline${ }^{*}$ These values are not certified but are listed for information. & \\
\hline
\end{tabular}

\section{Special Experimental Apparatus and Procedures}

Experimental Setups. The two experimental setups used in this study were (1) static and (2) continuous flow. Appendix E shows schematics of these two systems.

Organic Solvent Extraction Procedure. Extraction was performed by shaking $1 \mathrm{~g}$ of sample with $30 \mathrm{ml}$ of acetone /dichloromethane $1 / 1$ for $30 \mathrm{~min}$ in a mechanical shaker. A known procedure was used to clean up the soil samples to remove the non-polar material other than PAHs (Schwab et al, 1999; Berset et al, 1999; Dupreyron, 1998; Hewitt, 1988).

Because the extraction of PAH with solvent can also cause other nonpolar compounds to be extracted, it was necessary to purify the extract before the instrumental analysis. The cleanup was performed in open chromatographic columns filled with $8.5 \mathrm{~g}$ of silica (activated at $130^{\circ} \mathrm{C}$, overnight). After conditioning the silica with $60 \mathrm{ml}$ of hexane, the extract was loaded. A first 
fraction was eluted with $75 \mathrm{ml}$ of hexane, and then $\mathrm{PAH}$ was eluted in a second fraction with $75 \mathrm{ml}$ of dichloromethane/hexane 60/40. The PAH fraction was concentrated in a rotary evaporator under reduced pressure. After adding the internal standard (1234-tetrahydronaphthalene), the sample was injected in HRGC-MS.

Determination of Soil pH. The $\mathrm{pH}$ of the samples was determined potentiometrically in slurry using an electronic $\mathrm{pH}$ meter. We placed $5 \mathrm{~g}$ of soil in a round glass flask and added $5 \mathrm{ml}$ of Milli-Q water. The mixture was shaken vigorously for 15 se and let stand for $30 \mathrm{~min}$. After this time, the electrodes were placed in the slurry and the $\mathrm{pH}$ was measured.

Determination of PAH Adsorption in Soils. Two solutions of pyrene in dichloromethane/acetone $1 / 1$ were prepared. The concentration of pyrene in one of them (solution A) was $154 \mu \mathrm{g} / \mathrm{ml}$, while the other (solution B) was ten-fold diluted $(15.4 \mu \mathrm{g} / \mathrm{ml}$ ) in comparison with solution A. A sample of each solution was taken and, after the addition of the internal standard, was analyzed by HRGC-FID to establish the reference level.

We then prepared four soil samples by mixing either bentonite or sand with known volumes of Solutions A and B. The prepared samples were allowed to equilibrate, and liquid samples were withdrawn from each sample at regular time intervals $(0,1,30,180 \mathrm{~min}$ and so on) to measure the amount of pyrene remaining in the soil sample. The liquid samples removed from the soil/solvent mixture were analyzed by HRGC-FID.

\section{Results for Spiked Soil Experiments}

We conducted experiments with sand and bentonite spiked with selected PAHs at $275^{\circ} \mathrm{C}$ with varying parameters to determine the rate of removal of organic from spiked soil samples. Table 7 gives the results of experiments with pyrene-spiked sand and bentonite." The table also compares the results of experiments with and without added sodium carbonate.

\footnotetext{
* We conducted a mass balance study to determine the optimal extraction times; these experiments are described in Appendix F. Based on the results of the optimization study, we selected 4 hours of extraction time to achieve maximum solubility at $275^{\circ} \mathrm{C}$.
} 
Table 7

RECOVERIES OF PYRENE OBTAINED IN THE TREATMENT WITH WATER AND $\mathrm{Na}_{2} \mathrm{CO}_{3}$ SOLUTIONS UNDER HYDROTHERMAL CONDITIONS $\left(275^{\circ} \mathrm{C}, 4 \mathrm{~h}\right)$ OF SPIKED SAND AND SPIKED BENTONITE AT TWO CONCENTRATION LEVELS

\begin{tabular}{|c|c|c|c|c|}
\hline & \multirow[b]{2}{*}{ Level } & \multirow[b]{2}{*}{ Water } & \multicolumn{2}{|c|}{ Extracting Agent } \\
\hline & & & $\mathrm{Na}_{2} \mathrm{CO}_{3} 0.1 \%$ & $\mathrm{Na}_{2} \mathrm{CO}_{3} 1 \%$ \\
\hline \multirow[t]{2}{*}{ Sand } & $350 \mu \mathrm{g} / \mathrm{g}$ & $12.2 \%$ & $16.5 \%$ & $38.4 \%$ \\
\hline & $5000 \mu \mathrm{g} / \mathrm{g}$ & $52.8 \%$ & ------- & $54.7 \%$ \\
\hline \multirow{2}{*}{ Bentonite } & $375 \mu \mathrm{g} / \mathrm{g}$ & $10.4 \%$ & ------ & ------- \\
\hline & $5000 \mu \mathrm{g} / \mathrm{g}$ & $3.7 \%$ & ------- & $34.2 \%$ \\
\hline
\end{tabular}

In general, the recoveries of pyrene obtained in the treatment of both soils with sodium carbonate solutions are better than those obtained in the extractions with water alone. A trend similar to that for pyrene is observed in the recovery of fluoranthene from the sand. The results obtained in these extractions are shown in Table 8. The extraction with sodium carbonate solutions yielded higher recoveries than the corresponding with water. In the conditions assayed ( $1 \mathrm{~g}$ of sand spiked at $350 \mu \mathrm{g} / \mathrm{g}$ level, temperature of extraction $275^{\circ} \mathrm{C}, 4 \mathrm{~h}$ of extraction), the percentage of fluoranthene recovered was $61.4 \%$.

Table 8

COMPARISON BETWEEN PYRENE AND FLUORANTHENE EXTRACTION (LEVEL $350 \mu \mathrm{g} / \mathrm{g}$ )

\begin{tabular}{lcl} 
& Water & $\mathrm{Na}_{\mathbf{2}} \mathrm{CO}_{3} \mathbf{1} \%$ \\
\cline { 2 - 3 } Pyrene & $12.2 \%$ & $38.4 \%$ \\
Fluoranthene & $19.0 \%$ & $61.4 \%$ \\
\hline
\end{tabular}

We also measured the $\mathrm{pH}$ of the treated samples to understand the effect of $\mathrm{pH}$ on the extraction efficiency. Examples of the measured final $\mathrm{pH}$ of the reactor content in relation to the sample content are given in Table 9. 
Table 9

EXAMPLES OF pH VALUES AND APPEARANCE OF PRECIPITATE IN EXPERIMENTS PERFORMED WITH WATER AND SODIUM CARBONATE SOLUTIONS UNDER HYDROTHERMAL CONDITIONS AT $275^{\circ} \mathrm{C}$

\begin{tabular}{lcccc}
\hline \multicolumn{1}{c}{ Sample } & Reagent & $\begin{array}{c}\text { Recovery of } \\
\text { Pyrene }\end{array}$ & $\begin{array}{c}\text { pH (After } \\
\text { Treatment) }\end{array}$ & $\begin{array}{c}\text { Precipitate? } \\
\text { (Color) }\end{array}$ \\
\hline Bentonite, $1 \mathrm{~g}, 5000 \mu \mathrm{g} / \mathrm{g}$ & Water & $3.7 \%$ & 4.1 & yes (dark brown) \\
Sand, $2 \mathrm{~g}, 5000 \mu \mathrm{g} / \mathrm{g}$ & Water & $10.3 \%$ & 6.4 & yes (brown) \\
Sand, $1 \mathrm{~g}, 5000 \mu \mathrm{g} / \mathrm{g}$ & $1 \% \mathrm{Na}_{2} \mathrm{CO}_{3}$ & $54.7 \%$ & 10.4 & no \\
Bentonite, $1 \mathrm{~g}, 5000 \mu \mathrm{g} / \mathrm{g}$ & $1 \% \mathrm{Na}_{2} \mathrm{CO}_{3}$ & $34.2 \%$ & 10.1 & no \\
Sand, $10 \mathrm{~g}, 5000 \mathrm{~g} / \mathrm{g}$ & $1 \% \mathrm{Na}_{2} \mathrm{CO}_{3}$ & $55.8 \%$ & 10.4 & no \\
\hline
\end{tabular}

As seen in Table 9, for lower $\mathrm{pH}$ samples, a higher amount of precipitate is correlated with a reduced recovery of pyrene. These precipitates are suspected to be iron oxide produced in the corrosion of the stainless steel reactors during the process. They can change substantially the properties of water at high temperature, producing a decrease in the amount of extracted pyrene. The use of sodium carbonate solutions seems to solve this problem. It acts as a buffer, keeping the $\mathrm{pH}$ at values around 10, and the amounts of pyrene obtained in the extractions are higher.

The comparison of the results obtained in the extraction of both types of soils (sand and bentonite) indicates that extraction of bentonite is more difficult than extraction of sand. It is probably due to the smaller particle size in bentonite, which can favor higher adsorption of PAH. This effect can probably be solved with a mechanical stirring of the mixture (soil + extracting agent) or obliging the solution to pass through the soil in a column.

In general, the highest recoveries obtained in the tested conditions are between $50 \%$ and $60 \%$. These recoveries correspond to percentage removal of $\mathrm{PAH}$ from sand/soil under static conditions. Therefore, this is the lower limit for the extraction efficiency. We conducted a series of experiments to determine the possible irreversible absorption of $\mathrm{PAH}$ into the soil/sand matrix. We also studied the extraction efficiency with extraction time and found that a 4-h reaction time is enough to achieve equilibrium. We determined the influence of the ratio amount of soil/amount of extracting agent (water or 1\% sodium carbonate solution) in the recovery of pyrene. Results are shown in Table 10. 
Table 10

\section{INFLUENCE OF RATIO AMOUNT OF SAND/AMOUNT OF EXTRACTING AGENT IN THE RECOVERY OF PYRENE (EXPRESSED IN \% AND $\mu \mathrm{g}$ )}

\begin{tabular}{ccccc}
\hline Amount of Sand/Amount of Water & \multicolumn{2}{c}{ Water } & \multicolumn{2}{c}{ 1\% Sodium Carbonate } \\
\hline $1 \mathrm{~g} / 30 \mathrm{ml}$ & $52.8 \%$ & $2663 \mu \mathrm{g}$ & $54.7 \%$ & $2757 \mu \mathrm{g}$ \\
$2 \mathrm{~g} / 30 \mathrm{ml}$ & $10.3 \%$ & $1039 \mu \mathrm{g}$ & ---- & ---- \\
$10 \mathrm{~g} / 30 \mathrm{ml}$ & $41.7 \%$ & $21188 \mu \mathrm{g}$ & $55.8 \%$ & $27841 \mu \mathrm{g}$ \\
\hline
\end{tabular}

From the results shown in Table 10, we conclude that, even in the most unfavorable case (the highest amount of soil and the lowest amount of extracting agent), the recovery of pyrene is around $50-60 \%$, especially when sodium carbonate solution is used. For this case, the equilibrium solubility of pyrene at $275^{\circ} \mathrm{C}(1 \mathrm{mg} / \mathrm{ml})$ is almost achieved. Therefore, a proportion of 3 (extracting agent) to 1 (soil) can be established as the minimum to use for the hydrothermal extractions. Also, these data are very encouraging because the maximum amount of PAH that can be removed is defined by the equilibrium solubility numbers given in Task 1, and complete removal of PAH is possible with stirring under flow conditions.

We believe more studies are necessary to understand the interactions between clay particles and PAHs. These studies were not suggested in our original proposal, but we believe such data would provide a fundamental understanding of the types of interactions that take place between soil and the organic matrix. Therefore, we conducted a few experiments to study the solubility reduction at temperatures above $275^{\circ} \mathrm{C}$. The data are discussed below.

\section{Solubility of Pyrene in Water Under Varying Conditions}

For this study, we selected a pyrene-water system because of the simplicity of sample preparation and analysis. Experiments were conducted in the temperature range $250^{\circ}-300^{\circ} \mathrm{C}$ under continuous-flow conditions. The parameters that varied were reactor material (stainless steel, quartz), added salt type (sodium carbonate, sodium sulfate), and the gas phase composition (air, argon). The observed results indicated that changing either reactor surface material or the gas phase composition resulted in no measurable change in extraction efficiency. However, there was a significant change in the appearance of the aqueous effluent in the reactor with added sodium sulfate. We believe sodium sulfate provides a high acidic medium at $250^{\circ} \mathrm{C}$, resulting in a brown precipitate that indicates reactor corrosion.

We have also identified trace quantities of 2-methyl-pyrene, 1,3-dimethyl-pyrene, 1pyrene-carboxaldehyde, and some phenol derivatives when pyrene is treated at $300^{\circ} \mathrm{C}$. These 
products can be considered as partial oxidation or hydrolysis products of the PAH. We have not detected these polar compounds in the experiments conducted below $250^{\circ} \mathrm{C}$.

\section{PAH $\rightarrow$ [Hydrolysis] $\rightarrow$ polar compounds \\ $\mathrm{PAH} \rightarrow$ [Oxidation] $\rightarrow$ polar compounds}

We believe that these polar compounds can easily be absorbed onto the soil matrix. Therefore, the reduction in recovery of pyrene at high temperatures can be attributed to formation of these pyrene derivatives. We are planning to investigate this further in the future.

\section{Organic Adsorption Mechanisms}

To optimize the conditions for removal of trace amounts of organics from soil, a better understanding of the interaction between soil particles and the organic molecules is necessary. The types of interaction involved in soil organic matter and clay include physical adsorption or interaction through van der Waals forces; electrostatic interactions (cation and anion exchange process); and cation and anion bridging, whereby the polyvalent metal forms a bridge between the organic molecule and the inorganic surface through coordination complexes, chemical adsorption, and H-bonding. However, the exact mechanism by which organics are bound to an inorganic clay/soil matrix is not clearly understood (Chefetz et al, 2000; Sparks, 1995). Therefore, in complex mixtures of organics and soil, identification of exact mechanisms becomes very difficult.

An adsorption isotherm, which describes the relation between the concentration of the organic in the solution and the quantity of the organic on the surface at constant temperature, can be used to describe the type of interaction between the organic and the surface. Therefore, we decided to carry out experiments to measure the adsorption isotherms for simple systems. We began our study by measuring desorption of a single PAH adsorbed onto sand. In this experiment, we used pyrene as the model compound. Sand was soaked in the pyrene. The initial pyrene loading on the sand was varied in the range of 0.3-6000 ppm. The "contaminated" sand was then mixed with $\mathrm{H}_{2} \mathrm{O}$ and loaded in the cell. The adsorption experiments were carried out at $275^{\circ} \mathrm{C}$. The equilibrium concentration was then measured by analysis of the solution. The results of these experiments are shown in Figure 9, which is presented as an equilibrium-based isothermal model similar to the empirical adsorption model described by Freundlich's Equation:

where

$$
\mathrm{q}=\mathrm{K}_{\mathrm{d}} \mathrm{C}^{1 / 2}
$$

$\mathrm{q}=$ adsorbate per unit mass of adsorbent,

$\mathrm{C}=$ equilibrium adsorptive concentration, and

$\mathrm{K}_{\mathrm{d}}=$ distribution coefficient. 
The linearity of the plot of $\log [q]$ vs. $\log [C]$ indicates a C-type isotherm ${ }^{1}$ for the pyrenesand-water system, suggesting a partitioning mechanism whereby the $\mathrm{PAH}$ is distributed between the interfacial face and the bulk solution without any specific bonding between sand and pyrene. However, in real soil containing soil organic material (humic substances) we expect to see a different adsorption isotherm. It is of great importance to study the adsorption isotherm for real soil-PAH-water systems, not only for the advancement of the HWE technology, but also for identifying possible organic mobility mechanisms within the soil matrix, which in turn predicts the possibilities of migration of organics into ground water.

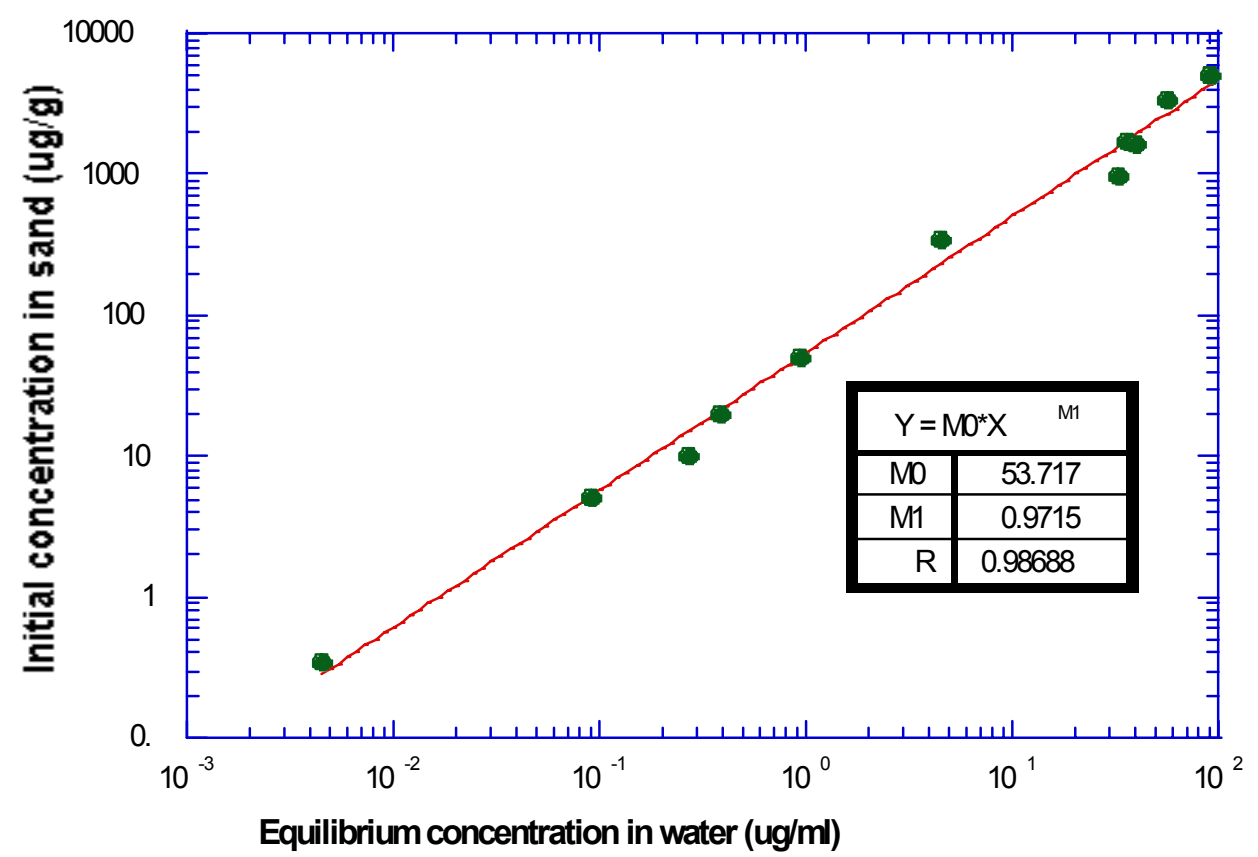

Figure 9. Adsorption isotherm for pyrene-sand system in water at $275^{\circ} \mathrm{C}$.

\section{Results for Industrial Soil Samples}

Soil from Organic Wood Preserve Site. A soil sample from the Organic Wood Preserve Site provided by Matrix Remediation was extracted with water and 1\% sodium carbonate solution under hydrothermal conditions $\left(275^{\circ} \mathrm{C}, 4 \mathrm{~h}\right.$, in stainless steel reactors). In addition, the sample was extracted by shaking with organic solvent, dichloromethane, and acetone (1/1). The results obtained for each sample are shown in Table 11.

In addition, the $\mathrm{pH}$ was determined for the two aqueous extracts. The $\mathrm{pH}$ was 5.5 when water was used as the extracting agent, and the $\mathrm{pH}$ was 10.2 when the extraction was performed with $1 \%$ sodium carbonate solution. The $\mathrm{pH}$ of the original soil was 7.6.

\footnotetext{
${ }^{1}$ There are four types of isotherms: S, L, H and C [3]
} 
A trend similar to that in spiked soil samples is observed in these results. The extraction with sodium carbonate solution is more effective than the extraction with water for most PAHs.

Table 11

COMPARISON OF THE CONCENTRATIONS OF PAH ( $\mu \mathrm{g}$ OF PAH / g OF SOIL) OBTAINED IN HYDROTHERMAL EXTRACTIONS (WATER AND SODIUM CARBONATE) AND IN ORGANIC SOLVENT EXTRACTION

\begin{tabular}{lccc}
\hline & Water & 1\% Sodium Carbonate & Organic Solvent \\
\hline Naphthalene & 3.26 & 4.18 & 0.24 \\
Phenanthrene & 0.96 & 0.90 & 1.31 \\
Fluoranthene & 7.30 & 8.90 & 11.7 \\
Pyrene & 18.2 & 28.2 & 23.3 \\
Chrysene & $---{ }^{1}$ & $---{ }^{1}$ & 16.5 \\
Benzo(a)pyrene & 4.58 & 4.82 & 9.18 \\
\hline
\end{tabular}

${ }^{1}$ Chrysene was not determined in these samples due to the presence of interference.

Moreover, if sodium carbonate extraction is compared with the organic solvent extraction, the recoveries of $\mathrm{PAH}$ are $52-76 \%$. For the most concentrated PAH, pyrene, hydrothermal extraction with sodium carbonate at $275^{\circ} \mathrm{C}$ is more effective than the organic extraction.

Soil Sample from Tallman Oil Company Site. Our analysis of this sample showed very little heavy PAHs. The BTEX, toluene, and benzene were removed very efficiently from this sample at $275^{\circ} \mathrm{C}$.

\section{Results for EPA-Certified Reference Material (CRM103)}

This sample was subjected to several tests to compare extraction efficiencies under different conditions. A detailed sample analysis was also conducted to compare with the EPAcertified PAH concentrations. Hydrothermal extraction was conducted in two types of reactors: (1) a static stainless steel reactor (Appendix E) used in spiked sample analysis and (2) a continuous-flow system (Appendix E). The hydrothermal extraction was conducted at $275^{\circ} \mathrm{C}$ and at 800 psi. The use of continuous system greatly enhanced the extraction efficiency as shown in Table 12. We also compared the efficiency of the hydrothermal process with other accepted soil remediation methods such as organic solvent extraction and thermal-desorption. We found the efficiency of continuous extraction to be equal to or greater than that for organic solvent extraction. A comparison of hydrothermal extraction versus organic extraction is shown in Figure 10. 
Table 12

\section{COMPARISON OF RESULTS FROM STATIC AND CONTINUOUS HYDROTHERMAL EXTRACTION SYSTEMS AT $275^{\circ} \mathrm{C}$ AND AT 800 PSI}

\begin{tabular}{lcc}
\hline PAH & Static Extraction & Continuous Extraction \\
\hline Naphthalene & 13 & 39 \\
Phenanthrene & 990 & 2131 \\
Fluoranthene & 550 & 1440 \\
Pyrene & 392 & 1304 \\
Chrysene & 76 & 344 \\
Benzo(a)pyrene & 13 & 99 \\
\hline
\end{tabular}

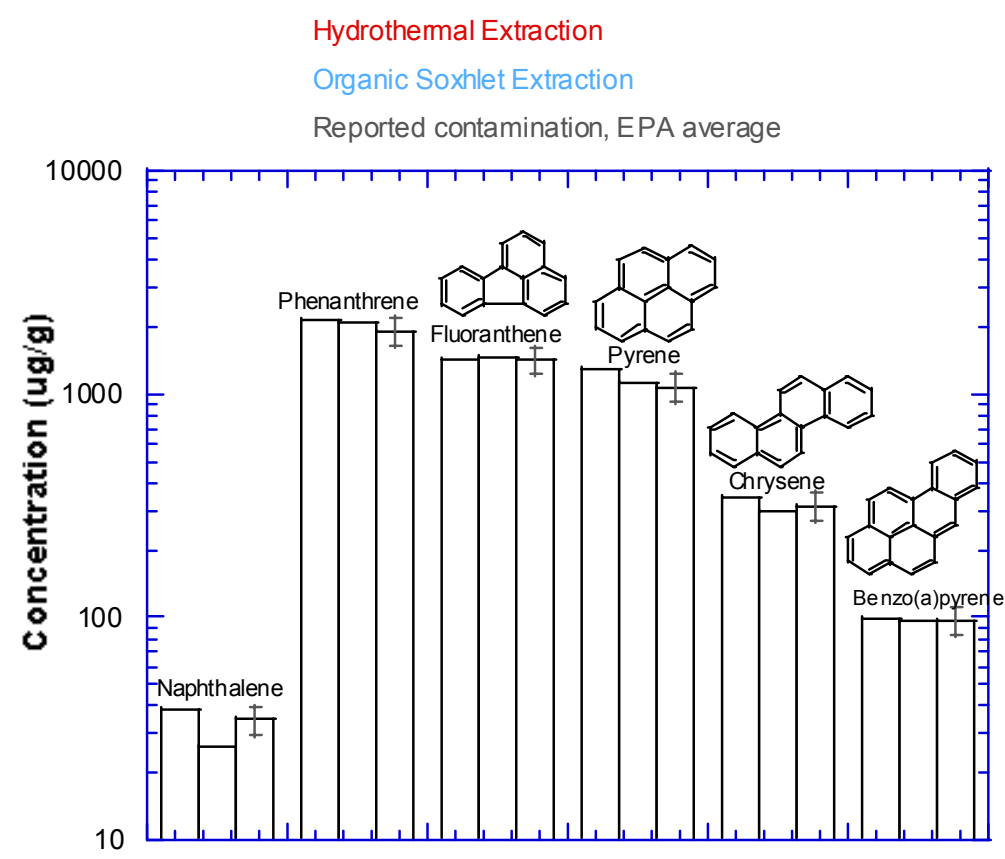

Figure 10. Comparison of PAH removal effciencies from EPA-certified contaminated soil sample.

These results clearly show that hydrothermal extraction is as efficient as organic extraction. Figure 11 compares the variation of percentage removal of each PAH with volume of water used in the continuous flow extraction system. The water volume used here is the upper limit, since we have not optimized the flow rate in this experiment. These optimizations are discussed in Task 4. 


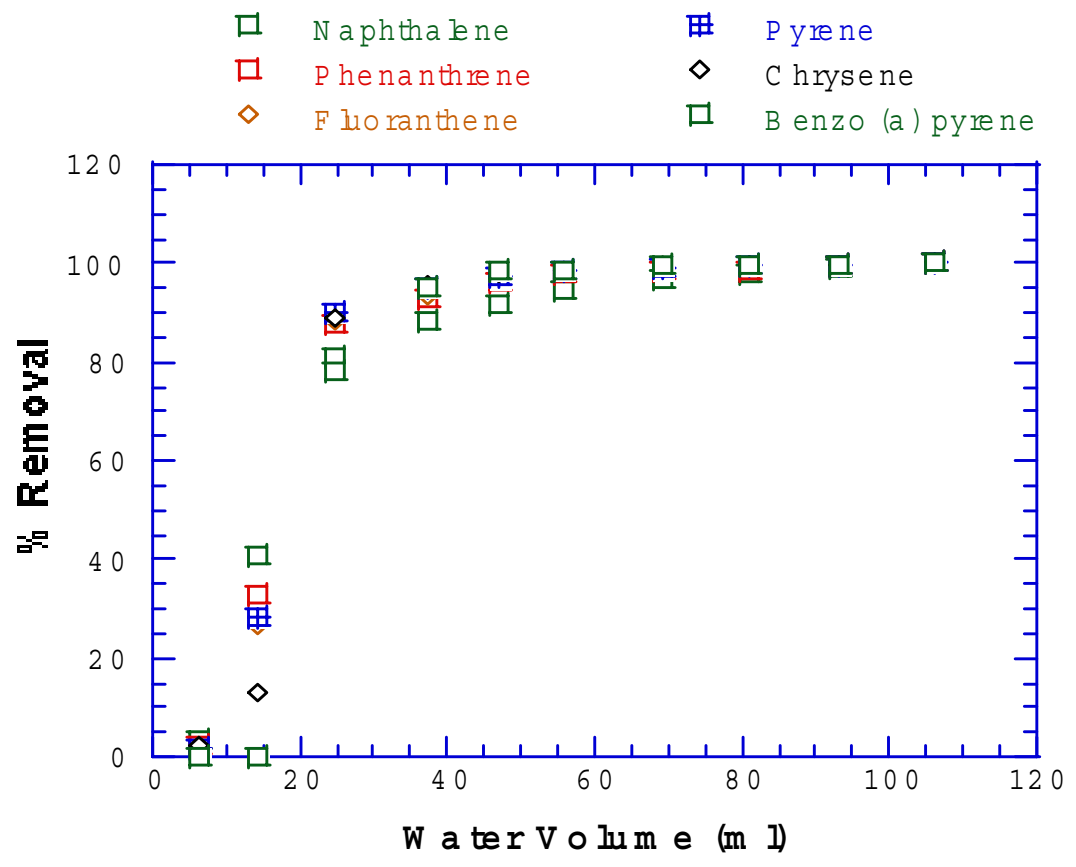

Figure 11. Variation of percentage PAH removal efficiency with volume of water at $275^{\circ} \mathrm{C}$ and $800 \mathrm{psi}$.

\section{Technology Comparison}

This work was carried out as part of Task 4 of this project. However, we thought it more appropriate to report this work under Task 2. We believe thermal desorption (TD) technology, which is a commonly used soil remediation technology, is an ideal candidate for technology comparison (Maguire et al, 1995). We have reviewed six site reports on several remedial technologies in Task 3 (Task 3 was conducted in parallel with Task 2). A fact sheet on TD technology for soil remediation at the McKin Company Superfund Site is given in Appendix G. When comparing technologies, it is essential to compare removal efficiencies for a reference soil sample treated under similar conditions. Therefore, we decided to measure the efficiency of both TD and HWE for removing PAHs from EPA-certified samples under controlled conditions. We designed and built a bench-scale system that can be easily modified to function either as a HWE, TD, or combined TD-HWE system for testing the standard soil samples. The bench-scale system and its different modes of operation are described in Appendix $\mathrm{H}$.

The observed results under different modes of operation — HWE, TD, and HWE/TD — are discussed below. 


\section{Comparison of HWE and TD: EPA Sample}

Both HWE and TD experiments were conducted using EPA-certified soil at $275^{\circ} \mathrm{C}$ and $375^{\circ} \mathrm{C}$. The information on organic composition of the EPA sample and the analytical method used for confirming organic composition was given in Table 6.

In HWE experiments, the system pressure was maintained above the saturated pressure of water to ensure presence of liquid water. The results at $275^{\circ} \mathrm{C}$ under $\mathrm{HWE}$ and TD conditions are given in Figures 12 and 13, respectively.
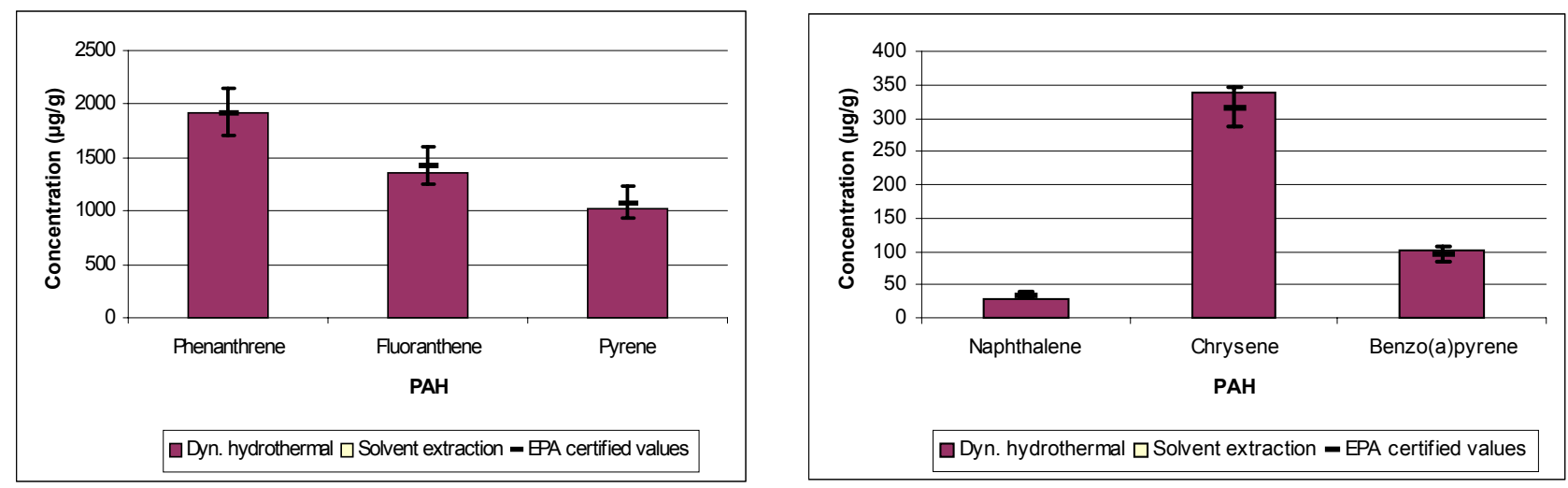

Figure 12. Recoveries of PAHs under HWE conditions at $275^{\circ} \mathrm{C}$ and $800 \mathrm{psi}$.
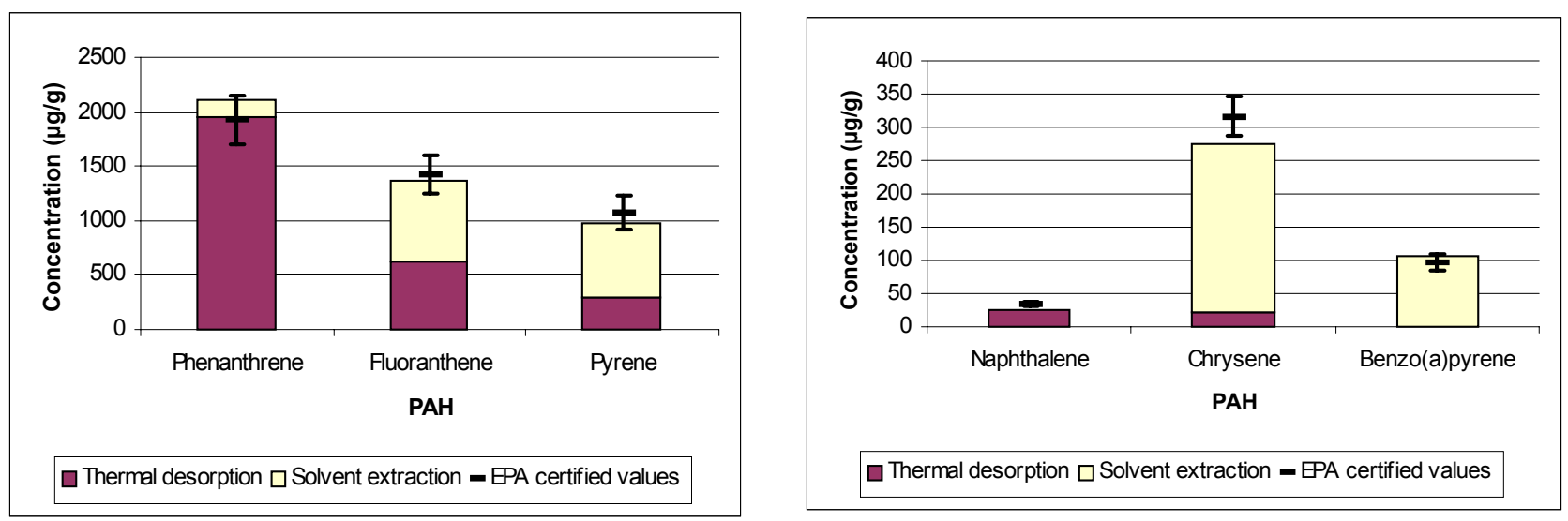

Figure 13. Recoveries of PAHs under TD conditions at $275^{\circ} \mathrm{C}$.

The data clearly show that TD is not very effective in removing heavy PAHs at $275^{\circ} \mathrm{C}$. Thermal desorption technology is somewhat effective for removing lighter PAHs such as phenanthrene and naphthalene. However, it is not effective at all for removing pyrene, chrysene or benzo(a)pyrene. We expected the efficiency of TD to be improved at a higher temperature and carried out experiments to determine its efficiency at $375^{\circ} \mathrm{C}$. However, the process showed little improvement in efficiency at $375^{\circ} \mathrm{C}$, indicating that PAHs are strongly bound to the soil 
matrix. These results are shown in Figure 14. In typical TD operations, temperatures as high as $600^{\circ} \mathrm{C}$ are necessary for removing PAHs [4].
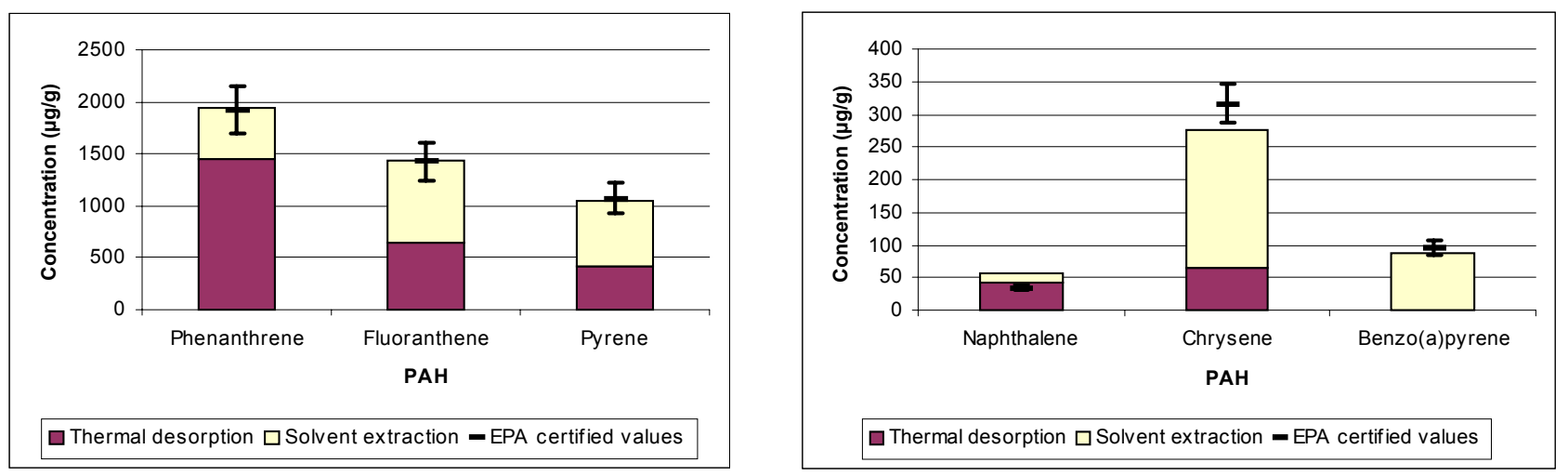

Figure 14. Recoveries of PAHs under TD conditions at $375^{\circ} \mathrm{C}$.

SRI data clearly demonstrate that HWE is more suitable for removing heavy PAHs from contaminated soil matrices.

\section{Comparison of TD with Added Steam: EPA-Certified Sample}

Since the TD process is an EPA-approved technology, any advancement of this technology would be very useful. Therefore, we conducted a series of experiments to determine the effect of steam on the TD process under ambient pressure conditions at $275^{\circ}-375^{\circ} \mathrm{C}$. The experimental procedure and the bench-scale reactor system used for this study are given in Appendix B. The results of these experiments at $275^{\circ} \mathrm{C}$ are shown in Figure 15.
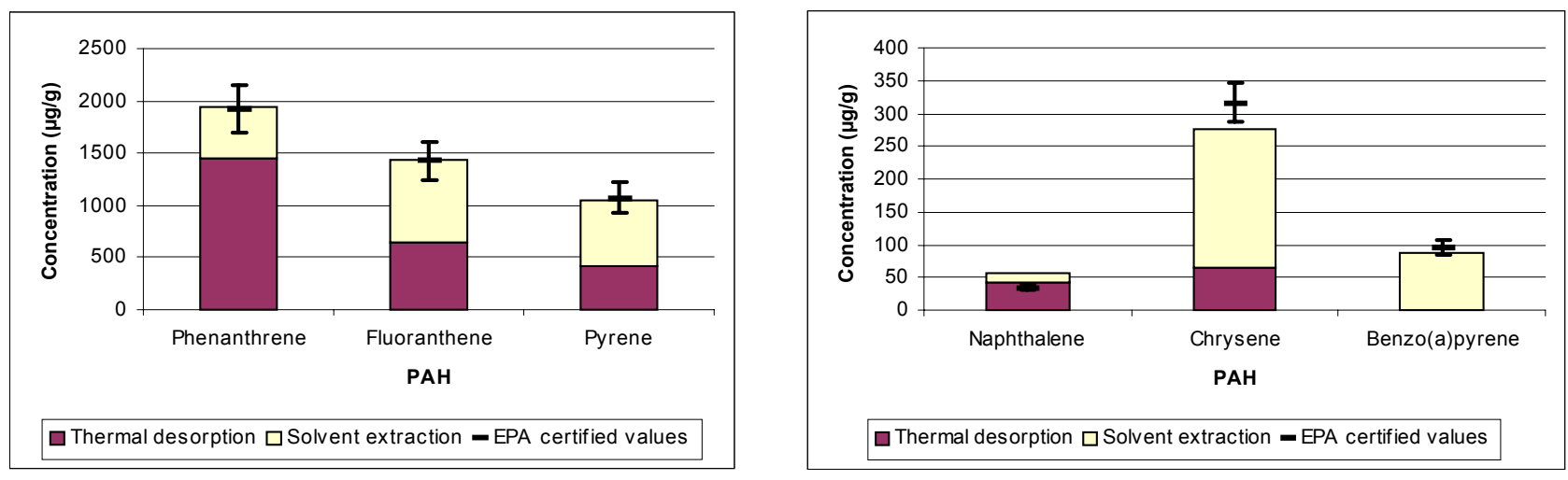

Figure 15. Recoveries of PAHs under steam-assisted thermal desorption conditions at $275^{\circ} \mathrm{C}$. Steam flow 0.06 to $0.12 \mathrm{ml} / \mathrm{min}$. 
Comparison of TD data alone (Figures 13 and 14) with steam-assisted data (Figure 15) clearly shows an enhancement of removal efficiency for all six selected PAHs under steamassisted conditions. Table 13 gives a summary comparison of TD and steam-assisted TD. Note that the mass imbalance in naphthalene is due to loss of sample during sample collection. The effectiveness of the steam-added process is more pronounced in PAHs such as pyrene, fluoranthene, chrysene, and benzo(a)pyrene, and we think complete removal of benzo(a)pyrene can be achieved under optimized conditions. Therefore, more studies are needed to improve the efficiency of steam-assisted TD for removal of heavy PAHs.

\begin{tabular}{lcc}
\hline \multicolumn{3}{c}{ Table 13 } \\
COMPARISON OF THERMAL DESORPTION AND STEAM-ASSISTED THERMAL \\
DESORPTION AT 275
\end{tabular}

\section{Technology Comparison Matrix}

Table 14 provides a summary of technology efficiencies for remediating soils containing VOCs, SVOCs, and PAHs.

\section{Table 14}

SUMMARY OF TECHNOLOGY EFFICIENCIES IN SOIL REMEDIATION

\begin{tabular}{cccc}
\hline Technology & VOCs & Efficiency & \\
\hline HWE at $275^{\circ} \mathrm{C}$ & $\sqrt{ }$ & SVOCs & PAHs \\
TD at $275^{\circ} \mathrm{C}$ & $\sqrt{ }$ & $\sqrt{ }$ & $\sqrt{ }$ \\
& & & Poor \\
\hline
\end{tabular}




\section{TASK 3: EVALUATE SITE REPORTS}

We have completed evaluation of site reports related to remediation of sites containing PAHs. We have evaluated six sites:

1. Thermal desorption at the McKin Company Superfund site, Gray, Maine

2. Soil vapor extraction at the Sacramento Army Deport Superfund site.

3. Bioremediation at the Champion International Superfund site, Libby, Montana.

4. Land treatment at the Burlington Northern Superfund Site, Brainerd/Baxter, Minnesota

5. Slurry Phase Bioremediation Application at the Southern Wood Preserving Superfund Site, Canton, Mississippi

6. Composting Application at the Dubose Oil Product Co. Superfund Site, Cantonment, Florida

We conducted this work in parallel with Tasks 1 and 2 to better select the suitable model compounds. We have created a database to compare the contaminants and the remediation goals in each site.

The main goal of this the evaluation of site reports was to identify pollutants present in these sites and use that as a basis for selecting model compounds used in Tasks 1 and 2 of this study (Sims, 1990; Mangas et al, 1998). 


\section{RESULTS OF PHASE 2 WORK}

\section{TASK 4. BENCH-SCALE DEMONSTRATION}

This task involves demonstration of HWE technology at an advanced bench-scale level and determination of some important reactor parameters for engineering evaluation in Task 5. We have also proposed to compare HWE with other existing technologies. The comparison of HWE with thermal desorption is reported under Task 2 of this report, and only the advanced bench-scale demonstration is discussed here.

Advanced bench-scale demonstration of HWE involves design and building of the benchscale system and demonstration of the efficiency of the technology using real-world soil containing VOCs, SVOCs and PAHs. Below, we discuss the details of the bench-scale system and the testing procedures for performance evaluation.

\section{Bench-Scale System}

For this study, we modified one of SRI's continuously stirred tank reactors. Figure 16 shows a photograph of the modified system. This system consists of a reagent feed system, a 300-mL stirred autoclave, and a reactor effluent handling system. The liquid feed system consists of two high-pressure pumps, a pre-heater, and high-pressure stainless steel tubing. The pre-heated reagents (salt solution and water) are pumped into the reactor using two pumps: a Rainin high-pressure pump (Model HPLX) and an ISCO syringe pump (Model LC-286). The reactor is a conventional, 300-mL, stirred Autoclave Engineers batch reactor constructed of Hastelloy C-276. The allowable working pressure is 4000 psi at a working temperature of $374^{\circ} \mathrm{C}$. The reactor is equipped with a $1-\mathrm{kW}$ electric heater, $1 / 8$-in. thermowell, $1 / 8$-in. inlet and outlet nozzles, and a 1/4-in. pressure relief line fitted with an Inconel rupture disk set at 4000 psi. Pressure is measured using transducer gauges on the inlet line and in the reactor. The autoclave is fitted with a six-blade magnetically driven agitator. The effluent handling system consists of a series of filters, a liquid/gas separator, and a back-pressure regulator. 


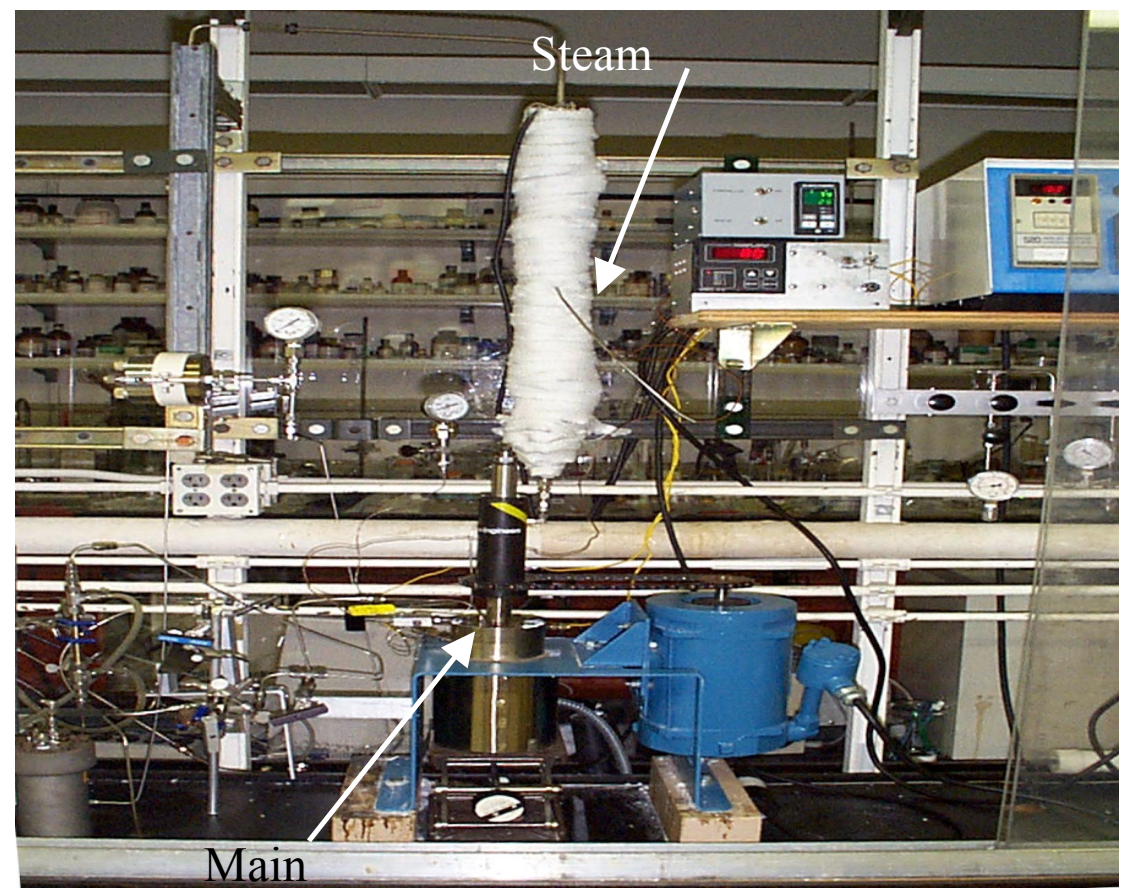

Figure 16. Bench-scale reactor system for treatability studies.

Even though a fully continuous system is preferred, only a semi-continuous operation can be performed using this system. We believe - and the engineers confirmed - that the demonstration using a fully continuous system would not be feasible at this stage because the soil feeding and removal system have not been developed. That is a task to undertake in the future, before development of the pilot plant.

In a typical run, soil samples to be cleaned are placed inside the stainless steel cladding and lowered into the reactor (we have modified the reactor with a removable stainless steel cladding for convenient soil introduction and removal). The reactor is closed and the extraction process begins by introducing steam at $250^{\circ} \mathrm{C}$ into the reactor. During this process, the reactor was also heated using band heaters to maintain the soil temperature at or above $275^{\circ} \mathrm{C}$. It takes about 2 hours to bring the main reactor to $275^{\circ} \mathrm{C}$. Once the reactor conditions are equilibrated at $275^{\circ} \mathrm{C}$ and $800-1000$ psi pressure, the water fraction containing organics from the reactor is removed via the effluent removal loop. During this process, the reactor pressure is maintained at a desired pressure by adding steam to the reactor. Effluent removal can be done in two ways: liquid phase removal and gas phase removal. To achieve a satisfactory removal of heavy organic components, a liquid phase removal is preferred. This process involves removal of the reactor contents while maintaining the reactor pressure above the saturated vapor pressure of water. In our demonstration we used a combination of both gas phase and liquid phase removal. We noted 
that during the effluent removal, the reactor temperature would decrease to about $250^{\circ} \mathrm{C}$. After each extraction, fresh steam was introduced into the reactor to replenish the reactor. In a controlled operation, the amount of water removed from the reactor and the amount of fresh water required to maintain the pressure would be the same. When charging the reactor with water, a flow rate of $5 \mathrm{ml} / \mathrm{min}$ or less is used to maintain the steam temperature at $250^{\circ} \mathrm{C}$ with help of the pre-heater.

We analyzed the collected effluent using both gas chromatography/mass spectrometry (GC/MS) and GC/FID to determine the pollutant removal efficiency. A few examples of parameters that can be adjusted to attain the required removal goals are the amount of water, sample amount, and number of washes. Once the extraction process was complete, the system was allowed to cool down, and we retrieved the clean soil sample from the reactor. We then analyzed the organic content in the soil using the method described in Phase 1.

\section{Performance Testing with Single-Component-Spiked Soil Samples}

Once the construction of the system was completed it was necessary to check the performance of each section of the bench-scale system for proper operation. We began our testing with single-contaminant soil samples to test the system operation. These tests were conducted with soil samples spiked with pyrene at a concentration level of $5000 \mu \mathrm{g} / \mathrm{g}$. We used two soil samples in this study: (1) sand supplied by Mallinckrodt consisted of more than $90 \%$ crystalline quartz $\left(\mathrm{SiO}_{2}\right)$ - a very fine powder that consisted principally of aluminum silicate (clay); and (2) soil samples taken from Menlo Park, CA, consisting of organic material (humic substances). Table 15 shows measured soil characteristics of these two soil samples.

Table 15

SOIL CHARACTERISTICS OF STUDIED SAMPLES

\begin{tabular}{ccc}
\hline Sample & pH & Particle Size \\
\hline Sand & 7.1 & $0.2-0.4 \mathrm{~mm}$ \\
Real soil & 6.6 & $0.4 \mathrm{~mm}$ \\
\hline
\end{tabular}


The main purpose of this initial testing was to test the proper functioning of each of the sections in the bench-scale treatment system. During this testing, we varied the following parameters: flow rate, heating rate, amount of water and soil, reactor pressure, reactor temperature, etc. Under these varying conditions, operation of each section of the system was carefully monitored and recorded to avoid any system failure during the testing of the realworld soil. We took special care to monitor the reactor pressure and leaks from various joints.

We also conducted a few tests to determine the optimal water/soil ratio suitable for this system. Based on the results of these experiments, the optimum water to soil ratio was selected as 1:6. To maintain this ratio, the maximum amount of soil that can be used in a single run is $15 \mathrm{~g}$. As can be noted from the data shown in Table 16, the organic removal efficiency can be improved by increasing the number of washings or extraction cycles.

Table 16

INFLUENCE OF DIFFERENTS PARAMETERS IN THE RECOVERY OF PYRENE (EXPRESSED IN \% AND $\mu \mathrm{g}$ )

\begin{tabular}{cccc}
\hline $\begin{array}{c}\text { Amount of Sand or } \\
\text { Soil/Amount of Water }\end{array}$ & $\begin{array}{c}\text { Ratio } \\
\text { Soil (or Sand)/Water }\end{array}$ & No. of washings & Recovery \\
\hline $25 \mathrm{~g}$ sand/ $125 \mathrm{~mL}$ & $1: 5$ & 2 & $90.5 \%$ \\
$25 \mathrm{~g}$ sand / $125 \mathrm{~mL}$ & $1: 5$ & 3 & $99.1 \%$ \\
$25 \mathrm{~g} \mathrm{soil} / 125 \mathrm{~mL}$ & $1: 5$ & 3 & $90.6 \%$ \\
$15 \mathrm{~g}$ soil/ $90 \mathrm{~mL}$ & $1: 6$ & 3 & $94.1 \%$ \\
\hline
\end{tabular}

As the intent of this study was not to optimize the conditions to reach the maximum extraction efficiency but to demonstrate the functioning of the bench-scale system, parameters were not adjusted to reach $100 \%$ recovery of the pyrene from the soil sample. The next section discusses the technology demonstration with soil samples containing high levels of pollutants. 


\section{Technology Demonstration with Highly Concentrated Soil Samples}

The final test of the performance evaluation is to test the bench-scale system with realworld soil. For this purpose, we selected CORSA-PREMEX drilling mud, which contains about $20 \mathrm{wt} \%$ total petroleum hydrocarbons (TPH), with a major fraction containing VOCs for this demonstration. We believe this soil is ideal for this demonstration because it contains a whole range of pollutants, including VOCs, SVOCs, PAHs, and heavy PAHs. The cleanup goal for this particular drilling mud was to reduce the TPH level down to $200 \mathrm{mg} / \mathrm{kg}$. To remediate this soil, we first apply a stem flushing technique to remove the VOCs, followed by HWE to remove SVOCs and PAHs.

Although the reported pollution concentration for this site is about $20 \mathrm{wt} \% \mathrm{TPH}$, the exact concentration may change with the sampling and storage method. Figure 17 shows the sample containers and their appearance as received. Our initial examination of the sample indicated the presence of some mobile fluid. Therefore, before the analysis, we drained the excess fluid from the soil and allowed it to dry. This pre-treated (drained and dried) sample contained about $6.6-6.8 \mathrm{wt} \% \mathrm{TPH}$, indicating that more than $75 \%$ of the contaminants can be removed from the mud by removing the mobile fluid under ambient conditions. Our analysis identified organics in the range C11-C25 present in varying amounts. SRI analysis of this soil is given in Appendix I.

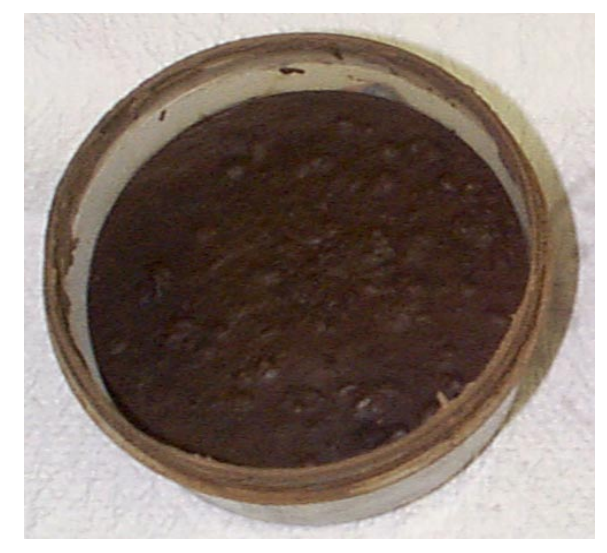

Figure 17. Photograph of the drilling mud container as received.

In remediating this mud, our approach in this treatment was first to apply a steam flushing technique at $100^{\circ} \mathrm{C}$ under ambient pressure conditions to remove most of the volatiles, followed by $\mathrm{HWE}$ at $275^{\circ}-290^{\circ} \mathrm{C}$ and $800-1000$ psi for removing SVOCs and PAH. Appendix J 
gives a description of the steam flushing and the data for VOC removal efficiency. The results from steam flushing clearly suggested that more than $50 \%$ of the TPH could be removed from the mud from this process alone. Therefore, prior to HWE treatment, each sample was pretreated using steam flushing to remove most of the VOCs. In this test, we performed steam flushing and HWE separately for convenience. However, it would be more cost effective to use a single system for both steam flushing and HWE.

During the HWE process optimization, we varied several parameters to improve the process efficiency. Table 17 shows a few examples of conditions varied during this optimization.

Table 17

A FEW EXAMPLES OF VARIED EXPERIMENTAL PARAMETERS

\begin{tabular}{ccccc}
\hline Experiment \# & $\begin{array}{c}\text { Number of } \\
\text { wash cycles }\end{array}$ & $\begin{array}{c}\text { Sample } \\
\text { size }(\mathbf{g})\end{array}$ & $\begin{array}{c}\text { Reactor water } \\
\text { content } \mathbf{( g )}\end{array}$ & Stirring \\
\hline 201 & 4 & 20 & 120 & No \\
205 & 4 & 15 & 90 & Yes \\
211 & 4 & 15 & $90^{*}$ & Yes \\
213 & 4 & 15 & $90^{*}$ & Yes \\
\hline
\end{tabular}

* $1 \%$ sodium carbonate

We have reported above only a sample set of experiments in which we conducted a full analysis of organics present in each fraction (reactor effluent, reactor washings, soil fraction, etc.). Several other runs were carried out to optimize the effluent removal from the reactor as well. As the goal of this was to demonstrate the efficiency of HWE for complete extraction of organics form the soil matrix, the conditions used here may not be the most cost-effective conditions. More studies are needed to optimize the conditions for improving cost effectiveness.

Table 18 compares the results of the drilling mud extraction experiments. Only pure water is used in runs 201 and 205 as the extracting solvent for organic removal. However, two different extracted fluid removal methods are applied in these two runs. In run number 201 we removed extracted fluid under liquid conditions, while in run number 205 we applied a combination of liquid and gaseous removal. As there was an increase in pollutant removal efficiency under the conditions applied in run 205, all the other experiments (211-226) were conducted under combined liquid and gaseous sample removal conditions. Also, it is clear from 
these data that the use of $1 \%$ sodium carbonate greatly enhances the extraction efficiency. This was expected based on the results of Task 2 experiments.

TABLE 18

COMPARISON OF RESULTS OF THE DRILLING MUD EXTRACTION EXPERIMENTS

\begin{tabular}{ccccc}
\hline Experiment \# & $\begin{array}{c}\text { TPH untreated } \\
(\mathbf{m g} / \mathbf{k g})\end{array}$ & $\begin{array}{c}\text { TPH after steam } \\
\text { flushing }(\mathbf{m g} / \mathbf{k g})\end{array}$ & $\begin{array}{c}\text { TPH after HWE } \\
(\mathbf{m g} / \mathbf{k g})\end{array}$ & $\begin{array}{c}\text { Total removal } \\
(\%)\end{array}$ \\
\hline & & & & \\
201 & 65995 & 47341 & 4239 & 93.5 \\
205 & 65695 & 33895 & 2674 & 95.9 \\
$211^{*}$ & 65695 & 30457 & 109 & 99.8 \\
$213^{*}$ & 65695 & 26974 & 165 & 99.7 \\
\hline
\end{tabular}

* $1 \%$ sodium carbonate

The results in Table 18 clearly show that the remediation goal for the drilling mud was achieved under SRI HWE conditions. As this mud contained both VOCs and SVOCs, the ability of the HWE technology was satisfactorily demonstrated. As a final confirmation, we also treated EPA certified soil. The experimental conditions used in testing the EPA sample were similar to the conditions used in run 211 in drilling mud experiments. We performed several optimization experiments (as shown in Appendix K) to obtain the similar remediation level that we have achieved with smaller scale (1-g) samples in Task 1 (see Table 19). 
Table 19

PAH REMOVAL UNDER HWE CONDITIONS

\begin{tabular}{lcc}
\hline \multicolumn{1}{c}{ PAH } & $\begin{array}{c}\text { Maximum Untreated } \\
\text { Soil Concentration }\end{array}$ & $\begin{array}{c}\text { HWE Treated } \\
\text { Soil Concentration }\end{array}$ \\
\hline Naphthalene & 34.8 & $\mathrm{ND}(<0.2 \mathrm{ppm})$ \\
Phenanthrene & 2133.6 & $\mathrm{ND}(<0.2 \mathrm{ppm})$ \\
Fluoranthene & 1592.6 & $\mathrm{ND}(<0.2 \mathrm{ppm})$ \\
Pyrene & 1216.3 & $\mathrm{ND}(<0.2 \mathrm{ppm})$ \\
Chrysene & 345.8 & $\mathrm{ND}(<0.5 \mathrm{ppm})$ \\
Benzo(a)pyrene & 96.5 & $\mathrm{ND}(<0.5 \mathrm{ppm})$ \\
\hline
\end{tabular}

\section{TASK 5: EVALUATE PARAMETERS FOR TECHNOLOGY TRANSFER}

\section{Issues and Technical Barriers}

Technology cost and performance are affected by waste characteristics and treatment technology operating conditions. Some commonly measured parameters that affect the cost and performance of remediation technologies (including HWE) are soil classification, clay content, particle distribution, moisture content, air permeability, $\mathrm{pH}$, porosity, total organic carbon (TOC), total petroleum hydrocarbons (TPH), air flow rate, operating pressure/vacuum, temperature, and residence time. Detailed descriptions of these parameters are given in Appendix L. However, hot water technology is not affected by many of the parameters that affect the other remediation technologies. Our experiments in Tasks 1, 2, and 4 were designed to measure the impact of these factors and to mitigate the negative effects of parameters important to hot water technology (i.e., temperature, pressure, residence time, $\mathrm{pH}$, clay content, and particle distribution). The major cost contributors to HWE technology are the required pressure and temperature conditions. We expect some of this cost to be recovered by the fuel value of the separated contaminants.

Below we discuss the engineering evaluation of HWE based on the results obtained in Task 4 . 


\section{Engineering Evaluation}

This work was conducted in collaboration with Sequoia Engineering \& Design Associates (Sequoia). The goal of this study was to evaluate the engineering parameters to identify the key information necessary for building a pilot plant for implementation of HWE technology.

The data from the bench-scale study were provided to Sequoia for preliminary design of the HWE treatment system. These data included total soil/waste mass flow rate, soil/waste compositional analysis, soil type and initial particle size distribution, initial soil moisture content, and sodium carbonate mixing ratio. In addition, reaction kinetics/residence time data, optimum reactor operating temperature/pressure, and the suggested waste recovery partitioning ratio between pretreatment and the HWE unit operations were also provided as required for a reasonable design.

The preliminary system is designed to contain the following components:

- Contaminated soil pretreatment and feed system

- Main reactor system

- Treated soil removal system

- Hydrocarbon recovery system.

\section{Contaminated Soil Pretreatment and Feed System}

It may be possible to employ high-pressure hot water jetting equipment to facilitate soil size reduction and transport into the HWE reactor as a slurry via a screw conveyor. The soil would be loaded onto a size-control screen (within a loading hopper) above a trough containing a screw conveyor. Hot water jets would be automatically or manually directed against the exposed face of the soil pile to break down clumps and allow the resulting slurry to pass through the screen into the screw conveyor, and subsequently into the HWE reactor. For this concept to be feasible, it will be necessary to investigate if there is some maximum mixing ratio for slurry water that should not be exceeded to maintain a $>99 \%$ removal efficiency.

\section{Main Reactor System (HWE)}

As a preliminary approach, we could consider performing the HWE process under saturated conditions, with a generous vapor space above the liquid phase to assist solid/liquid disengagement and separation from the water vapor hydrocarbon stream. The reactor would be 
heated by direct injection of steam into the bottom portion of the reactor vessel. The steam would also serve to strip and transport hydrocarbons from the soil/liquid phase in the reactor, and could be designed to provide a degree of added agitation. Carryover of solids should be minimal. The hydrocarbon would leave the reactor as a water-saturated vapor for subsequent separation, recovery, and water treatment. Water and carbonate would be added to the reactor to maintain liquid level and required carbonate concentration. The HWE treated soil may be self-drying upon depressurization before the next soil loading cycle. If the soil can be effectively pretreated via a steam/water flush, then the only difference between pretreatment and HWE would be the elevated pressure and addition of carbonate during the HWE process step. The same hydrocarbon (HC) recovery cycle would work for both pretreatment and HWE. To minimize soil handling/transport operations, it may be best to have two or three pretreatment/HWE reactors operating in parallel on a semi-batch process. Loading and unloading the reactors would thus be performed at ambient pressure, another significant simplification. Heat exchangers would be provided on the HWE reactor outlet to preheat steam boiler feedwater and improve reactor heat balance. We are also considering other alternatives such as slurry phase transport.

\section{Treated Soil Removal System}

Two possible removal systems were considered, depending on the soil/water ratio in the main reactor

1. Transport as concentrated slurry: We would consider transporting the treated soil from the HWE reactor as concentrated slurry, possibly allowing the soil to dewater and dry by gravity drainage and natural evaporation, respectively. There would be no need for separate dust suppression or soil-quench systems. However, this would require that the residual HWE process water be of suitable quality for direct land disposal.

2. Dry removal: Upon completion of the HWE step, we would depressurize the reactor while injecting superheated steam to maintain high soil temperature for $\mathrm{HC}$ and residual water removal, as suggested. The soil would become bone dry during this step, so we would consider venting this step via a venturi separator or waterquench tank for dust control. Once this step is complete, we would add water for slurrying and transport from the reactor. A hydraulic-motor-driven agitator would provide high torque at low speeds, which would be necessary for mixing the highly concentrated slurry. 


\section{Hydrocarbon Recovery System}

The method for separating hydrocarbon and water may be significantly affected by the nature of the specific wastes to be separated (i.e., vapor pressure and density). If we use the vapor phase $\mathrm{HC}$ transport concept, as mentioned above, then we could subsequently cool the vapor stream and separate the water and condensable HCs in a simple gravity-type gas/liquid separator for subsequent liquid/liquid separation. Final distillation can be done using fractional distillation or stripping to achieve required $\mathrm{HC} /$ water separation efficiency. The separated noncondensable vapor would be used for fuel. It is the water-soluble HCs and/or low-volatility HCs that pose a concern in terms of being able to develop one "standard" HC/water separation system. Perhaps we could use a single distillation column with multiple feed inlet nozzles along the height of the column, allowing us to vary the stripping/rectification ratio to best match a given application. Also, it is likely that the specific HC/water separation system used in conjunction with the HWE reactor will be dependent on the waste type and the optimal process configuration and operating parameters that are being determined during treatability testing with the pilot plant.

Other alternative processes also need to be considered to address the above process operations. Figure 18 shows the preliminary process flow diagram (PFD) prepared by Sequoia for the removal of $\mathrm{HC}$ and water from the reactor in the vapor state. 


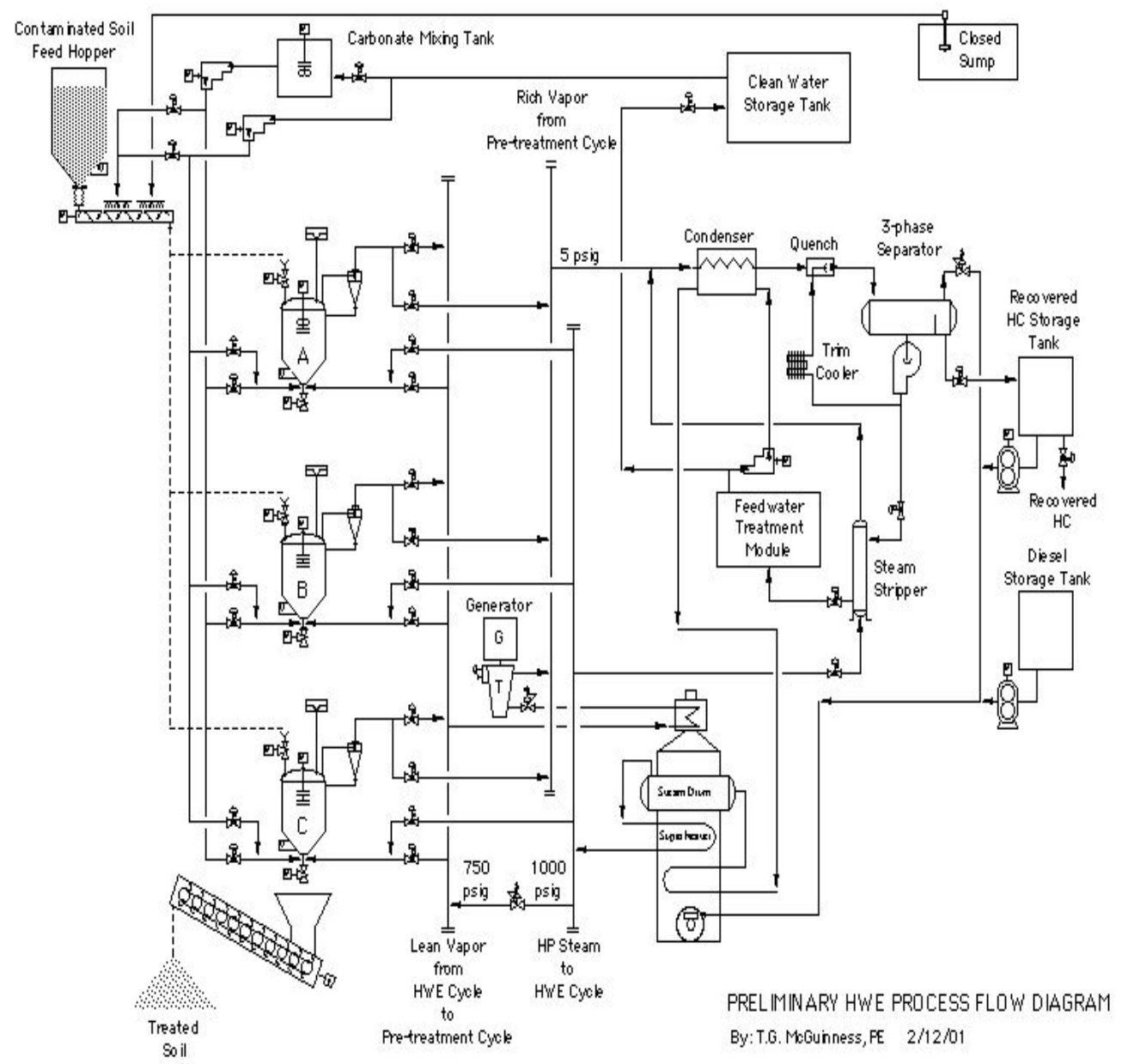

Notes: 1. Diagram shows scheme for removing all $\mathrm{HC}$ and water from the reactor in the vapor state.

2. Process flow diagram for removing $\mathrm{HC}$ and water from the reactor in the liquid state is under development.

Figure 18. Preliminary HWE process flow diagram.

The above system is designed to perform all required treatments on a single load of soil in the same reactor vessel, thereby eliminating reactor-to-reactor soil transfer operations. The basic sequence of events for a single batch of soil is as follows:

1. Load soil into reactor vessel A.

2. Pre-treat soil in Reactor A by steam stripping and mechanical agitation at nearambient pressure, with or without the presence of sodium carbonate solution, for 15-720 minutes to achieve 50-99\% contaminant removal efficiency.

3. Continue steam injection and agitation, while pressurizing Reactor A to $1000 \mathrm{psig}$ to begin the $\mathrm{HWE}$ cycle. Hold Reactor $\mathrm{A}$ at $275^{\circ} \mathrm{C}$ and 1000 psig with stripping steam for the required HWE cycle time of 30-240 minutes to achieve $99-99.9 \%$ contaminant removal efficiency. Optionally, we may save energy by utilizing the relatively "lean" $275^{\circ} \mathrm{C}$ vented steam from the HWE-cycle Reactor A to strip HCs 
from adjacent lower pressure Reactor B (or Reactor C) undergoing the pretreatment cycle, or to assist pressurizing Reactor B (or Reactor C) for an HWE cycle.

4. Isothermally depressurize Reactor A to ambient pressure and $275^{\circ} \mathrm{C}$, while injecting steam to maintain temperature and strip residual water/HCs.

5. Unload treated soil from Reactor A, and repeat Steps 1 to 4 for the subsequent batch.

Note that although there may be multiple reactors (to be determined), there will be only one contaminated-soil feed system and one treated-soil removal system, which could be mounted on rails or gantries so they could be moved independently to any of the reactors when required.

We (Sequoia and SRI) currently do not envision the flow of any solid or liquid phases from the reactor to the $\mathrm{HC}$ recovery system, apart from minor carryover, which we will deal with later at the P\&ID level of detail. Using HP steam as the HC stripping and transport medium enables primary three-phase separation to be performed in the reactor vessel itself, assuming the liquid phase(s) will eventually be completely vaporized therein. The HC recovery and water treatment system is designed to operate at near atmospheric pressure and temperature to minimize equipment cost.

Sequoia's preliminary diagram shows a power recovery turbogenerator between the lean vapor header ( $\sim 750 \mathrm{psig})$ and rich vapor header ( $\sim 5 \mathrm{psig})$, as there may be a surplus of steam/vapor leaving the HWE cycle exceeding the requirements of the pretreatment cycle reactor(s). The decision whether or not to include this turbogenerator will be driven by economics. The preliminary mechanical layout of the main reactor vessel, also prepared by Sequoia, is given in Figure 19. 


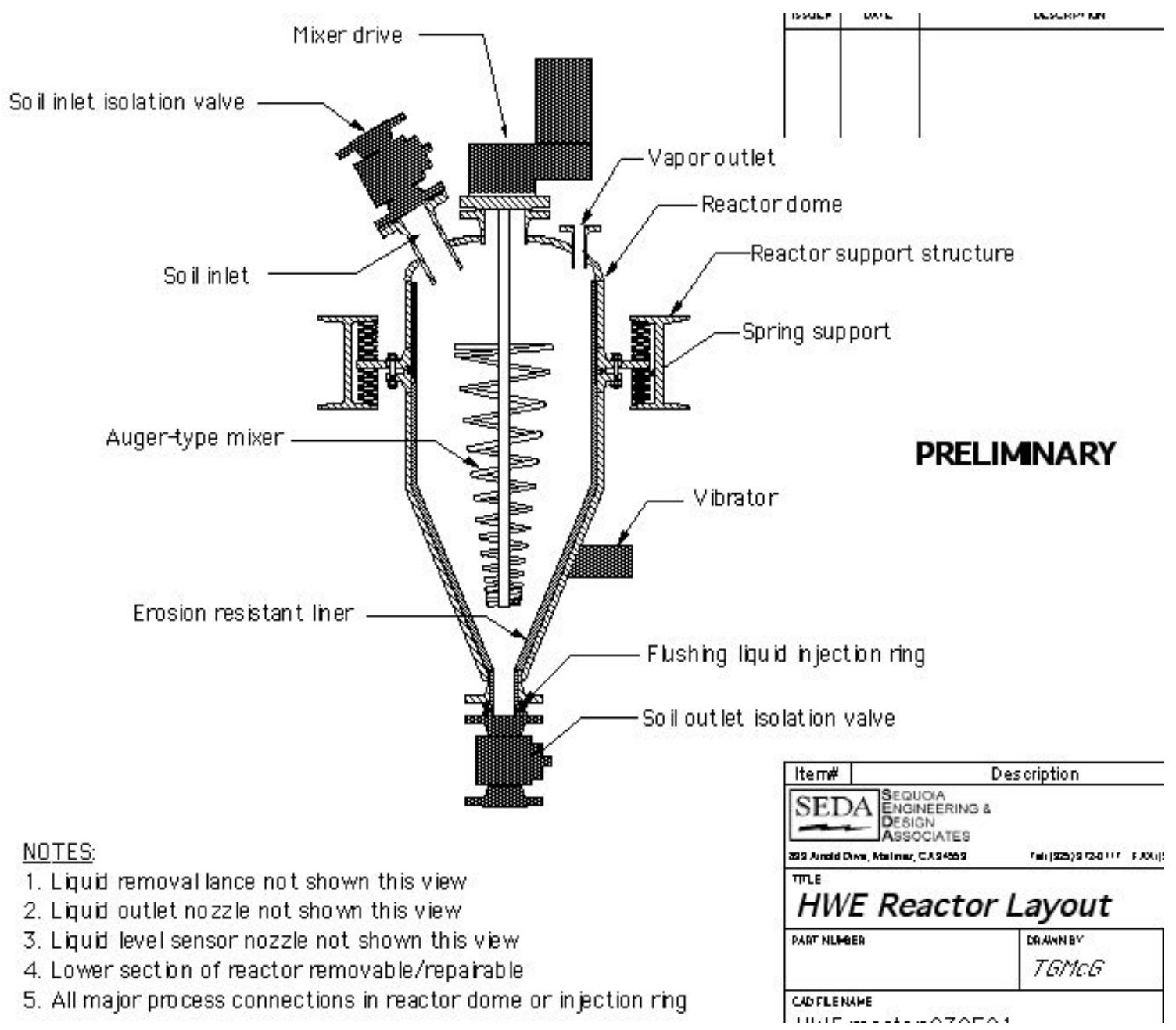

Figure 19. Preliminary mechanical layout of the main reactor vessel.

Another process configuration to consider is the HWE reactor as previously depicted, but with the HCs and water leaving the reactor in the vapor and liquid state, followed by separation of the HCs from the liquid water by evaporation. This might be considerably less energy-intensive than HWE with steam stripping and condensation/gravity separation. Sequoia reported that removing the HCs in the liquid phase may be the least energy intensive with a lower operating cost. Also, the solid/liquid and liquid/liquid separation processes may be more complicated and more sensitive to the composition of the aqueous stream, which always seems to be a major source of uncertainty when dealing with waste. Further analysis of these systems needs to be considered, but is beyond the scope of this study. 
Appendix M, provided by Sequoia, gives the preliminary reports on HWE reactor vessel sizing and the basis of design information (Tables M1 and M2). These tables were prepared considering the size of HWE reactors required to achieve rates in the 4-60 ton $/ \mathrm{hr}$ range (the rate the soil treatment plant should operate, according to the information provided in the DOE guidance report). As a rough guess, 10-20 ton/hr might be the operating range of the full-scale plant, with 1-2 tons/hr for the pilot plant.

Sequoia Engineering estimates that an additional $\$ 50,000$ is required for completing the optimization study to determine the plant capacity with the minimum life-cycle costs. 


\section{CONCLUSIONS}

During this study, our main focus was to complete the proposed main tasks: (1) fundamental studies on solubility of PAHs in water and (2) development and demonstration of HWE for remediation of real-world soils. We have completed the proposed work successfully with the demonstration of HWE using an advanced bench-scale level system. In addition to the proposed work, we have developed key designs for the scaleup process that was beyond the scope of the current project. We have also gained knowledge on the importance of several adsorption mechanisms for developing an effective technology for complete removal of heavy pollutants from soil. We will continue to seek funding for continuation of this work because we believe such information would be important not only for HWE technology, but also for other technologies that involve separation of both inorganic and organic molecules from soil matrices.

The next step of the development of the HWE process is the successful pilot demonstration of this technology. Once pilot tested, this technology can be implemented quite easily, since most of the basic components are readily available from mature technologies (e.g., steam stripping, soil washing, thermal desorption). We believe that a 1 -ton/hr plant would be ideal for a pilot-scale demonstration of this technology.

In August 2000, we presented our work at the American Chemical Society meeting in Washington, D.C., and were well received. We are now preparing two publications from the work conducted under this contract. Also, a description of this technology was published in the Summer 2001 "Eye on Environment," a DOE newsletter. 


\section{ACKNOWLEDGMENTS}

SRI would like to thank DOE's National Petroleum Technology Office for providing funds and the opportunity to develop this technology. Our special thanks go to Nancy Comstock, DOE project manager, for providing guidance and opportunities for highlighting this technology. SRI would also like to thank Sequoia Environmental for preliminary process design and Matrix Remedial for supplying industrial soils. 


\section{REFERENCES}

Berset, J.D., M. Ejem, R. Holzer, P. Lischer, "Comparison of different drying, extraction and detection techniques for the determination of priority polycyclic aromatic hydrocarbons in background contaminated soil samples," Analytica Chimica Acta 383, 263-275 (1999).

Chefetz, B., A.P. Deshmukh, P.G. Hatcher, E.A. Guthrie, "Pyrene Sorption by Natural Organic Matter," Environ. Sci. Tech. 34/14 (2000).

Dupreyron, S., "Extraction of polycyclic aromatic hydrocarbons from soils: A comparison between focused microwave assisted extraction, supercritical fluid extraction, subcritical solvent extraction, sonication and Soxhlet techniques," Intern. J. Environ. Anal. Chem. 73(3), 191-210 (1998).

Hawthorne, S.B., Y. Yang, D.J. Miller, "Extraction of Organic Pollutants from Environmental Solids with Sub- and Supercritical Water," Anal. Chem. 66(18), 2912 (1994).

Hewitt, A., "Comparison of Sample Preparation Methods for the Analysis of Volatile Organic Compounds in Soil Samples: Solvent Extraction vs Vapor Partitioning," Environ. Sci. Tech. 32, 143-149 (1988).

Mackay, D and W.Y. Shiu, "Aqueous Solubility of Polynuclear Aromatic Hydrocarbons," J. Chem. Eng. Data 22, 399 (1977).

Maguire, V., W.Y. Svrcek, A.K. Mehrotra, "A Study of Interactions Between Soil Fractions and PAH Compounds in Thermal Desorption of Contaminated Soils," The Canadian Journal of Chemical Engineering, Vol. 73, December 1995.

Mangas, E., M.T. Vaquero, L. Comellas, F. Broto-Puig, "Analysis and fate of aliphatic hydrocarbons, linear alkylbenzenes, polychlorinated biphenyls and polycyclic aromatic hydrocarbons in sewage sludge-amended soils," Chemosphere 36(1), 61-72 (1998).

Schwab, A.P., J. Su, S. Wetzel, S. Pekarek, M.K. Banks, "Extraction of Petroleum Hydrocarbons from Soil by Mechanical Shaking," Environ. Sci. Tech. 33, 1940-1945 (1999).

Sims, R.C., "Soil Remediation at Uncontrolled Hazardous Waste Sites: A Critical Review," J. Air Waste Management Assoc. 40, 704-732 (1990).

Sparks, D.L., Environmental Soil Chemistry, Academic Press, London (1995). 


\section{APPENDIX A \\ UV SPECTRA AND PHYSICAL PROPERTIES OF SELECTED PAHS}

UV absorption spectra for pyrene, fluoranthene, and 9,10-dimethyl-anthracene are shown in Figure A1 (3 panels).

P YRENE

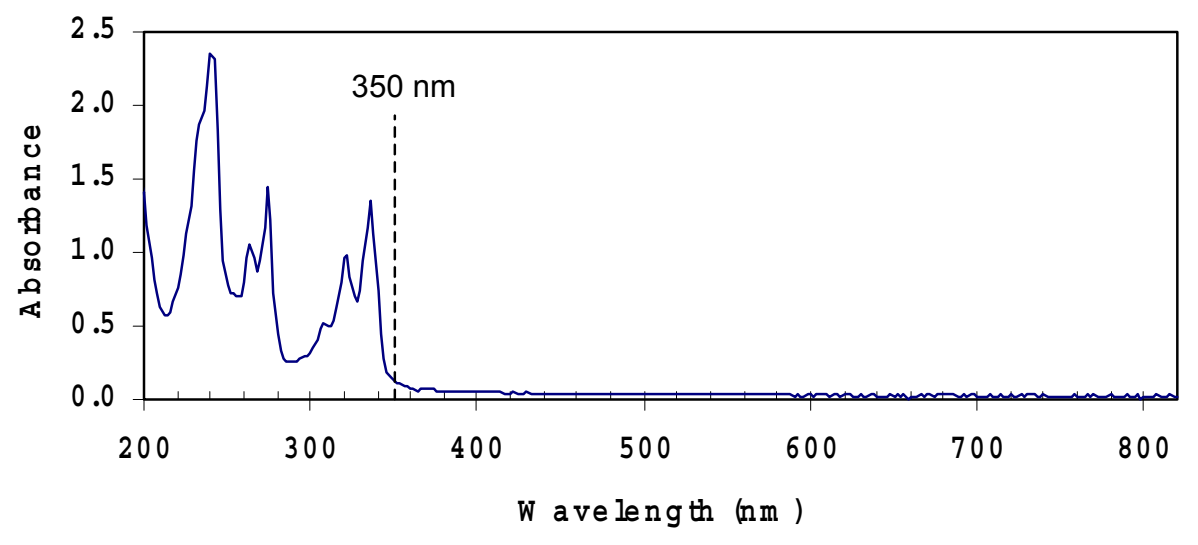

FLUO RANTHENE

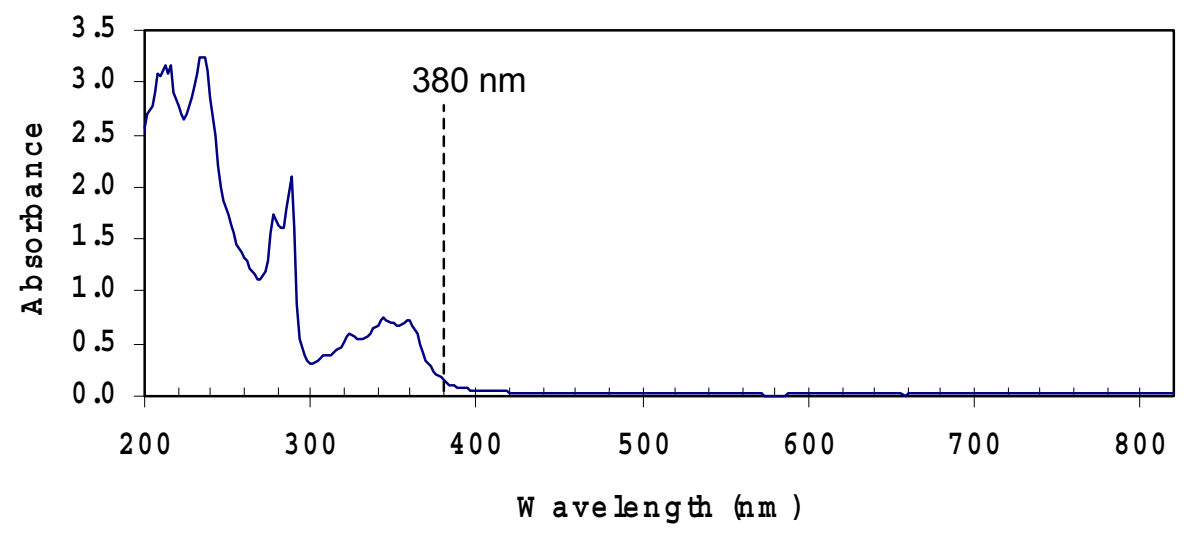




\section{9,10-DIMETHYLANTHRACENE}

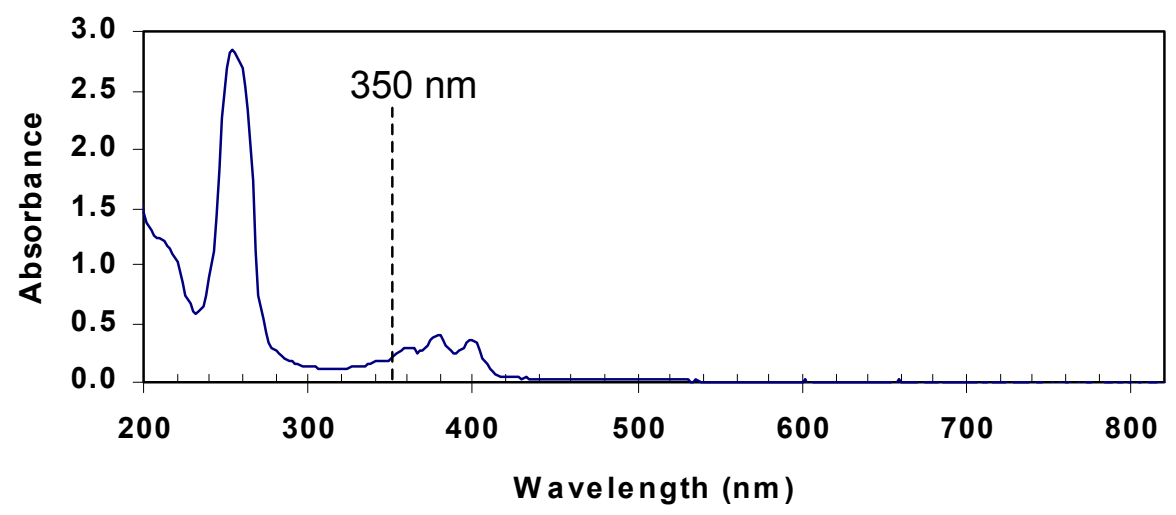

Figure A1. Spectra and wavelength chosen for pyrene, fluoranthene and 9,10-dimethylanthracene.

\section{IMPORTANT PHYSICAL PROPERTIES}

Table A1 gives some important physical properties of selected PAHs. Low-temperature solubility data in Table A1 indicate that the solubility at room temperature depends somewhat on the molecular weight of the PAH. However, we anticipate that the solubility of PAHs at higher temperatures will vary with the molecular weight and also with their melting/boiling points.

\section{Table A1}

PHYSICAL PROPERTIES OF SELECTED PAHS

\begin{tabular}{|c|c|c|c|c|}
\hline$\underline{\text { Compound }}^{\mathrm{a}}$ & Purity (\%) & $\begin{array}{l}\text { Molecular } \\
\text { Weight (g) }\end{array}$ & $\begin{array}{l}\text { Melting/Boiling } \\
\left.\text { Point ( }{ }^{\circ} \mathrm{C}\right) \\
\end{array}$ & $\begin{array}{c}\text { Solubility }^{b} \\
\left(1 \text { bar, } 20^{\circ} \mathrm{C}\right)\end{array}$ \\
\hline Naphthalene & $>99$ & 128.17 & $80-82 / 217.7$ & 32 ppm \\
\hline Phenanthrene & 99.5 & 178.23 & $99-101 / 340$ & 1.3 ppm \\
\hline Fluoranthene & $>98$ & 202.26 & $109 / 384$ & 0.26 ppm \\
\hline Pyrene & $>99$ & 202.26 & $149-150 /$ & $0.14 \mathrm{ppm}$ \\
\hline Chrysene & 98 & 228.29 & $252-254 / 448$ & $0.002 \mathrm{ppm}$ \\
\hline \multicolumn{5}{|c|}{$\begin{array}{l}\text { a Source: Aldrich Chemical Company } \\
{ }^{\mathrm{b}} \text { Mackay and Shiu, } 1977 .\end{array}$} \\
\hline
\end{tabular}




\section{APPENDIX B \\ THE UV CELL AND THE EXPERIMENTAL PROCEDURE}

A schematic of the quartz reactor setup is shown in Figure B1.

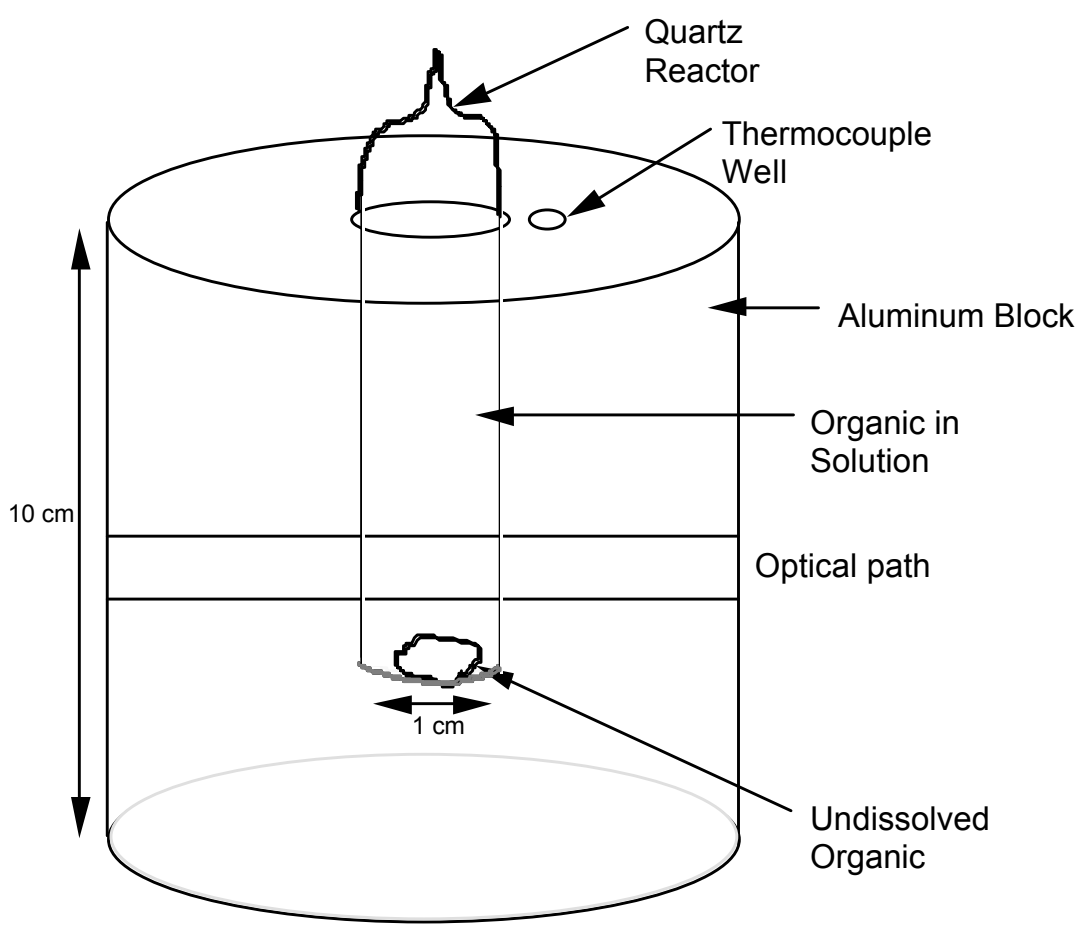

Figure B1. Schematic of the block heater assembly.

The temperature of vaporization indicates the RT energy at which the molecules fly apart, so it gives an idea of the energy of interaction among molecules to the liquid phase. As molecules are heated, they lose adherence $(\Delta \mathrm{H})$ and gain entropy in the gas phase $\left(\Delta \mathrm{S}_{\mathrm{vap}}-\Delta \mathrm{S}_{\mathrm{liq}}\right)$, which is somewhat equivalent to what happens during solution. Molecules are dispersed, but the weak interactions with $\mathrm{H}_{2} \mathrm{O}$ will not introduce significant effects. However, the entropy of the system will increase by going to solution and $\mathrm{T} \Delta \mathrm{S}$ will become more negative.

\section{Experiments in Quartz Reactors}

Several quartz tubes, $4 \mathrm{~mL}$ size (o. $\mathrm{d} .=1 \mathrm{~cm})$ containing $2 \%$ pyrene in water were prepared by weighing 40-45 mg pyrene into each tube containing $2 \mathrm{~mL}$ of water. These tubes were then flame sealed, with care taken not to heat the contents of the reactor. A Hewlett 
Packard UV spectrophotometer equipped with a diode-array detector was used to measure the absorbance of each slurry. These tubes were heated by using a thermostated aluminum block heater located on the cell compartment of the spectrophotometer (see Figure 1). At room temperature, undissolved pyrene particles settled at the bottom of the quartz tube just below the optical path of the spectrophotometer (solubility at $20^{\circ} \mathrm{C}$ is only $0.14 \mathrm{ppm}$ ). On heating, the solubility of pyrene increased and the absorbance of the solution changed accordingly. These quartz tubes were shaken manually to ensure the maximum solubility, and particles were allowed to settle before making absorbance measurements. Absorbances of the homogeneous liquid phase due to pyrene were measured at $80^{\circ}, 100^{\circ}, 115^{\circ}, 125^{\circ}, 150^{\circ}, 175^{\circ}$, and $190^{\circ} \mathrm{C}$.

Absorbances of known concentrations of pyrene solution are also being measured in parallel at these temperatures to determine the molar absorption coefficient. From these measurements, we can determine the equilibrium (saturated) solubilities of pyrene. Similar experiments were also performed with fluoranthene in water, pyrene in a solution containing $1 \%$ sodium carbonate, and fluoranthene in a solution containing $1 \%$ sodium carbonate. In the future, we will also study the solubility of chrysene, phenanthrene, and naphthalene.

\section{STATIC STAINLESS-STEEL REACTOR SYSTEM}

The static experiments at high temperature range $\left(200^{\circ}-300^{\circ} \mathrm{C}\right)$ were conducted using the setup shown in Figure B2.

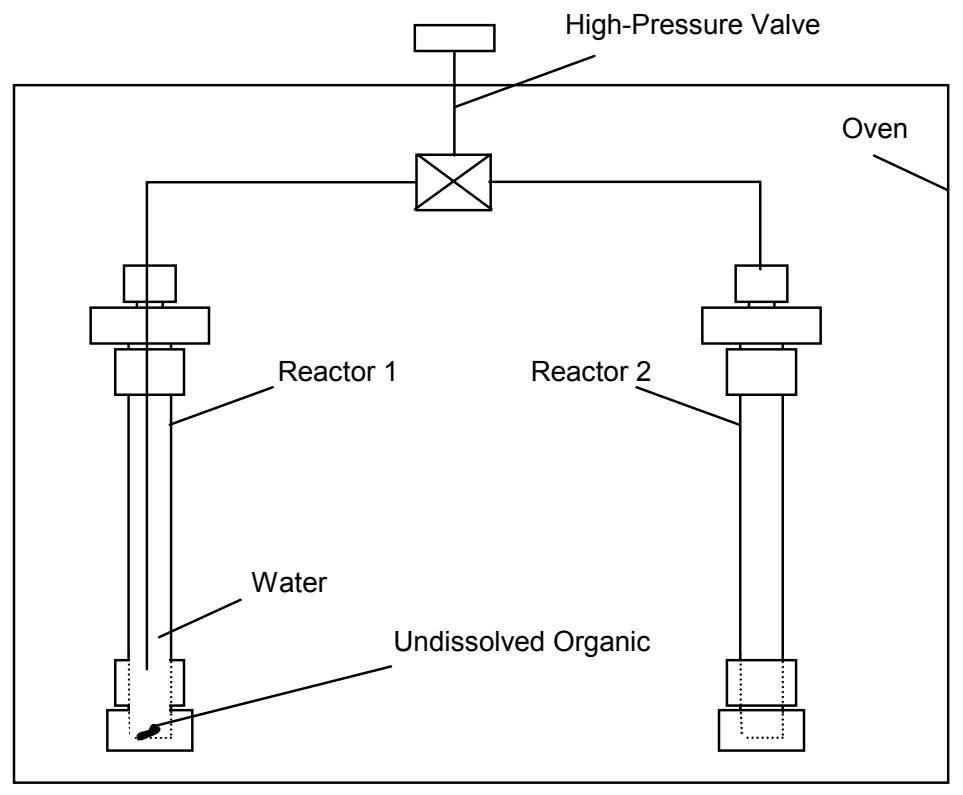

Figure B2. Schematic of the stainless-steel reactor system. 
The experiments were conducted as follows. First, both reactors were weighed empty. Then, $50 \mathrm{mg}$ of PAH was weighed into Reactor 1 and $2 \mathrm{ml}$ of water was added and weighed into the same reactor. Both reactors were connected to the valve that was checked to be closed. The oven controller was set at the experiment temperature (between $200^{\circ} \mathrm{C}$ and $300^{\circ} \mathrm{C}$ ). After $4 \mathrm{~h}$, the valve was opened and some amount of liquid water (with dissolved PAH) passed to Reactor 2 due to the pressure of water vapor in Reactor 1 . The valve was closed again, and the oven was cooled to room temperature. The reactors were disconnected from the valve and were weighed to determine the amount of water in each one. PAH was extracted from water in each reactor by liquid-liquid extraction with dichloromethane. The extract was transferred to toluene and, finally, the amount of PAH was determined by GC-MS. 


\section{APPENDIX C CHROMATOGRAPHIC CONDITIONS}

Chromatograph: HP 5890

Column: DB-5MS (20 m x $0.18 \mathrm{~mm}$ i.d., $0.18 \mu \mathrm{m}$ film thickness)

Carrier gas: Helium 5.0 (5 psi)

Injection: Manual; splitless (1 min)

Injector temperature: $250^{\circ} \mathrm{C}$

Splitter flow: $50 \mathrm{ml} / \mathrm{min}$

Septum purge flow: $5 \mathrm{~m} / \mathrm{min}$

Interface temperature: $300^{\circ} \mathrm{C}$

Temperature programmed:

\begin{tabular}{|l|c|c|}
\cline { 2 - 3 } \multicolumn{1}{c|}{} & Initial Temperature: $75^{\circ} \mathrm{C}$ & Initial Time: $1.2 \mathrm{~min}$ \\
\hline Rate A: $30^{\circ} \mathrm{C} / \mathrm{min}$ & Final temperature: $90^{\circ} \mathrm{C}$ & Final time: $1 \mathrm{~min}$ \\
\hline Rate B: $10^{\circ} \mathrm{C} / \mathrm{min}$ & Final temperature: $300^{\circ} \mathrm{C}$ & Final time: $5 \mathrm{~min}$ \\
\hline
\end{tabular}

Detector: HP 5970 Mass Selective Detector

Ionization: Electronic impact $(70 \mathrm{eV})$

Acquisition: Single Ion Monitoring

\begin{tabular}{cll}
\hline Time & $\begin{array}{c}\text { Monitored Masses } \\
(\text { dwell 50) }\end{array}$ & \multicolumn{1}{c}{ Compounds* $^{*}$} \\
\hline $0-13$ & $128,152,154,166$ & $\begin{array}{l}\text { Naphthalene, acenaphthylene, acenaphthene, } \\
\text { fluorene } \\
\text { Phenanthrene, anthracene, fluoranthene, } \\
\text { pyrene, 4-methylpyrene } \\
13-21.5\end{array}$ \\
$21.5-27$ & 228,252 & $\begin{array}{l}\text { Benzo(a)anthracene, chrysene, } \\
\text { benzo(b)fluoranthene, benzo(k)fluoranthene, } \\
\text { benzo(a)pyrene } \\
\text { Indeno(1,2,3-c,d)pyrene, } \\
\text { dibenzo(a,h)anthracene, benzo(g,h,i)perylene }\end{array}$ \\
\hline
\end{tabular}

* All these compounds can be analyzed under these conditions; however, only those marked in bold are included in the standards. 
The chromatogram of a standard is shown here in Figure C1.

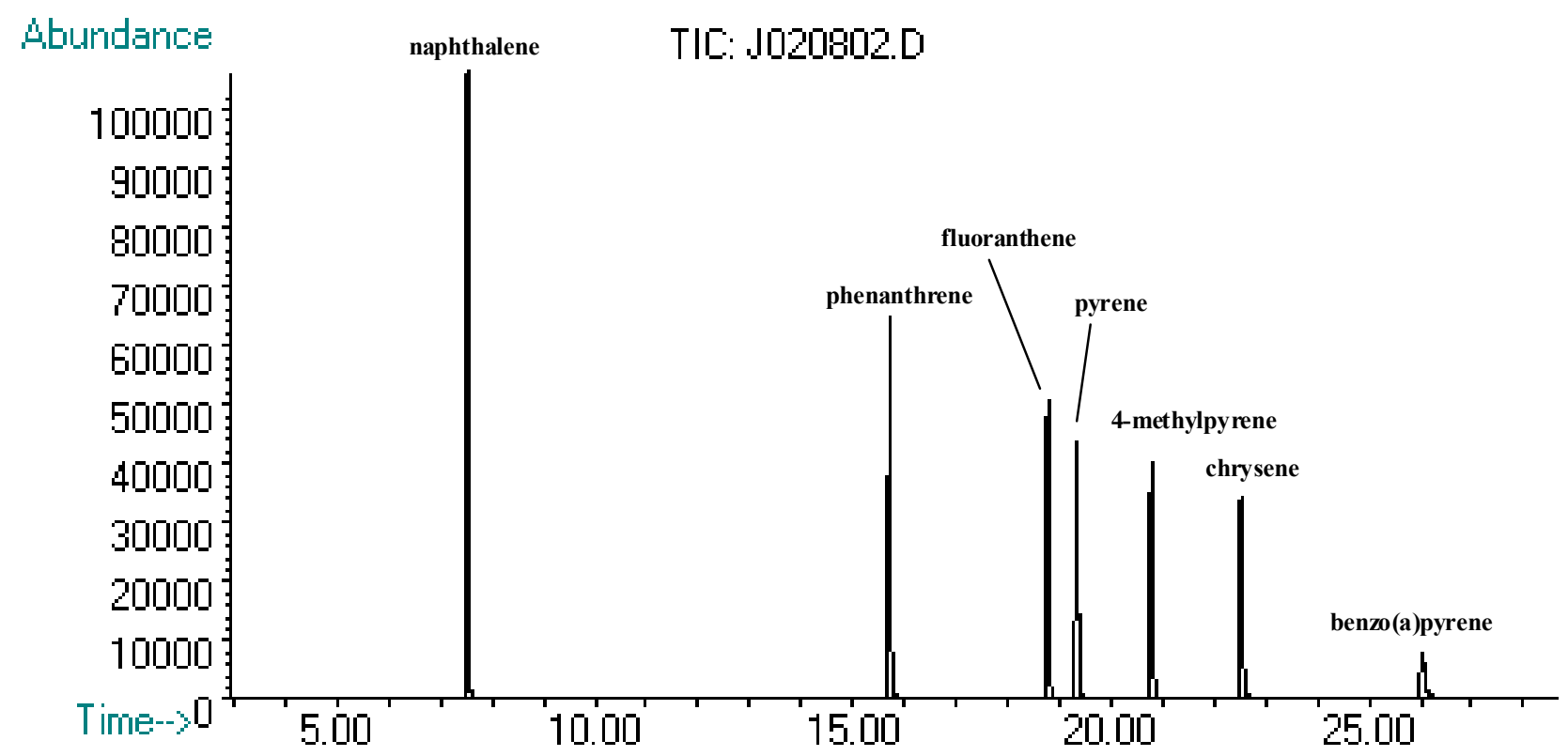

Figure $\mathrm{C} 1$. Chromatogram of standard $(10 \mu \mathrm{g} / \mathrm{ml}$ in each $\mathrm{PAH})$. 


\section{APPENDIX D \\ SAMPLE CHROMATOGRAMS FOR SOIL SAMPLES}

SRI developed an analytical protocol for extraction and analysis of heavy PAHs from the soil matrix. Figure D1 shows the GC/MS (scan mode) chromatogram that corresponds to the organics presents in the soil sample before the hydrothermal treatment; the data presented below are for the soil sample from the wood preserve site. The extract obtained by shaking the soil in dichloromethane/acetone 1/1 was injected in GC/MS both in SCAN and SIM mode.

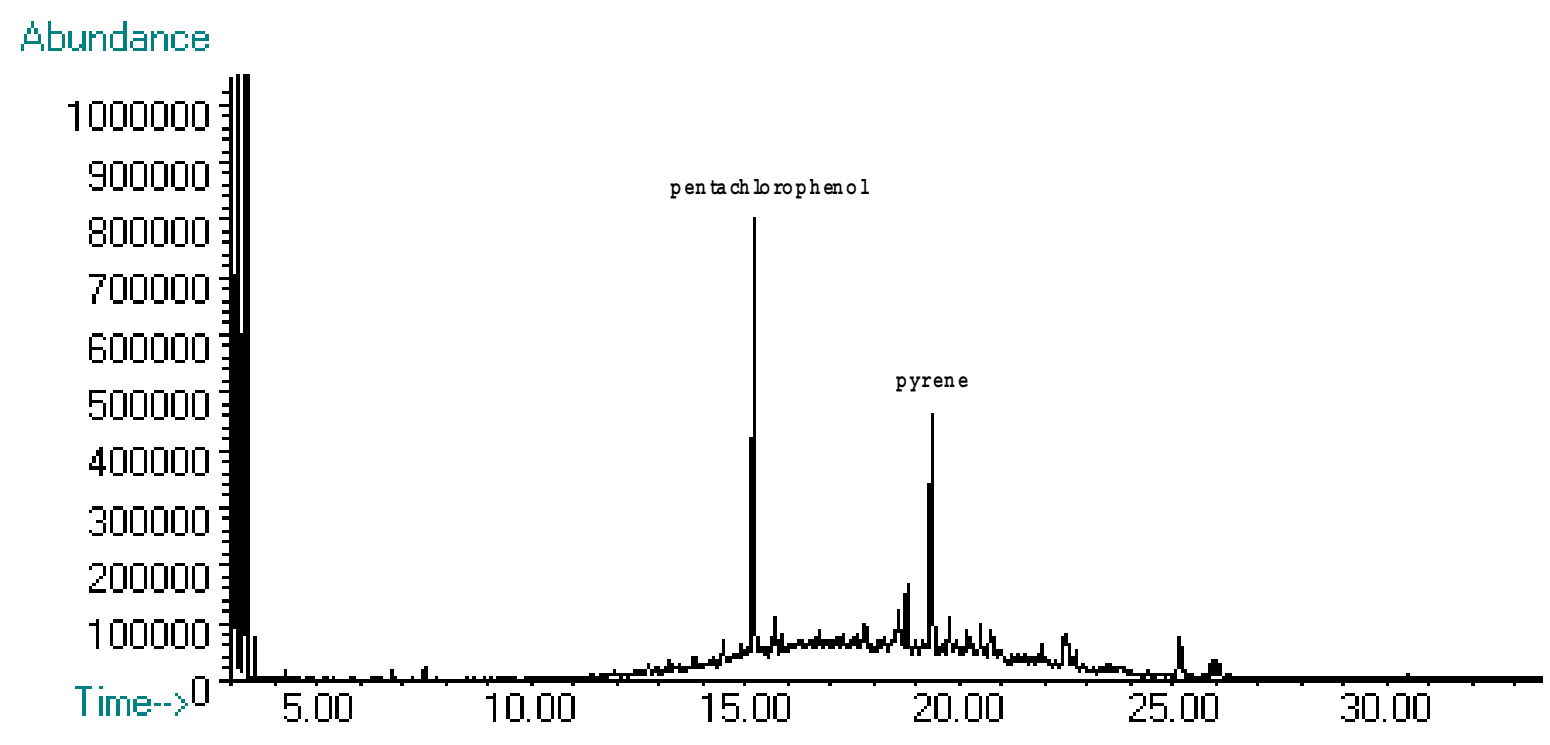

Figure D1. GC/MS (scan) chromatogram from solvent extraction of soil.

The most abundant peaks in the chromatogram were identified as pentachlorophenol and pyrene by their respective mass spectra. In addition, pyrene was confirmed by coincidence of retention time with that of a standard. Figure D2 shows the mass spectra of pentachlorophenol and pyrene. 


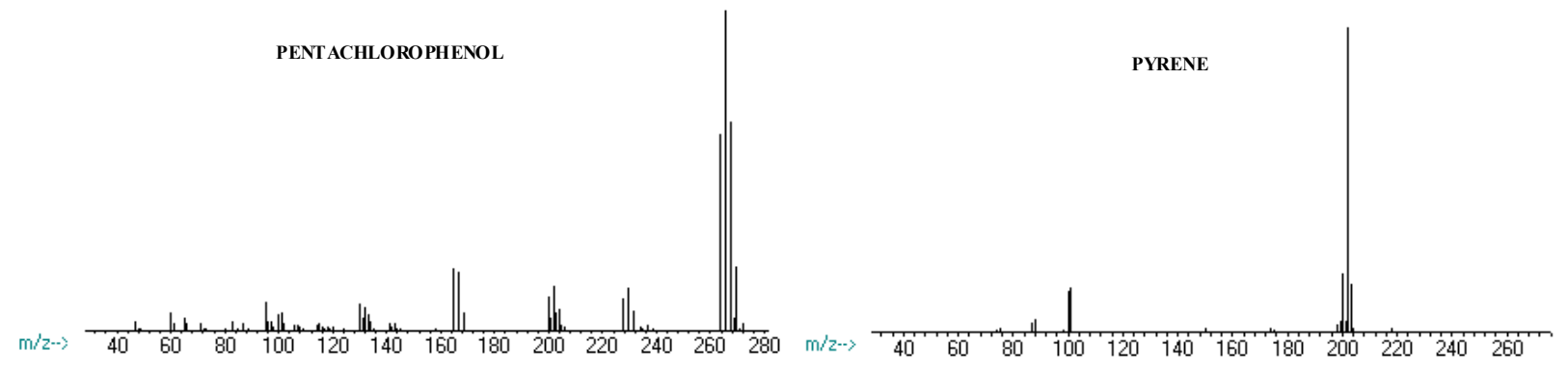

Figure D2. Mass spectra of peaks at retention times of 15.2 and 19.4 .

In addition, baseline spectra of the central part of the chromatogram (12 min-25 min) revealed a high amount of hydrocarbons (probably, branch hydrocarbons of high molecular weight) in the extract. These compounds can be removed from the extract by clean-up in silica or alumina open chromatographic columns, avoiding their injection in the GC/MS equipment.

The GC/MS analysis of the same sample in SIM mode results in the total ion chromatogram shown in Figure D3, where several of the 16 PAHs regulated by the EPA were detected.

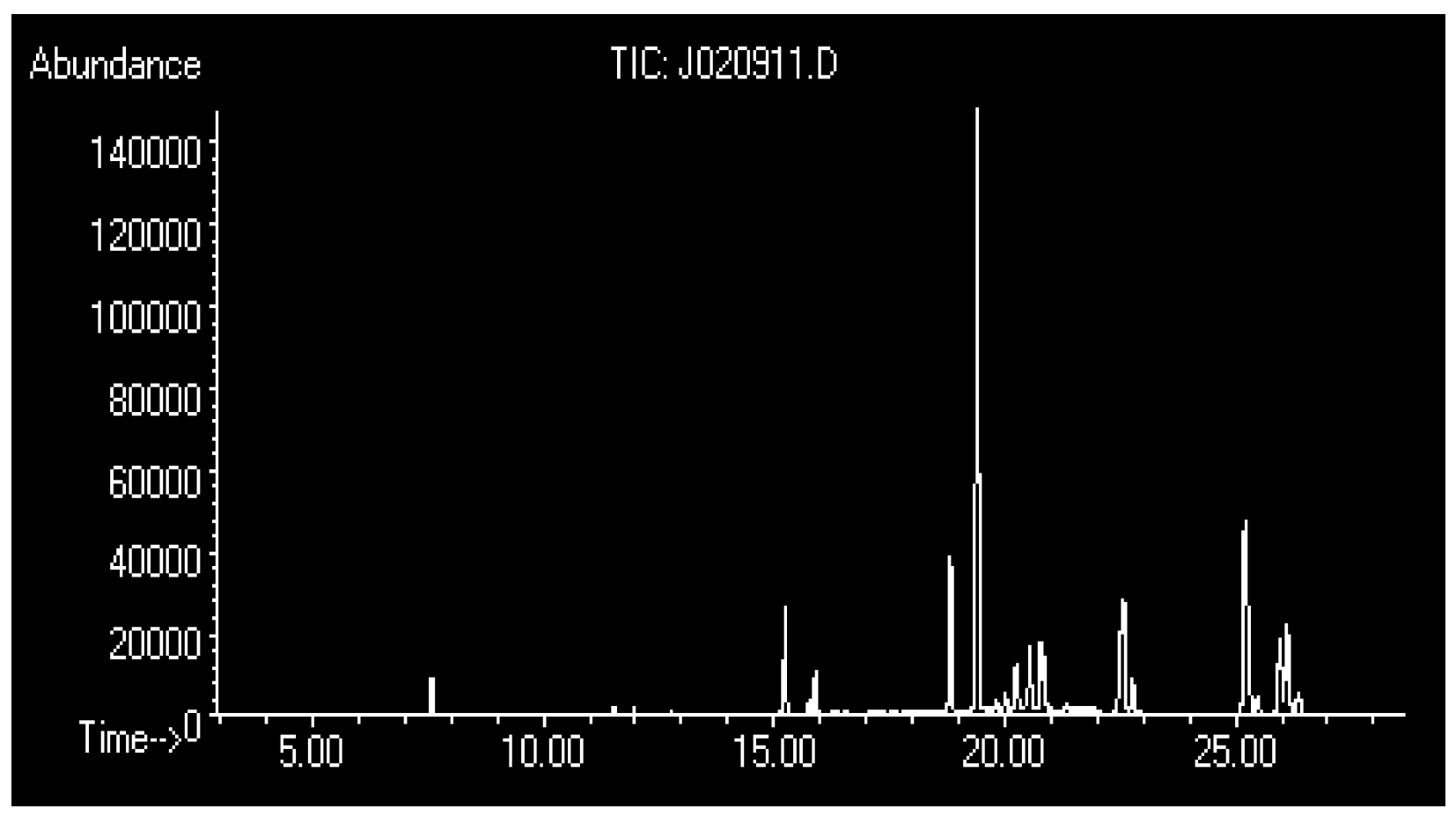

Figure D3. Total ion chromatogram of solvent extraction of soil. 


\section{APPENDIX E STATIC STAINLESS STEEL SETUP}

The experimental setup was similar to the setup shown in Figure B2 of Appendix B. The experiments were conducted as follows. First, Reactor 2 was weighed empty. Then, Reactor 1 was prepared by weighing a known amount of soil and by adding $30 \mathrm{ml}$ of the extracting agent with a calibrated pipette. The influence of soil amount was studied by extracting $1 \mathrm{~g}, 2 \mathrm{~g}$, and $10 \mathrm{~g}$ with the same amount of extracting agent. Milli-Q water and solutions of sodium carbonate at $0.1 \%$ and $1 \%$ were studied as extracting agents. Both reactors were then connected to the valve assembly as shown in Figure E1. The oven was set at $275^{\circ} \mathrm{C}$. The reactor was allowed to stay at this temperature for $4 \mathrm{~h}$ to attain the equilibrium solubility. Although extraction time was set at $4 \mathrm{~h}$ for most experiments, the influence of extraction time was also studied by changing the extraction times in the range 2-24 hours. Once the equilibrium was attained, the interconnecting valves were opened to pass a representative liquid sample from Reactor 1 to Reactor 2 . The valves were then closed to isolate the reactors and the reactors were allowed to cool to room temperature. After this treatment, the contents in the reactors were analyzed using GC/MS method described in appendix D.

In addition, solvent extractions of the spiked soils were performed to compare the efficiency of the hydrothermal process with solvent extraction. $1 \mathrm{~g}$ of soil was extracted with $15 \mathrm{ml}$ of acetone/dichloromethane $1 / 1$ by shaking in a mechanical shaker for $15 \mathrm{~min}$. The organic extract was separated and the extraction with $15 \mathrm{ml}$ more was repeated. Both organic extracts were combined and analyzed by HRGC-MS.

\section{CONTINUOUS FLOW SET-UP}

Figure E1 shows the schematic of the continuous flow setup for soil cleanup. A soil sample to be cleaned is filled into a stainless steel reactor. Both sides of the reactor are fitted with stainless steel frits to hold the sample in place. The required pore size of the frits is determined by the soil particle size. The prepared reactor containing soil is connected to the high-pressure liquid pump and the sample collection system as shown in Figure E1. 


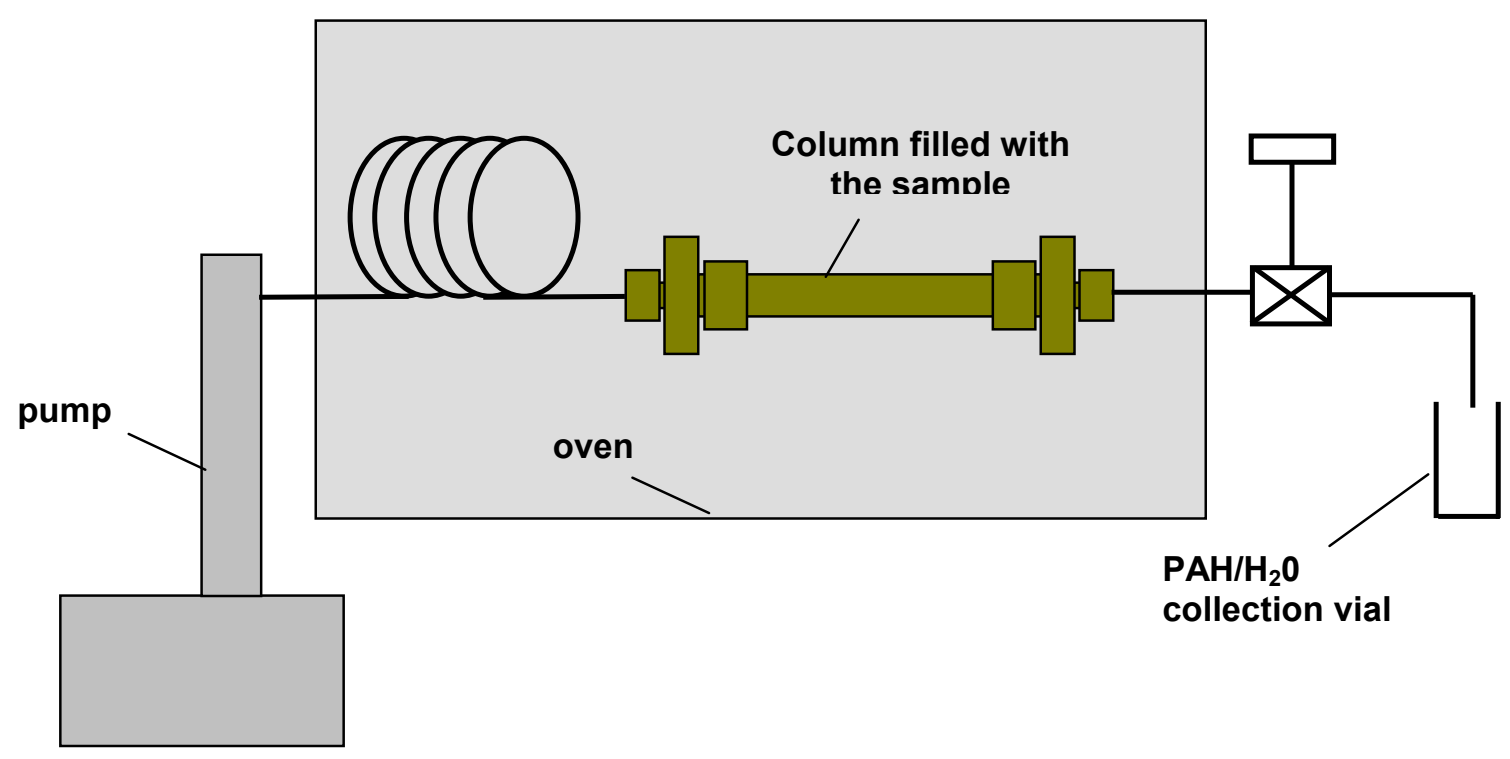

Figure E1. Schematic of a small-scale continuous soil cleaning system.

The soil sample is then extracted with hot water for a desired time at a selected temperature. The required residence for the complete cleanup can be changed by adjusting the water flow rate. The effluent from the reactor is then collected at the outlet to determine the organic removal efficiency. The samples were collected sequentially to evaluate the rate of removal of PAH from soil. 


\section{APPENDIX F \\ MASS BALANCE STUDY}

Since the recoveries with pyrene in the extraction with organic solvent were only $60 \%$ $70 \%$ for the $350-\mu \mathrm{g} / \mathrm{g}$ level, an experiment to measure the adsorption of pyrene in sand and bentonite was conducted to measure the mass balance. Table F1 shows the level of pyrene obtained in the supernatant solution 5 minutes after the addition of soil to a solution of pyrene in dichloromethane/acetone 1/1,30 minutes after a first shaking of the mixture soil-solvent, and 3 hours after a second shaking of the mixture.

Table F1

PYRENE OBTAINED IN THE ADSORPTION EXPERIMENT (IN \% RELATED TO THE CONCENTRATION OF THE INITIAL SOLUTION)

\begin{tabular}{ccccc}
\hline Soil & Initial Solution & $\begin{array}{c}\mathbf{5} \text { min after the } \\
\text { Addition of Soil } \\
\text { (W/O Shaking) }\end{array}$ & $\begin{array}{c}\text { 30 min after the } \\
\text { First Shaking }\end{array}$ & $\begin{array}{c}\mathbf{3} \mathbf{h} \text { after the Second } \\
\text { Shaking }\end{array}$ \\
\hline Sand & $154 \mu \mathrm{g} / \mathrm{ml}$ & $100.2 \%$ & $101.2 \%$ & $99.6 \%$ \\
& $15.4 \mu \mathrm{g} / \mathrm{ml}$ & $98.9 \%$ & $99.8 \%$ & $99.1 \%$ \\
\hline \multirow{2}{*}{ Bentonite } & $154 \mu \mathrm{g} / \mathrm{ml}$ & $100.8 \%$ & $101.5 \%$ & $99.4 \%$ \\
& $15.4 \mu \mathrm{g} / \mathrm{ml}$ & $101.3 \%$ & $100.6 \%$ & $100.6 \%$ \\
\hline
\end{tabular}

The results obtained in this experiment indicate that the adsorption of PAH in soil is not important in the conditions assayed. Probably, the adsorption in the soil when the solvent is removed (as it is made to prepare the spiked samples) and stored for some days until it is used could be higher than that measured now in a wet system. An alternative way to measure the adsorption of PAH can be the successive extraction of the same soil sample with different extraction techniques (e.g., shaking, sonication, Soxhlet). 


\section{APPENDIX G \\ FACT SHEET ON THERMAL DESORPTION}

Remediation Technique Procedure: Thermal desorption

Site: McKin Company Superfund Site, Gray, Maine

Prepared by: EPA, March 1995

Type of Matrix Processed through the Treatment System: Soil (ex situ)

Contaminant Characterization: Halogenated volatile organic compounds (VOCs) and petroleum products, including polynuclear aromatic hydrocarbons (PAHs) and aromatic compounds. Excavated soil treated in this application contained up to $3,310 \mathrm{mg} / \mathrm{kg}$ of TCE. However, remedial investigation indicated concentrations as high as $1,500 \mathrm{mg} / \mathrm{kg}$ for TCE, $49 \mathrm{mg} / \mathrm{kg}$ for methylene chloride, and $21 \mathrm{mg} / \mathrm{kg}$ for xylenes.

Quantity of Soil Treated During Applications: 11,500 cubic yards

Historical Activity that Generated Contamination at the Site: Waste Collection, Transfer, Storage, and Disposal Facility.

\section{Matrix Characteristics Affecting Treatment Cost or Performance*:}

Soil classification

Clay content and/or particle size distribution

Moisture content

Oil and grease or total petroleum hydrocarbons

Bulk density

Lower explosive limit

* the values for these parameters are not provided in the available references

\section{Supplemental Treatment Technology Types:}

Pretreatment (solids): Screening, mixing

Post-treatment (air): Baghouse, scrubber

Post-treatment (water): Carbon adsorption 
Operating Parameters Affecting Treatment Cost or Performance

\begin{tabular}{|l|c|c|}
\hline \multicolumn{1}{|c|}{ Parameter } & Value & Measurement Method \\
\hline Air Flow Rate & $15,000 \mathrm{acfm}$ & -- \\
\hline Residence Time per Pass & 2 minutes & -- \\
\hline Number of Passes & 3 & -- \\
\hline Total Residence Time & 6 minutes & -- \\
\hline System Throughput & 8 to 9 cubic yards/batch & -- \\
\hline $\begin{array}{l}\text { Temperature of Soil Exiting Heating } \\
\text { Chamber }\end{array}$ & 250 to $400^{\circ} \mathrm{F}$ & Sensor at soil discharge chute \\
\hline
\end{tabular}

\section{Cleanup Goals/Standards}

Performance standard for TCE in soil of $0.1 \mathrm{mg} / \mathrm{kg}$ averaged over a treatment volume. The petroleum-contaminated areas at McKin were specified as $1 \mathrm{mg} / \mathrm{kg}$ for individual aromatic organic compounds, $1 \mathrm{mg} / \mathrm{kg}$ for individual PAHs, and $10 \mathrm{mg} / \mathrm{kg}$ for total PAH constituents.

Treatment Performance Data

\begin{tabular}{|c|c|c|}
\hline VOCs & $\begin{array}{l}\text { Maximum Untreated soil } \\
\text { Concentration (mg/kg) }\end{array}$ & $\begin{array}{l}\text { Range of Treated Soil } \\
\text { Concentration }(\mathrm{mg} / \mathrm{kg})\end{array}$ \\
\hline Chloroform & 30 & Not analyzed \\
\hline 1,2-Dichlorobenzene & 320 & ND (0.02) \\
\hline Trans-1,1-Dichloroethene & 6.1 & ND (0.02) \\
\hline Tetrachloroethane & 120 & ND (0.02) \\
\hline 1,1,1-Trichloroethane & 19 & ND (0.02) \\
\hline Trichloethene & 3.310 & ND (0.02) to 0.04 \\
\hline PAHs & $\begin{array}{l}\text { Maximum Untreated soil } \\
\text { Concentration (mg/kg) }\end{array}$ & $\begin{array}{l}\text { Range of Treated Soil } \\
\text { Concentration }(\mathrm{mg} / \mathrm{kg})\end{array}$ \\
\hline Acenaphthene & & ND (0.66) \\
\hline Anthracene & & ND $(0.17)$ to 0.975 \\
\hline Benzo(a)anthracene & & ND $(0.17)$ to 0.42 \\
\hline Chrysene & & ND $(0.17)$ to 0.495 \\
\hline Fluoranthene & & ND (0.33) to 0.38 \\
\hline Fluorene & & ND (0.66) \\
\hline Naphthalene & & ND (0.66) \\
\hline Phenanthrene & & ND $(0.33)$ to $2.5^{*}$ \\
\hline Pyrene & & ND $(0.33)$ to 0.76 \\
\hline
\end{tabular}

$\mathrm{ND}=$ Not detected. Number in parentheses is the detection limit

*The average concentration of Phenanthrene measured during the application was $0.92 \mathrm{mg} / \mathrm{kd}$. This value was accepted by EPA and MDEP as indicative of a successful application. 


\section{Treatment System Cost}

(Note: These costs do not include costs for mobilization, site characterization, pilot-scale treatability study, waste material disposal, site closure, and demobilization.)

\begin{tabular}{|l|c|c|}
\hline \multicolumn{1}{|c|}{ Cost elements } & $\begin{array}{c}\text { Cost breakdown for } \\
\text { treatment of VOC- } \\
\text { contaminated area soils }\end{array}$ & $\begin{array}{c}\text { Cost breakdown for } \\
\text { treatment of petroleum- } \\
\text { contaminated area soils }\end{array}$ \\
\hline Salaries and wages & $\$ 405,450$ & $\$ 88,910$ \\
\hline Rental & $\$ 596,250$ & $\$ 130,880$ \\
\hline Supplies & $\$ 453,150$ & $\$ 93,370$ \\
\hline Subcontracts & $\$ 620,100$ & $\$ 135,980$ \\
\hline Fuel & $\$ 47,700$ & $\$ 10,460$ \\
\hline Other professional services & $\$ 262,350$ & $\$ 57,530$ \\
\hline Other professional services & $\$ 262,350$ & $\$ 57,530$ \\
\hline TOTAL & $\$ 2,385,000$ & $\$ 517,130$ \\
\hline
\end{tabular}

\section{Observations}

The following improvements to the design and operation of the full-scale remediation system were made based on the results of the pilot-scale treatability study:

- Fugitive dust emissions were controlled by enclosing materials handling processes.

- Temperature, residence time, and airflow were optimized for TCE removal efficiency.

- Wetting procedures were determined to be ineffective and difficult to utilize in the system.

- Addition of a special filter to the exhaust gas treatment system reduced smoke particulates.

The mixing of clean soil and petroleum-contaminated soil eliminated agglomeration of the petroleum-contaminated soil in the thermal desorption unit.

The treatability study established a correlation with increased dryer temperatures (from $150^{\circ} \mathrm{F}$ to $380^{\circ} \mathrm{F}$ ) and increased airflow (up to $15,000 \mathrm{cfm}$ ) with higher removal efficiencies of TCE. Higher removal efficiencies of TCE were also achieved by treatment of soils with multiple passes through the unit, thus increasing residence time.

A temperature of $300^{\circ} \mathrm{F}$ was determined to be optimum on the basis that no significant reduction of TCE concentrations occurred below $250^{\circ} \mathrm{F}$, and above $350^{\circ} \mathrm{F}$ the soil behaved as a viscous fluid on the conveyor bed and reacted violently with water during wetting. 


\section{APPENDIX H \\ THE BENCH-SCALE REACTOR SYSTEM}

Appendix E describes the bench-scale continuous flow treatment system designed for demonstrating the hydrothermal extraction process. Here we discuss the different modes of operation of this system to demonstrate the TD process, the combination of HWE and TD, and steam-assisted TD.

\section{Continuous Flow Setup for HWE}

See Figure E1 in Appendix E.

\section{Bench-Scale Setup: Thermal Desorption}

See Figure E1 for a schematic of the system used for these experiments. Under TD conditions, sample loading is similar to that in HWE operation. The only difference is that the water-metering pump is disconnected from the system, since TD is performed under dry conditions.

Thermally desorbed organics were collected over dichloromethane. Great care was taken in collecting these samples to avoid any loss of material due to sample volatilization. Collected samples were extracted using the similar procedure given in our last report.

After the completion of the thermal desorption experiment, the flow rate of argon was measured with a "bubble flowmeter." The reactor containing the soil sample was then removed from the oven, and the collected soil was extracted with a mixture of dichloromethane/acetone $(1: 1)$ and analyzed using GC/MS to determine the remaining organics after the treatment.

\section{Bench-Scale Setup: Steam-Assisted Thermal Desorption}

When the reactor system was operated under steam-assisted thermal desorption conditions, both the water metering pump and the gas supply were kept connected (Figure E1, Appendix E). Soil sample loading was similar to that of the HWE experiment. After connecting the reactor containing the soil sample, valve V2 was kept closed and valve V1 was adjusted to set a desired argon flow rate. Then, valve V2 was opened and water was pumped by the high-pressure liquid pump at low flow rates in the range $0.6-0.2 \mathrm{ml} / \mathrm{min}$. The oven was then heated to the desired temperature and the samples were collected and analyzed to determine the organic removal efficiency. 


\section{APPENDIX I \\ CORSA-PEMEX SAMPLE}

This sample, which contains $20 \% \mathrm{TPH}$, is obtained from a drilling mud site in Mexico. Our analysis of this sample indicated the presence of TPHs in the range $\mathrm{C}_{11}-\mathrm{C}_{25}$. The chromatogram of this sample analyzed through GC/MS is shown in Figure I1.

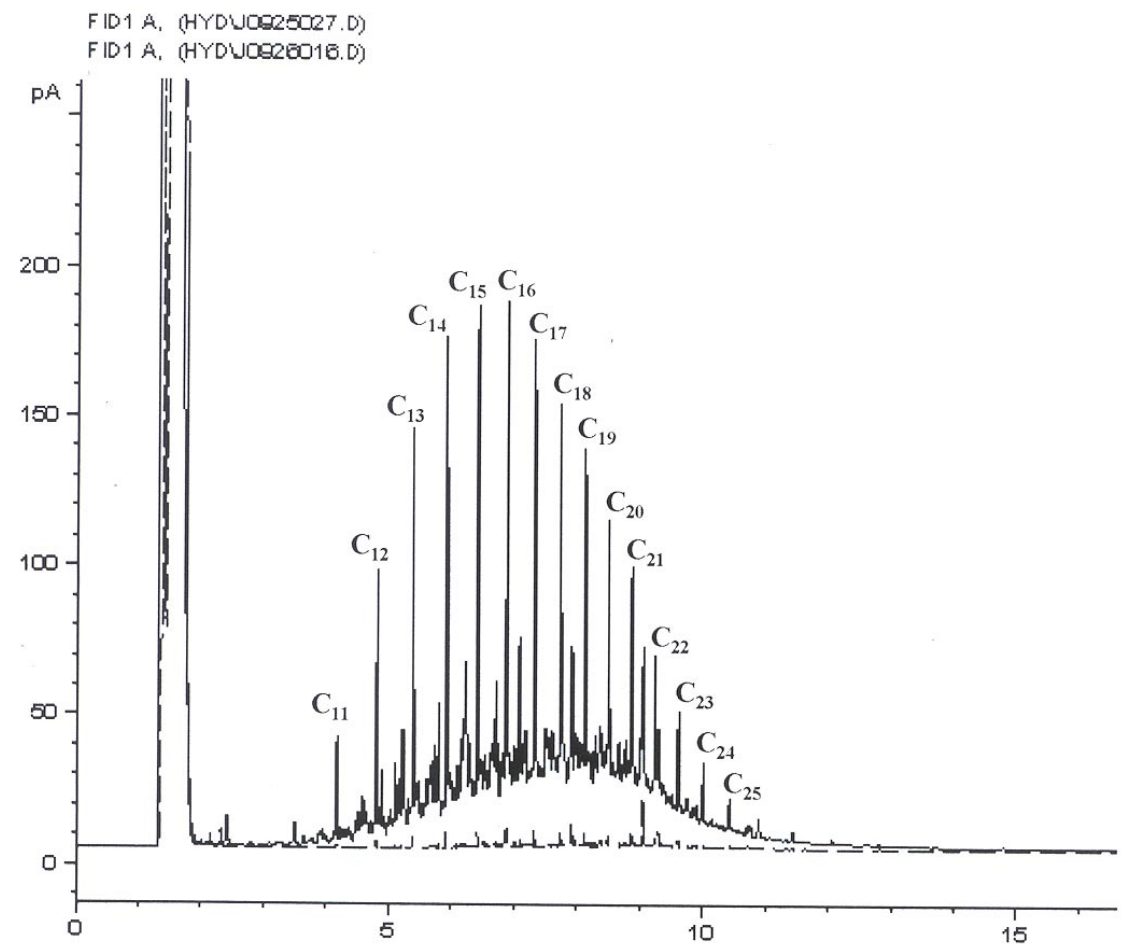

Figure I1. Chromatogram of a standard ( $100 \mu \mathrm{\mu g} / \mathrm{ml} \mathrm{TPH})$ analyzed through GC/FID. 


\section{APPENDIX J \\ PRETREATMENT USING STEAM FLUSHING}

The steam flushing system was constructed with the use of a coffeemaker. In a typical run, a known amount of the sample (100-200 g) would be loaded into the coffeemaker and flushed with steam at $100^{\circ} \mathrm{C}$ to remove volatiles. The recovered volatiles and the remaining organics in the sample were analyzed to determine the efficiency of steam-flushing for removal of VOC faction from the mud. Table J1 shows the results of the extraction of the several samples of the mud by this technique.

\section{Table J1}

\section{EXTRACTION BY STEAM FLUSHING TECHNIQUE AT $100^{\circ} \mathrm{C}$}

\section{Number of Washes: 4}

Volume: $50 \mathrm{~mL}$

Total amount of water: $200 \mathrm{~mL}$

Sample's amount: $25 \mathrm{~g}$

TPH Reduction: $48.4 \%$

Number of Washes: 4

Volume: $50 \mathrm{~mL}$

Total amount of water: $200 \mathrm{~mL}$

TPH Reduction: $36.8 \%$

Sample's amount: $25 \mathrm{~g}$

Number of Washes: 5

Volume: $50 \mathrm{~mL}$

Total amount of water: $250 \mathrm{~mL}$

Sample's amount: $20 \mathrm{~g}$

Number of Washes: 3

Volume: $100 \mathrm{~mL}$

Total amount of water: $300 \mathrm{~mL}$

TPH Reduction: $53.6 \%$

Sample's amount: $25 \mathrm{~g}$

\section{Number of Washes: 5}

Volume: $100 \mathrm{~mL}$

Total amount of water: $500 \mathrm{~mL}$

TPH Reduction: $52.9 \%$

Sample's amount: $25 \mathrm{~g}$

Only a partial list of the optimization experiments with steam flushing techniques is given above. The optimization results indicated that more than $50 \%$ of the TPH can be removed 
from the mud by doing two washing cycles, and very little improvement is seen with more washing cycles. Therefore, two to three washing cycles are recommended for this particular mud sample.

Note: For samples containing different proportions of TPH, optimization is necessary before deciding the number of washing cycles required for complete removal of VOCs. 


\section{APPENDIX K RESULTS FOR EPA SAMPLE}

Tables K1-K3 report the removal efficiencies observed for EPA sample under different experimental conditions. The corresponding experimental conditions for data reported in Tables $\mathrm{K} 1-\mathrm{K} 3$ are given in Table K4.

\begin{tabular}{lcc}
\hline \multicolumn{3}{c}{ Table K1 } \\
\multicolumn{1}{c}{ EPA Sample - Bench Scale System - first experiment } \\
\hline \multicolumn{1}{c}{ Component } & PAH after HWE (mg/kg) & Total removal (\%) \\
\hline Naphthalene & 0.00 & 100 \\
Phenanthrene & 7.63 & 99.6 \\
Fluoranthene & 2.69 & 99.8 \\
Pyrene & 2.34 & 99.8 \\
Chrysene & 4.63 & 98.7 \\
Benzo(a)pyrene & 8.52 & 92.1 \\
\hline
\end{tabular}

Table K2

EPA Sample - Bench Scale System - second experiment

\begin{tabular}{lcc}
\hline \multicolumn{1}{c}{ Component } & PAH after HWE (mg/kg) & Total removal (\%) \\
\hline Naphthalene & 0.00 & 100 \\
Phenanthrene & 7.89 & 99.6 \\
Fluoranthene & 1.90 & 99.9 \\
Pyrene & 1.50 & 99.9 \\
Chrysene & 2.96 & 99.1 \\
Benzo(a)pyrene & 3.55 & 96.7 \\
\hline
\end{tabular}


Table K3

EPA Sample - Bench Scale System - third experiment

\begin{tabular}{lcc}
\hline \multicolumn{1}{c}{ Component } & PAH after HWE $(\mathbf{m g} / \mathbf{k g})$ & Total removal (\%) \\
\hline Naphthalene & 0.00 & 100 \\
Phenanthrene & 5.36 & 99.7 \\
Fluoranthene & 1.31 & 99.9 \\
Pyrene & 1.19 & 99.9 \\
Chrysene & 2.08 & 99.4 \\
Benzo(a)pyrene & 2.45 & 97.7 \\
\hline
\end{tabular}

Table K4

EPA Sample - Bench Scale System

\begin{tabular}{c|c|c|c|c}
\hline Experiment & $\begin{array}{c}\text { Number of } \\
\text { wash cycles }\end{array}$ & Sample size (g) & $\begin{array}{c}\text { Reactor water content } \\
\mathbf{( g )}\end{array}$ & Stirring \\
\hline First & 4 & 15 & $\begin{array}{c}90(1 \% \text { sodium } \\
\text { carbonate })\end{array}$ & yes \\
\hline Second & 6 & 15 & $\begin{array}{c}90(1 \% \text { sodium } \\
\text { carbonate })\end{array}$ & yes \\
\hline Third & $6^{*}$ & 15 & $\begin{array}{c}90(1 \% \text { sodium } \\
\text { carbonate })\end{array}$ & yes \\
\hline
\end{tabular}

* 4 washes at $275^{\circ} \mathrm{C}$ and 2 washes at $290^{\circ} \mathrm{C}$ 


\section{APPENDIX L SOME COMMONLY MEASURED SOIL PARAMETERS}

Some commonly measured parameters that affect the cost and performance of remediation technologies (including hot water technology) are presented below.

Soil Classification. This parameter is a semi-empirical measurement of sand, clay, gravel, and loam content. Soil characteristics limit each technology. For example, sandy soils are typically more amenable than clayey soils to soil vapor extraction. However, we expect soil characteristics to have very little effect on the efficiency of hot water extraction.

Clay Content and Particle Size Distribution. Clay and particle size distribution affect air and flow through contaminant media. For example, in slurry phase bioremediation systems, particle size affects the ability to hold media in suspension. In soil washing, the particle size/contaminant concentration relationship affects the potential for physical separation and volume reduction. For thermal desorption systems, clay and particle size affect mass and heat transfer, including agglomeration and carry over to air pollution control devices. In hot water technology, the medium, water, is very aggressive and self-mixing. We expect a minimum effect from mass transfer limitations. We have designed an appropriate series of experiments to be performed in Task 2 to demonstrate this aspect.

Moisture Content. The moisture content of the matrix typically affects the performance, both directly and indirectly, of in situ technologies (such as bioventing and soil vapor extraction) and of ex-situ technologies (such as stabilization, incineration and thermal desorption). For example, air flow rates during soil vapor extraction are affected by the moisture content of the soil. Thermal input requirements and air handling systems for incineration and desorption technologies can also be affected by soil moisture content. In hot water technology, the cost to heat the water media would be high. However, hot water technology is suitable for soil with a high moisture content and with problematic sediments, whereas other technologies are not suitable or not effective because of the high moisture content.

Air Permeability. This parameter is important for in situ soil remediation technologies that involve venting or extraction. But is not important for hot water technology.

$\mathrm{pH}$. The $\mathrm{pH}$ of the matrix can impact the solubility of contaminants and biological activity. Therefore, this parameter can affect technologies such as soil bioventing, soil flushing, land treatment, composting, and stabilization. The $\mathrm{pH}$ can also affect the operation of treatment technologies. A pH in the corrosive range (e.g., $<2$ and $>12$ ) can damage equipment. In hot water technology, corrosiveness and the effectiveness of the technology depend on the $\mathrm{pH}$ of the 
water. Added substances and a large amount of water would somewhat neutralize the starting $\mathrm{pH}$ and thereby reduce the corrosiveness.

Porosity. This parameter is important for in situ technologies, (such as soil bioventing and soil vapor extraction), because they rely on the use of a driving force to transfer contaminants into an aqueous or air-filled space. Porosity affects the driving force and thus the performance achieved by these methods. We expect porosity to have minimal impact on the performance of hot water technology because water would be incorporated into the soil matrix.

Total Organic Carbon (TOC). TOC affects the desorption of contaminants from the soil and impacts in situ soil remediation, soil washing, stabilization, and ground water bioremediation. The TOC content may limit the effectiveness of the hot water process both directly and indirectly. We have designed a specific set of experiments to evaluate the impact of TOC on the hot water process.

Oil And Grease (O\&G) Or Total Petroleum Hydrocarbons (TPH). O\&G and TPH affect the desorption of contaminants from the soil. For thermal desorption, elevated levels of TPH may result in agglomeration of soil particles, resulting in shorter residence times. An objective of the proposed work is to improve the hot water application to effectively remove O\&G and TPH.

Air Flow Rate. Air flow rate affects the rate of volatilization of contaminants in technologies such as soil bioventing and soil vapor extraction that rely on transferring contaminants from a soil or aqueous matrix to air. In the hot water technology, the water flow rate, not the air flow rate, would affect the performance.

Mixing Rate/Frequency. Mixing rate affects the rate of biological activity and the volatilization of contaminants. Mixing is important in hot water technology. However, we expect water under subcritical conditions to be self-mixing, thus eliminating the problems associated with inadequate mixing.

Operating Pressure/Vacuum. Operating pressure/vacuum affects the rate of volatilization of contaminants in technologies that rely on transferring contaminants from a soil or aqueous matrix to air or sparging medium. Operating pressure is a key parameter for systems based on hot water and the key parameter that affects the solubility of organics in water.

Temperature. For biodegradation technologies, temperature affects the rate of biological activity. For stabilization, incineration, and thermal desorption, temperature affects the physical properties of the contaminants and the rate of chemical reactions. In hot water technology, temperature affects the performance and efficiency of the system. Temperature also affects the physical properties of water and the separation of organics from the extracted stream.

Residence time. Residence time, a measure of the amount of time during which treatment occurs, is important for ex situ technologies such as land treatment, composting, slurry- 
phase soil bioremediation, incineration, and thermal desorption. Even in hot water technology, residence time determines the efficiencies of the process. 


\section{APPENDIX M \\ REACTOR VESSEL SIZING AND THE BASIS OF DESIGN INFORMATION}

Tables M1 and M2 give the preliminary reports on HWE reactor vessel sizing and the basis of design information provided by Sequoia Engineering.

\begin{tabular}{|c|c|c|c|c|}
\hline \multicolumn{5}{|c|}{$\begin{array}{c}\text { Table M1 } \\
\text { HWE Reactor Vessel Sizing }\end{array}$} \\
\hline Soil Composition & $\% \mathrm{v} / \mathrm{v}$ & $\begin{array}{l}\text { In-situ Unit } \\
\text { Weight } \\
\text { (lbm.ft3) }\end{array}$ & $\begin{array}{c}\text { Permeability } \\
\text { (darcies) }\end{array}$ & Porosity (\%) \\
\hline Silty clay, clay & & 114.00 & 0.10 & $33.4 \%$ \\
\hline Mixed sandy, silty, clayey soils & & 125.00 & 1.00 & $27.0 \%$ \\
\hline Primary sand & & 127.00 & 5.00 & $25.8 \%$ \\
\hline Sand and gravel & & 135.00 & 20.00 & $21.2 \%$ \\
\hline Density of pure silica & $\mathrm{lbm} / \mathrm{ft} 3$ & 171.25 & & \\
\hline In situ density of soil, "bank weight" & $\mathrm{lbm} / \mathrm{ft} 3$ & 118.06 & & $31.1 \%$ \\
\hline Load factor for loose soil & & 0.725 & & \\
\hline \multirow[t]{2}{*}{ Loose density of dry soil, unpacked } & $\mathrm{lbm} / \mathrm{ft} 3$ & 85.63 & & $50.0 \%$ \\
\hline & $\mathrm{lbm} / \mathrm{CY}$ & $2,311.93$ & & \\
\hline Reactor Diameter & in & 48.00 & & \\
\hline Reactor length, cylindrical portion & in & 120.00 & & \\
\hline Volume of reactor cylindrical section & $\mathrm{ft} 3$ & 125.66 & & \\
\hline Volume of loose soil in cylindrical section & $\mathrm{ft} 3$ & 78.69 & & \\
\hline Weight of loose soil in cylindrical section & $\mathrm{lbm}$ & $6,738.32$ & & \\
\hline Soil discharge cone height & in & 72.00 & & \\
\hline Diameter of soil outlet & in & 18.00 & & \\
\hline Volume of discharge cone & $\mathrm{ft} 3$ & 38.09 & & \\
\hline Cone diameter growth per inch & in/in & 0.42 & & \\
\hline Volume of loose soil in discharge cone & $\mathrm{ft} 3$ & 38.09 & & \\
\hline Weight of loose soil in discharge cone & $\mathrm{lbm}$ & $3,261.68$ & & \\
\hline \multirow[t]{2}{*}{ Loose soil depth above reactor bottom outlet } & in & 147.15 & & \\
\hline & $\mathrm{ft}$ & 12.26 & & \\
\hline Total soil volume & $\mathrm{ft} 3$ & 116.79 & & \\
\hline \multirow[t]{2}{*}{ Weight of loose soil in reactor } & lbm & $10,000.00$ & & \\
\hline & tons & 5.00 & & \\
\hline \multirow[t]{2}{*}{ Total reactor internal height } & in & 192.00 & & \\
\hline & $\mathrm{ft}$ & 16.00 & & \\
\hline Total reactor volume & $\mathrm{ft} 3$ & 163.76 & & \\
\hline
\end{tabular}




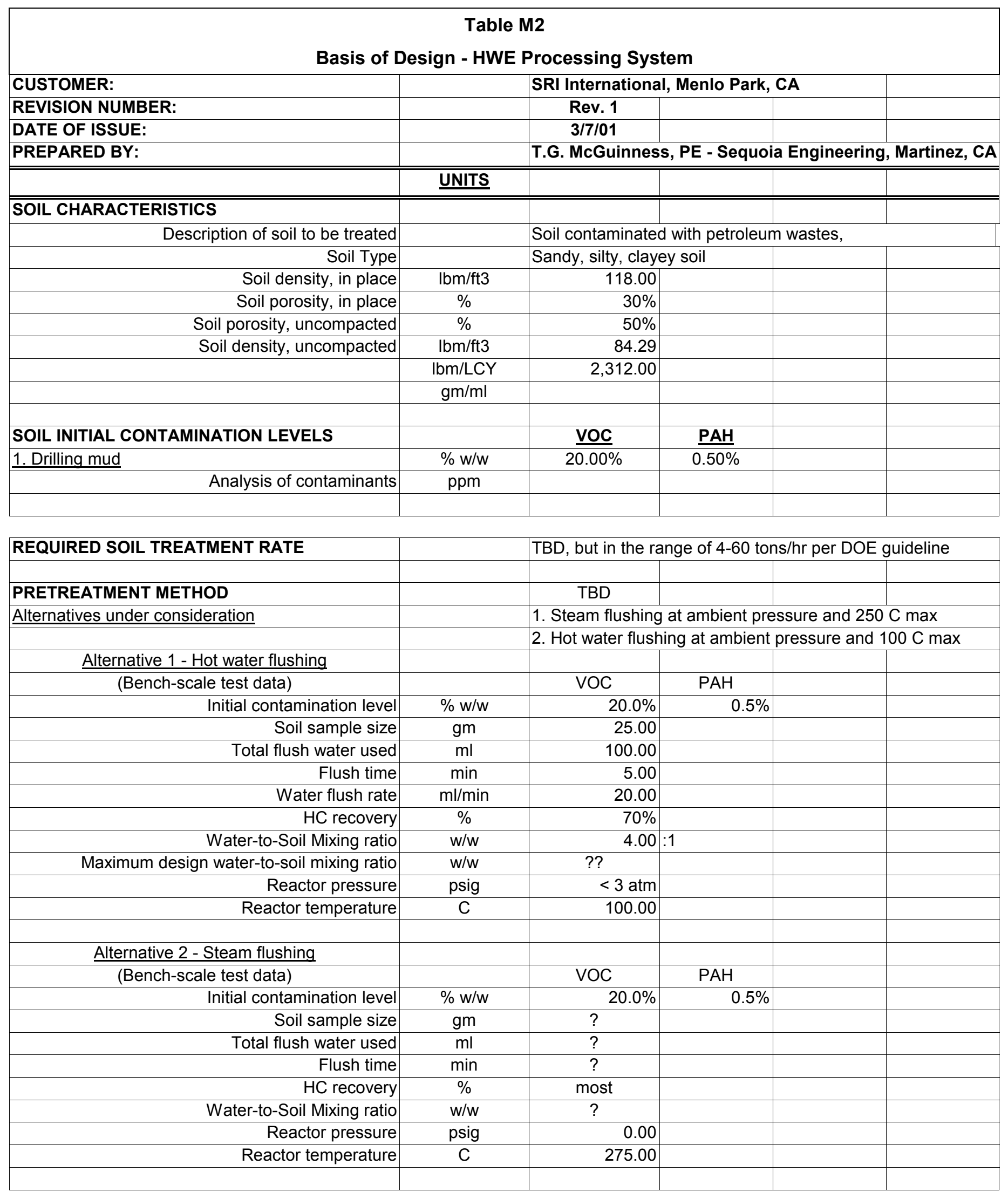




\begin{tabular}{|c|c|c|c|c|c|}
\hline \multicolumn{6}{|l|}{ HWE TREATMENT METHOD } \\
\hline \multicolumn{6}{|l|}{ Bench-scale test data } \\
\hline Soil sample size & gm & 5.00 & & & \\
\hline Water flush rate & $\mathrm{ml} / \mathrm{min}$ & 0.10 & & & \\
\hline Flush time & hours & 4.00 & & & \\
\hline Total flush water used & $\mathrm{ml}$ & 24.00 & & & \\
\hline Reactor pressure & psig & $1,000.00$ & & & \\
\hline Reactor temperature & $\mathrm{C}$ & 275.00 & & & \\
\hline HC recovery & $\%$ & $99 \%$ & + & & \\
\hline Water-to-Soil Mixing ratio & $w / w$ & 4.80 & $: 1$ & & \\
\hline Maximum design water-to-soil mixing ratio & $w / w$ & ?? & & & \\
\hline Carbonate concentration & $\% \mathrm{w} / \mathrm{w}$ & $1-10$ & & & \\
\hline PAH \& HC solubility in water at HWE conditions & $\% \mathrm{w} / \mathrm{w}$ & SRI data & & & \\
\hline Sodium carbonate replacement rate & Ibm/ton of soil & $? ?$ & & & \\
\hline \multicolumn{6}{|l|}{ REQUIRED EFFLUENT CHARACTERISTICS } \\
\hline Maximum soil PAH concentration, final & ppm & 1.00 & & & \\
\hline \multicolumn{6}{|l|}{ ECONOMIC DATA } \\
\hline Discount factor & $\%$ & $15 \%$ & & & \\
\hline System design life & years & 20.00 & & & \\
\hline Value of recovered hydrocarbons & $\$ / b b l$ & 27.00 & & & \\
\hline Plant availability factor & $\%$ & $85 \%$ & & & \\
\hline \multirow{6}{*}{ Support Staff } & & & Qty & Day Rate & \\
\hline & & Superintendent & $\frac{1 . y}{1}$ & Day reate & \\
\hline & & QC/lab Manager & 1 & & \\
\hline & & \begin{tabular}{|l|l} 
Engineer & \\
\end{tabular} & 1 & & \\
\hline & & Chemist & 1 & & \\
\hline & & Admin Clerk & 1 & & \\
\hline \multirow{3}{*}{ Operating Staff } & & Shift supervisor & 3 & & \\
\hline & & Operator & 9 & & \\
\hline & & Ops support & 3 & & \\
\hline \multirow{2}{*}{ Other Staff } & & Total $=$ & 20 & & \\
\hline & hrs/day & 24 & & & \\
\hline Plant Working Calendar & days/week & 7 & & & \\
\hline \multirow[b]{2}{*}{ Shift Schedule } & & & & & \\
\hline & $\begin{array}{c}\text { shifts/day } \\
\text { hrs/shift }\end{array}$ & $\begin{array}{r}3 \\
12\end{array}$ & & & \\
\hline Lodging Cost & \$/man-day & 75.00 & & & \\
\hline Per Diem Cost & $\$ /$ man-day & 50.00 & & & \\
\hline \multicolumn{6}{|l|}{ Cost of Consumables } \\
\hline Cost of electric power & \$/kW-hr & 0.10 & & & \\
\hline Cost of diesel fuel & $\$ / g a l$ & 1.00 & & & \\
\hline Cost of natural gas & \$/MMBTU & 5.25 & & & \\
\hline Cost of sodium carbonate & $\$ / \mathrm{lbm}$ & & & & \\
\hline Cost of water treatment chemicals & $\$ / \mathrm{lbm}$ & & & & \\
\hline
\end{tabular}

